\title{
Early school leaving in the Netherlands : a multidisciplinary study of risk and protective factors explaining early school-leaving
}

Citation for published version (APA):

Traag, T. (2012). Early school leaving in the Netherlands : a multidisciplinary study of risk and protective factors explaining early school-leaving. [Doctoral Thesis, Maastricht University]. Statistics Netherlands. https://doi.org/10.26481/dis.20121213tt

Document status and date:

Published: 01/01/2012

DOI:

10.26481/dis.20121213tt

Document Version:

Publisher's PDF, also known as Version of record

\section{Please check the document version of this publication:}

- A submitted manuscript is the version of the article upon submission and before peer-review. There can be important differences between the submitted version and the official published version of record.

People interested in the research are advised to contact the author for the final version of the publication, or visit the DOI to the publisher's website.

- The final author version and the galley proof are versions of the publication after peer review.

- The final published version features the final layout of the paper including the volume, issue and page numbers.

Link to publication

\footnotetext{
General rights rights.

- You may freely distribute the URL identifying the publication in the public portal. please follow below link for the End User Agreement:

www.umlib.nl/taverne-license

Take down policy

If you believe that this document breaches copyright please contact us at:

repository@maastrichtuniversity.nl

providing details and we will investigate your claim.
}

Copyright and moral rights for the publications made accessible in the public portal are retained by the authors and/or other copyright owners and it is a condition of accessing publications that users recognise and abide by the legal requirements associated with these

- Users may download and print one copy of any publication from the public portal for the purpose of private study or research.

- You may not further distribute the material or use it for any profit-making activity or commercial gain

If the publication is distributed under the terms of Article $25 \mathrm{fa}$ of the Dutch Copyright Act, indicated by the "Taverne" license above, 


\section{Early school-leaving in the Netherlands}

A multidisciplinary study of risk and protective factors explaining early school-leaving

Tanja Traag 


\section{Publisher}

Statistics Netherlands

Henri Faasdreef 312

2492 JP The Hague

\section{Prepress}

Statistics Netherlands

Grafimedia

\section{Cover}

Teldesign, Rotterdam

\section{Information}

Telephone +31 885707070

Telefax +31 703375994

Via contactform:

www.cbs.nl/infoservice

\section{Where to order}

E-mail:verkoop@cbs.nl

Telefax +314557062 68

\section{Internet}

www.cbs.nl

ISBN: 978-90-357-1827-2

(c) Tanja Traag, The Hague/Heerlen, 2012.

The author is fully responsible for the text of this dissertation. Reproduction is permitted for own or internal use. The text does not necessarily correspond with the official point of view of Statistics Netherlands 


\section{EARLY SCHOOL-LEAVING IN THE NETHERLANDS}

\section{A multidisciplinary study of risk and protective factors explaining early school-leaving}

\section{ACADEMISCH PROEFSCHRIFT}

ter verkrijging van de graad van doctor

aan de Universiteit Maastricht,

op gezag van de Rector Magnificus, Prof.dr. L.L.G. Soete

volgens het besluit van het College van Decanen,

in het openbaar te verdedigen

op donderdag 13 december 2012 om 10.00 uur

door

Tanja Traag

Geboren te Tegelen 


\section{Promotiecommissie:}

Promotor:

Prof.dr. R.K.W. van der Velden

Overige leden:

Prof.dr. J. Dronkers (voorzitter)

Prof.dr. B.F.M. Bakker (VU Amsterdam)

Prof.dr. F.L. Leeuw

Prof.dr. M.P.C. van der Werf (RU Groningen) 


\section{Acknowledgements}

Writing a thesis is not an easy task and many people contributed to me successfully finishing this project. First, I should thank my supervisor Rolf Van Der Velden, who believed in me all those years and repeatedly helped me get back on track. You motivated me to go on, you were honest, and sometimes tough when needed, and gave me the fruitful new insights I needed to continue. Especially, you pulled me through those most difficult final months. I also want to thank my co-authors, Olivier Marie, Angela Duckworth, and Miranda Lubbers for their input in my papers.

Second, I should thank Statistics Netherlands for giving me this chance. Special thanks to Pieter Everaers for giving me the opportunity to begin with, and thanks to Jos Schiepers, Wim de Witte, and Jan Van Laanen to help me fit this project into my regular CBS tasks. I would also like to thank my colleagues at Statistics Netherlands for providing support and a forum for discussion at times when I needed a second opinion. I would especially like to thank Christine Jol, Francis Van Der Mooren, Robert De Vries, Jannes De Vries and Rianne Kloosterman for their input at many stages of the project.

I also wish to thank everyone that was involved in making the VOCL datasets, which is supported by the Netherlands Organisation for Scientific Research (NWO) and is carried out by both Statistics Netherlands (CBS) and the Groningen Institute for Education Research (GION). Special thanks off course to the participants of these cohort studies and their parents, as well as the schools and teachers involved. It is thanks to your effort that we have these extensive cohort studies that can provide us with the type of results shown in this thesis.

Finally, I want to thank my family for their unconditional support, love and belief. Roy, my husband and best friend, you had to put up with quite some stress and drama at some points in time. Thankfully, you kept your head cool and managed to calm things down again. For Isabel and Mathijs, this thesis was about as hard for them as it was for me. The two of you had to understand that mummy was busy, working her laptop while you played silently. And I have to say, you did a great job! I love the three of you from the bottom of my heart. Finally, thanks to my parents that gave me all the support, love and care all those years to help me get me where I am today.

Tanja Traag, Herten, December 2012 



\section{Contents}

$\begin{array}{ll}\text { Acknowledgements } & 5\end{array}$

1 Introduction 9

1.1 The Dutch educational system 9

$\begin{array}{ll}1.2 & \text { Early school-leaving in the Netherlands } \\ 11\end{array}$

$\begin{array}{ll}1.3 & \text { International comparisons for early school-leaving } \\ 14\end{array}$

1.4 Policies for early school-leaving prevention in the Netherlands 16

$\begin{array}{ll}1.5 & \text { Outline of the study } \\ \end{array}$

2 The role of family resources, school composition and background characteristics in early school-leaving in lower secondary education 23

\begin{tabular}{ll}
2.1 & Introduction \\
\hline
\end{tabular}

$\begin{array}{ll}2.2 & \text { Theoretical framework } \\ 2.3 & 24\end{array}$

2.3 Data and methodology 28

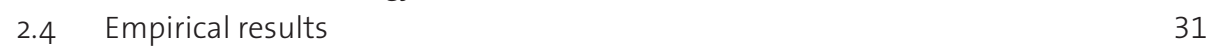

2.5 Conclusion and discussion 34

2.6 Appendix Measuring background variables, resources and control variables $\quad 36$

3 Social Bonding, Early School- Leaving, and Delinquency 39

$\begin{array}{lll}3.1 & \text { Introduction } & 39\end{array}$

3.2 Literature review and theoretical framework 40

$\begin{array}{lll}3.3 & \text { Data } & 42\end{array}$

3.4 Descriptives and modeling 46

3.5 Results 49

3.6 Conclusion $\quad 53$

3.7 Appendix 54

$4 \quad$ The effects of Cognitive and Non-Cognitive Skills on early school-leaving 57

$\begin{array}{lll}4.1 & \text { Introduction } & 57\end{array}$

4.2 Non-Cognitive Skills as predictors of school success 59

4.3 Research design 62

$\begin{array}{lll}4.4 & \text { Results } & 66\end{array}$

$\begin{array}{lll}4.5 & \text { Conclusion and discussion } & 76\end{array}$ 
$\begin{array}{lll}5.1 & \text { Introduction } & 79\end{array}$

5.2 Data and study design 82

$\begin{array}{lll}5.3 & \text { Results } & 90\end{array}$

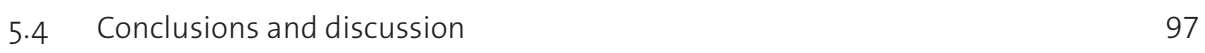

$\begin{array}{ll}5.5 & \text { Appendix } \\ & 99\end{array}$

6 Conclusion $\quad 101$

$\begin{array}{lll}6.1 & \text { Introduction } & 101\end{array}$

$\begin{array}{ll}6.2 & \text { Summary of findings } \\ 6.3 & 102\end{array}$

$\begin{array}{ll}\text { 6.3 Conclusion and discussion } & 105\end{array}$

7 Samenvatting (Summary in Dutch) 113

7.1 De invloed van gezinskenmerken, schoolsamenstelling en achtergrondkenmerken op voortijdig schoolverlaten $\quad 114$

$\begin{array}{lll}\text { 7.2 Sociale binding, voortijdig schoolverlaten en delinquentie } & 116\end{array}$

7.3 De invloed van cognitieve en niet-cognitieve vaardigheden op schoolsucces 117

7.4 Daar heb je vrienden voor. De invloed van kenmerken van vrienden op voortijdig schoolverlaten. 118

$\begin{array}{lll}7.5 & \text { Conclusie } & 119\end{array}$

$\begin{array}{lr}\text { References } & 121\end{array}$ 


\section{Introduction}

Reducing the number of early school-leavers is one of the challenges industrialized societies face these days. Due to the fact that the economy generates an increasing number of jobs that require at least some post-secondary schooling, students with little or no qualifications will most likely have diminishing economic prospects in the future economy (Rumberger, 2011). Reducing the number of early school-leavers was therefore one of the important goals in the so-called Lisbon Strategy to make the EU "the most competitive and dynamic knowledge-based economy in the world capable of sustainable economic growth with more and better jobs and greater social cohesion" by 2010 (European Parliament, 2000). Recently, new goals have been set for 2020 . The aim is to reduce the rate of early schoolleavers in the EU to no more than ten percent of the 18 to 24 year olds in 2020.

In the Netherlands, 162,000 people between 15 and 24 were no longer in education in 2010 and had little or no qualification. Early school-leaving has severe consequences for the life course of individual people, as well as a negative impact on society as a whole. It increases the risk of unemployment and low-paid jobs and the risk of dependency on social security benefits (Beckers \& Traag, 2005a, 2005b; Marks \& McMillan, 2001; Rumberger, 1987). To combat early school-leaving, we need more insight in the underlying factors that cause pupils to leave school prematurely. Notwithstanding the extensive research in this area, there are still significant blind spots.

The objective of this study is to address risk and protective factors for early school-leaving in the Netherlands, by integrating approaches from several disciplines and to make recommendations for policy as well as further research. This introductory chapter is outlined as follows. First, the Dutch educational system and the definition of early schoolleaving will be summarized. Section 1.2 describes the trends in early school-leaving in the Netherlands since 2002. In section 1.3, I describe how early school-leaving is distributed throughout Europe. Section 1.4 gives a short overview of the main policies that have been implemented in the Netherlands to reduce early school-leaving since 2000. Finally, section 1.4 describes the research questions that will be addressed in this study.

\subsection{The Dutch educational system}

The Dutch education system is highly stratified (see figure 1.1.1). After eight years of (pre-) primary education, students enter secondary education at the age of 12. Here they have 
to choose between three tracks: one preparing for university education (VWO, duration 6 years), one preparing for a college for higher vocational education (HAVO, duration 5 years) and one track preparing for vocational education at the upper secondary level (VMBO, duration 4 years). Track placement takes place on the basis of a nationwide test, called CITO-test'1) at the end of primary education and the advice of the primary school teacher. Subsequently, depending on the track chosen, students can either leave education or enter one of three upper secondary vocational tracks, higher vocational education, or university. In 1993, the Dutch Ministry of Education, Culture, and Science introduced the concept of a starting qualification ('startkwalificatie') to establish a minimum credential for young people that confers eligibility for the labor market. Those who do not attain a starting qualification are considered to be early school-leavers. Diplomas of tracks that provide a starting qualification are the pre-college track (HAVO), pre-university track (VWO) and upper secondary vocational education of at least two years (MBO at level two), which is the level of a "basic skilled worker" (Traag \& Van der Velden, 2011). Although compulsory education ends in the year that a pupil turns 16 ('leerplicht'), one is obliged to stay in education until the starting qualification is obtained or until one turns 18 ('kwalificatieplicht'). Since 2007, Dutch youths are obliged to learn or to work until the age of 18 or until completion of a full upper secondary (ISCED 3) qualification ('kwalificatieplicht'). Those who have not attained this minimum

\subsubsection{The Dutch education system}

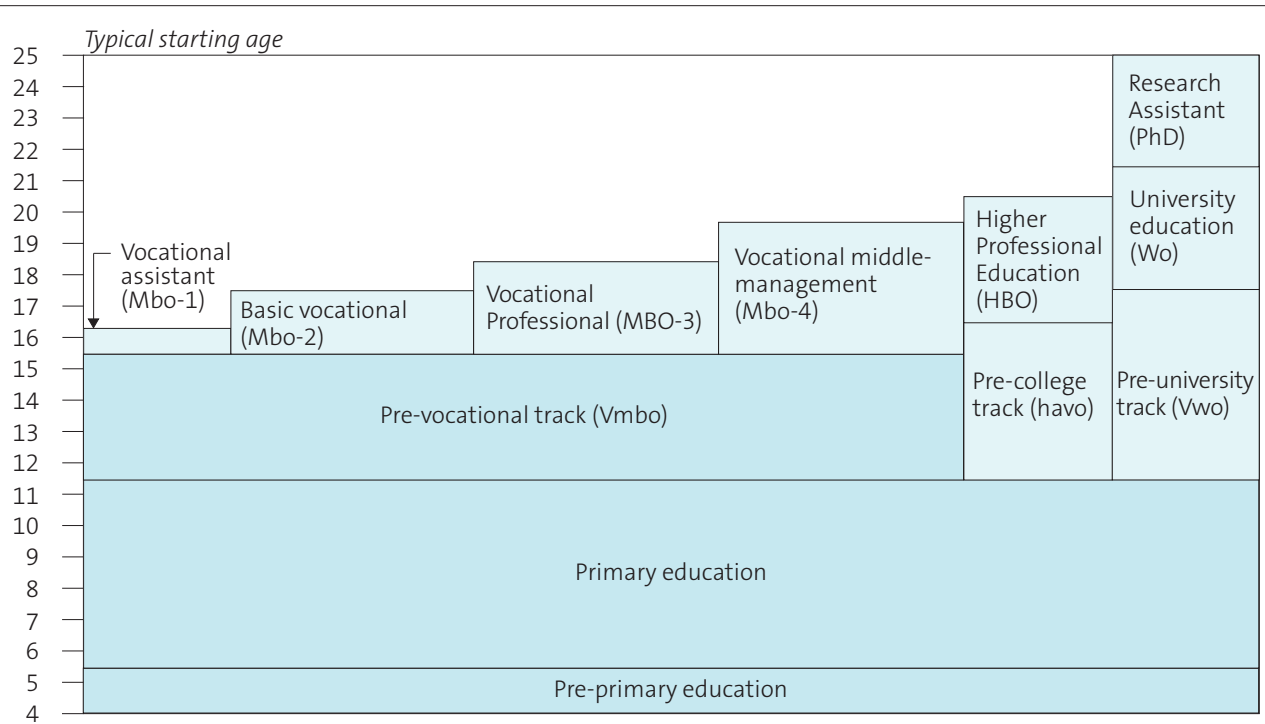

1) The majority of Dutch schools use the CITO or a comparable test to determine track placement, but schools are not obliged to use such tests. 
education level at age 18 are required to either resume education or work until the age of 27 ('leerwerkplicht', officially adopted in 2009).

\subsection{Early school-leaving in the Netherlands}

In the Netherlands, two different approaches are used to measure early school-leaving. One approach, used by Statistics Netherlands, measures the total volume of young people no longer in education that does not have a starting qualification in a certain year. This number is measured using the Labor Force Survey, a large scale household survey that is conducted throughout the year. This figure is also used for international comparisons by Eurostat and the OECD (see section 1.3). Since 2001, the total volume of early school-

\subsubsection{Total volume of $\mathbf{1 5}$ to $\mathbf{2 4}$ year olds no longer in education without a starting qualification, $\mathbf{2 0 0 0 - 2 0 1 0}$}

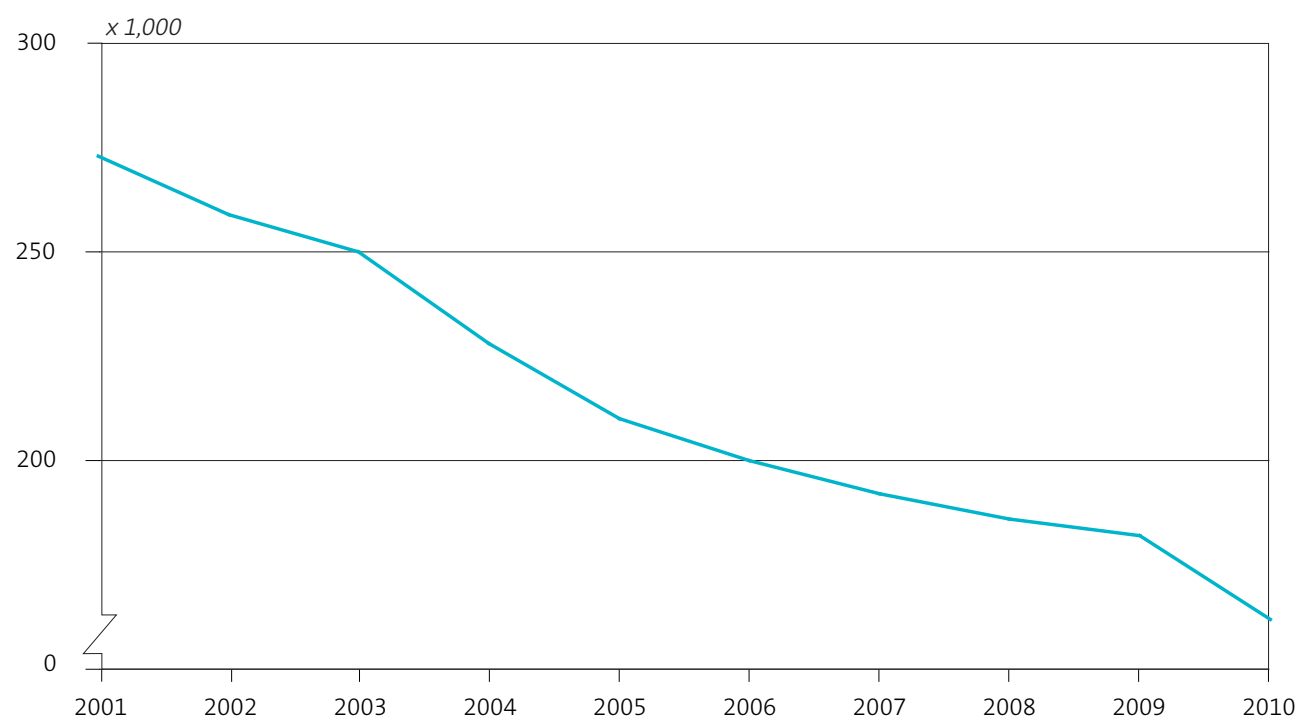

Source: Statistics Netherlands, Labor Force Survey. 
leavers has decreased quite rapidly from 273,000 in 2001 to 162,000 in 2010 (see figure 1.2.1). On the total population of 18 to 24 year olds, this reflects a decrease of 15.1 percent early school-leavers in 2001 to 10.1 percent in 2010. However, this still means that of among those youth that were not in education about one third had not attained the minimum level of education.

For political purposes, a somewhat different approach is used, where early school-leaving is measured as the number of young people that left education without a starting qualification within a school year. This is referred to as the number of new early schoolleavers. The measurement of the number of new early school-leavers is conducted by DUO ('Dienst Uitvoering Onderwijs' who is responsible for the execution of several acts and regulations, such as student grants and information management), commissioned by the Ministry of Education, Cultural Affairs and Science (OC \& W).

\subsubsection{Official numbers of new early school-leavers in the Netherlands, 2002-2014 (2014/ 15 shows the target number, which is marked in light grey)}

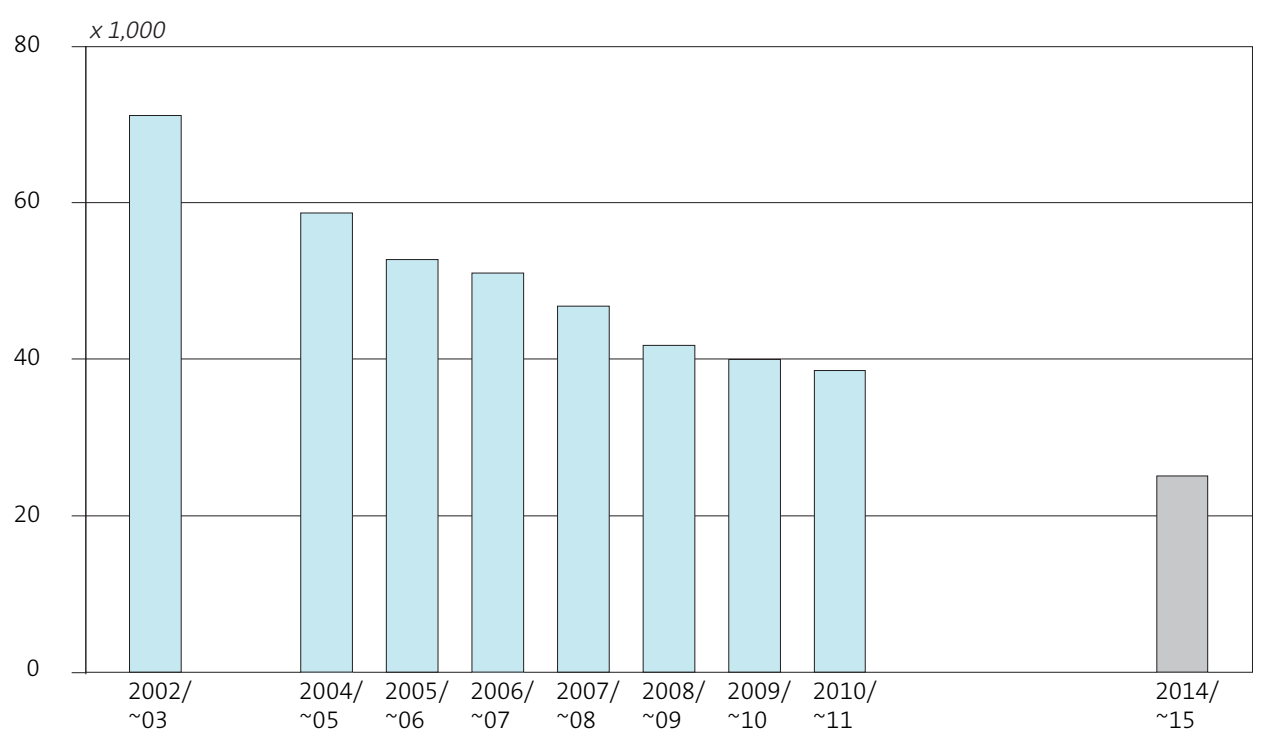

Source: Ministry of Education Cultural Affairs and Science, 2012.

Figure 1.2.2 shows the trend in new early school-leavers from 2002/ 03 to 2010/ 11 and includes the national target for $2014 / \sim 15$. For 2002, the Dutch government reported a total of 71,000 new early school-leavers, which was based on registration of students that were no longer enrolled in education by the Regional Report and Coordination 
Points (RMC). This RMC registration was installed as one of the first instruments in combating early school-leaving by improving the registration of absent students. However, this registration did not result in a full registration of early school-leavers (Van Tilborg \& Van Es, 2006). In 2005, a new registration was developed based on the Basic Registry Education (BRON), which uses educational registries to count those that were enrolled in year $t$ and no longer enrolled in $t+1$ and had not attained the minimum level of full upper secondary education. This change in registration coincided with a large reduction of the number of early school-leavers to 52,700 for the 2005/ 06 school year. In their annex to the early school-leaving report for the Dutch government, OC \& W states that this new calculation of early school-leavers makes it possible to make a coherent and reliable comparison of year to year changes in the number of early schoolleavers as of 2005. This also means that it is impossible to make comparisons with previous years, due to the change in methodology.

The Ministry of Education, Cultural Affairs, and Science is further enhancing the registration of early school-leavers by using multiple new sources. Some of these relate to the registration of early school-leavers, others relate to the definition of the population. This should further 'clean' the registration of those that were wrongfully counted as early school-leavers in the past. We start with the registration related measures:

- Until recently, students in private education were not registered in official data sources. However, private education is an important alternative route to attaining a starting qualification for some subgroups of secondary school pupils, especially within the precollege and pre-university tracks, resulting in an overestimation of the number of early school-leavers of about 1,800 students.

- Since the measurement of new early school-leavers is based on enrolment and achieved educational level in a certain school year, those that have not taken the exam are labeled as early school-leavers, regardless of the fact that they took the exam in the following school year. These students should not be counted as early school-leavers. It is unclear how many students have wrongfully been assumed to be an early schoolleaver because of this reason.

- One of the sources used in measuring early school-leaving is the population of 12 to 23 year olds that are registered as a resident of the Netherlands in a certain school year. Among others, this means that immigrants that entered the Netherlands within that same year are also included. This results in an overestimation of the early schoolleaving population of approximately 400 students.

- In 2010, a total of 530 youths between 15 and 20 years old were incarcerated based on figures provided by Statistics Netherlands. Although juvenile prisons do provide education for their inmates, enrolment and examination in these programs are not included in the official education registration. Therefore, those that are incarcerated before attaining the minimum level of qualification are considered to be early schoolleavers. There are no estimates available on how many incarcerated youths were wrongfully counted as early school-leavers. 
As indicated before some measures deal with the definition of the population ${ }^{2}$ :

- Those that were exempted from compulsory education have been counted as early school-leavers until now, since they did not attain the minimum level of education. Reasons for exemption are physical or mental disability, a lack of accessible schools that meet the parents' religious persuasions, parents work in a circus or a carnival, or the child attends a school abroad that is not officially recognized by the Dutch government. Rough estimates indicate that about 900 individuals have been labeled as an early school-leaver in spite of their exempted status.

- Until now, all students that did not attain the starter's qualification level were assumed to be early school-leavers, regardless of their subsequent careers. However, the Ministry of Education Cultural Affairs and Science has argued that those who attended the level of vocational assistant (ISCED $2 \mathrm{C}$ ) and found a job immediately after leaving school should not be counted as early school-leavers (Ministry of Education Cultural Affairs and Science, 2012). Previously these school-leavers could not be separately identified. It is estimated that this accounts for about 500 less early school-leavers. The Ministry of Education Cultural Affairs and Science also argues that students that work for the police force or in de Defense department should be excluded from the early schoolleaving population, which reduces the number of early school-leavers by another 400 .

Preliminary estimates show that this new measurement strategy would reduce the number of early school-leavers by 4,000 (Ministry of Education Cultural Affairs and Science, 2012).

\subsection{International comparisons for early school-leaving}

The European Union defines early school-leavers as people aged 18 to 24 who have only lower secondary education or less, and are no longer in education or training. Those who have only achieved pre-primary, primary, lower secondary or a short upper secondary education of less than two years are considered early school-leavers. Thus early schoolleavers can be

- People that left school before the end of compulsory education;

2) One can debate whether changing the definition is always in line with the original concept as was intended in the Lisbon goals. 
- People who completed some form of compulsory schooling but did not attain the upper secondary level;

- People who have followed pre-vocational or vocational courses, which did not lead to a qualification equivalent to the upper secondary level.

In 2010, about 14.4 percent of all 18 to 24 year olds in the EU left education with no more than lower secondary education and did not participate in any form of education or training (see figure 1.3.1). Although the rate of early school-leavers has decreased since 2001 in most EUcountries, a lot of progress will still have to be made to reach the EU benchmark of 10 percent set for 2020. Between the EU countries, there are large differences in the rate of early schoolleaving and the trends between 2001 and 2010. In the southern part of Europe, the rate is quite high with over 30 percent of early school-leavers in Turkey, Malta, Spain, and Portugal, although especially Malta and Portugal did show considerable decreases since 2001.

\subsubsection{Early school-leavers by EU country, 2001-2010}

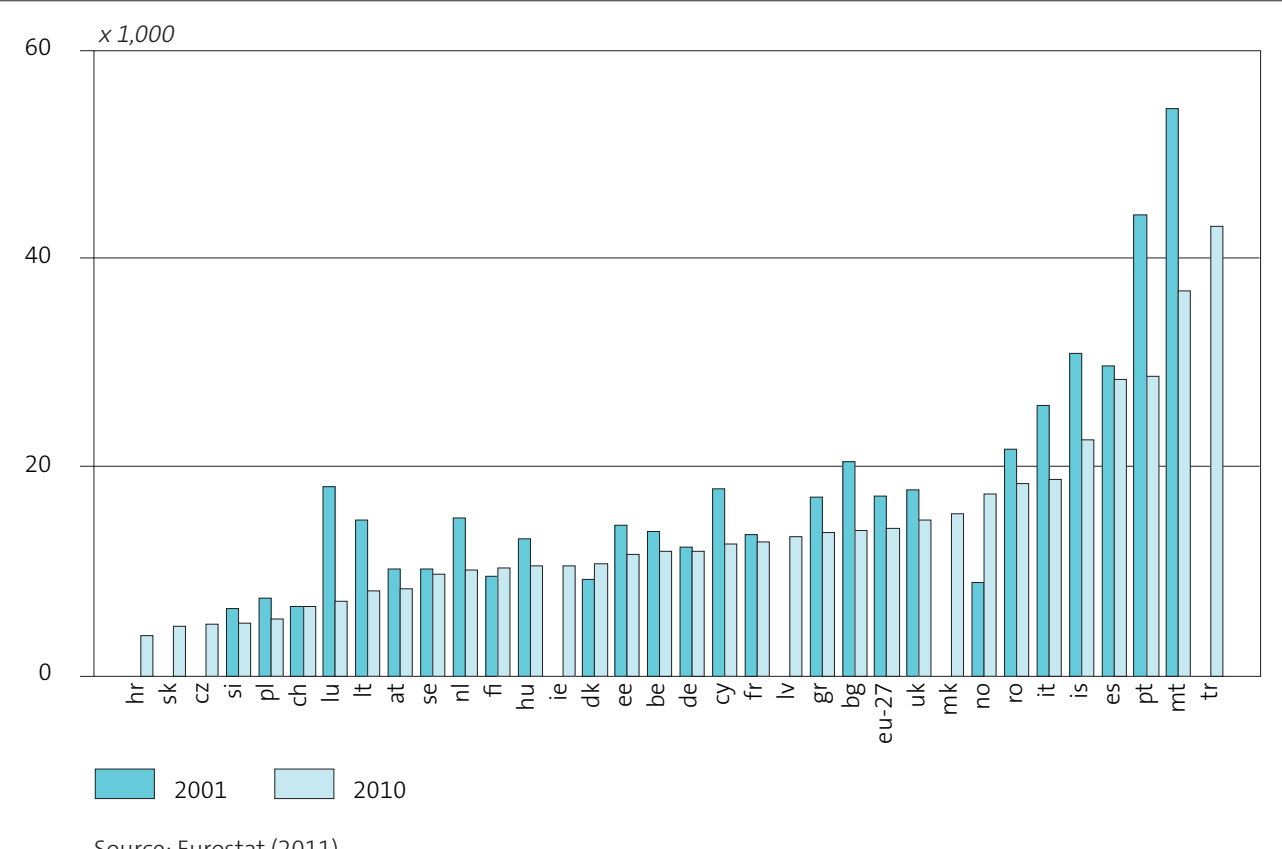

Source: Eurostat (2011).

Northern Europe showed much lower levels of early school-leaving in 2001. Remarkably however, the early school-leaving rates have increased in Norway, Finland and Denmark, while the decrease for Sweden was relatively small compared to trends in other 
countries. This is striking since the Nordic countries have long been seen as an example for other countries in terms of the prevention of early school-leaving and the increase of educational attainment. It is unclear why these countries show opposite trends. It may very well be possible that they have reached the limit of what can be achieved in combating early school-leaving. Within every population, a certain number of people are simply unable to achieve a minimum level of education. On the other hand, the rate of early school-leaving is extremely low in some of the Eastern European countries, such as Poland, Slovenia, and the Czech Republic and has decreased even further between 2001 and 2010. At the same time Romania and Bulgaria are struggling to meet their targets. How and why some of the Eastern European countries show such low rates of early school-leaving remains unclear. Possibly, the post-communist era brought about a scholastic culture that results in children staying in school longer (Mikiewiecz, 2011). On the other hand, there is doubt about the quality of the measurement of early schoolleavers in some of these countries, especially with respect to the inclusion of specific groups such as the Roma (European Commission, 2010). In the Netherlands, 15.1 percent of all 18 to 24 year olds did not attain the lower secondary level in 2001 and by 2010 the early school-leaving rate had dropped to 10.1 percent. This is relatively low within the EU. However, efforts still have to be made to meet the national benchmark of 8 percent by 2020.

\subsection{Policies for early school-leaving prevention in the Netherlands}

One way to decrease early school-leaving is by law enforcement. In 1969, compulsory education was introduced in the Netherlands. Compulsory education starts at age 5 (although most children start education at age 4) and lasts until the age of 16 . Since 2007, Dutch youth are obliged to learn or to work until the age of 18 or until completion of ISCED 3 ('kwalificatieplicht'). Those that have not attained this minimum educational level at age 18 are required to either resume education or work until the age of 27 ('leerwerkplicht', officially taken on in 2009). If these requirements are not met, they can be denied social benefits or assistance. On top of these laws, a number of regional as well as national policies were installed (see Van der Steeg \& Webbink, 2006 for an overview of early schoolleaving prevention policies):

- In 2002, a law was passed that obliged municipalities to organize the registration of early school-leavers in cooperation with schools (RMC, see section 1.2); 
- Preventative measures were taken in pre-vocational secondary education, and vocational education, that focused mainly at enforcing compulsory education;

- Since the early school-leaving rate is high in urban areas, some measures were aimed at tackling this especially problematic population.

In the Europe 2020 strategy, the target for the total volume of early school-leavers among Dutch 18 to 24 year olds is set at 8 percent. At the national level, the Ministry of Education, Cultural Affairs and Science aims at reducing the number of new early school-leavers to 25 thousand in $2014 / \sim 15$. To reach these benchmarks, a new set of policies has been set out. As was already discussed, the measurement of early school-leavers will be renewed by using multiple new sources to exclude those that were wrongfully viewed as early school-leavers. In addition, some policies that were already in effect will be continued:

- Monitor illegal absences more closely;

- Increase the quality of education, especially at the levels of vocational professional and vocational middle-management education;

- Improve the counseling of students in their educational and occupational choices in secondary and vocational education.

At the same time, new policies are set out that focus primarily on:

- Preventing early school-leaving during the first year of vocational education, when large numbers of students decide to leave education;

- Improving the transition from pre-vocational education to vocational education;

- Increasing the support for small schools providing vocational education;

In sum, these new measures that are taken on in 2012 aim at reducing the number of new early school-leavers to 25 thousand by $2014 / \sim 15$.

\subsection{Outline of the study}

As was shown in the preceding sections, early school-leaving is a large issue in the Netherlands as well as in other western countries, affecting thousands of young people. There is a large body of research on how and why some students do not or cannot attain a certain level of education. However, there are still some important gaps in our understanding of the mechanisms that cause early school-leaving. In this study, I try to fill in some of these gaps by using an exceptionally rich dataset, and combining theories and methods from different scientific disciplines. This results in four chapters dealing with four separate research question, which I summarize in section 1.5.1. In this study, two 
datasets are used, in combination with registry information. The data used are described in section 1.5.2.

\subsubsection{Research questions}

In this thesis, the following four research questions are addressed:

1. What family resources, school composition factors and background characteristics influence the risk of early school-leaving? Do the effects of family resources, school composition factors and background characteristics differ between subgroups of early school leavers?

2. Can differences in social bonding explain differences in juvenile delinquency and early school-leaving? In addition, does preceding delinquency affect early school-leaving?

3. Can differences in non-cognitive abilities explain individual differences in educational success above and beyond cognitive ability?

4. Does having future early school-leaving friends at age 12 increase one's own risk even when controlling for other peer characteristics?

Chapter 2 address the first research question what family resources, school composition factors and background characteristics influence the risk of early school-leaving and whether these effects differ between subgroups of early school-leavers. The socioeconomic status of an individual is an important predictor for early school-leaving. Children from low-income families, low educated parents, low social class and parents with low cultural capital are more likely to drop out of school (Lamb, 1994). At the same time, characteristics of the student, such as cognitive skills, and motivation (Alexander, Entwisle, \& Kabbani, 2001) have been shown to play an important role. Within a more pedagogical framework, a number of studies have shown the relevance of school composition factors as a correlate with early school-leaving. Despite the vast amount of studies, there is a lack of studies that use a more integrated model, assessing the importance of all of these factors at the same time. In Chapter 2, an elaborate model is developed, based on Human Capital and stratification theories, which enables us to better identify what characteristics explain early school-leaving. In this study we distinguish between four groups of school-leavers, separating 'real' dropouts and early school-leavers who left school after attaining a diploma in lower secondary education from those who continued education either parttime of full-time. We expect differences with respect to their characteristics, as well as to their opportunities in later life, as they have attained different levels of education. Therefore we anticipate that the effects will remain in the same direction, but be stronger for dropouts than for those who attained a qualification, albeit it a low one.

Chapter 3 aims at gaining a better understanding of the correlation between delinquency and early school-leaving. Deviant behavior has been shown to be highly correlated with educational failure (Jarjoura, 1993). However, it is unclear if deviance causes school failure, 
or if being unsuccessful in school makes one more prone to deviance. Many studies have shown that lacking social bonds makes adolescents more prone to deviance (Jenkins, 1997). In this study, we use insights from criminology by using Hirschi's theory of social bonding (Hirschi, 1969) as a possible mechanism for both dropping out of school and delinquent behavior. We use a very rich and unique dataset that combines valuable survey and administrative data which includes information on dropout and delinquency for a large adolescent population followed into young adulthood. This enables us to consider a dynamic setting which estimates the impact of informal social controls as well as changes in the level of social controls on sequential participation in dropout and delinquency.

In chapter 4, we assess the impact of individual differences in school motivation and personality traits on early school-leaving above and beyond differences in cognitive skills. In most studies investigating the impact of cognitive and non-cognitive skills on educational achievement, both categories of skills are treated as additive factors in explaining educational and labor market outcomes. But there is a complex interplay between the two factors as well, that is often overlooked. In this study, we use a psychological theory called Expectancy theory (Vroom, 1964). According to this theory performance is a multiplicative function of both ability and motivation. We will use a unique dataset that enables us to overcome the shortcomings of many studies which struggle with contemporaneous measures of educational outcomes and measures of cognitive and non-cognitive skills. By measuring both skill types at the age of twelve and observing subsequent early school-leaving, we are able to ensure a credible claim for causality. Also, we will contribute to the existing literature by explicitly looking at the interaction effects between cognitive and non-cognitive skills. We apply Vroom's formula to predict individual differences in early school-leaving risks, but also extend his formula by broadening motivation to include a wider array of non-cognitive skills, using both measures of achievement motivation in school as well as personality traits based on the Five Factor Personality Inventory. This approach will help us to get insight into how and why some adolescents are unable to obtain a full upper secondary qualification and thus become early school-leavers.

The effect of peer groups is taken up in chapter 5 . There are a large number of studies that demonstrate an impact of peer networks on academic performance. However, large-scale empirical research on the impact of peer characteristics on early school-leaving is rather limited. In the current study we will use a very unique dataset which allows us to better analyze how exposure to future early school-leavers increases one's own risk of early school-leaving above and beyond characteristics of both the student and their peers. We will distinguish between two -partially overlapping -peer groups, namely those who were nominated by our focal respondents as best liked classmates (non-reciprocal as well as reciprocal friends) and those who nominated our focal respondents (the peer group determining students' popularity). We then test whether the characteristics of these two groups affect the students' probability of early school-leaving. An additional advancement on previous studies is that we address the complex issue of providing evidence of peer 
effects, above and beyond alternative processes that might explain peer similarity. Similarity may be a product of homophily, which refers to the tendency of people to associate with others who are very much like themselves. A large body of empirical evidence suggests that people initially select each other based on visible traits and then choose their friends from the resulting group of similar others. This makes it difficult to disentangle the causal direction between peer relations and the similarity between peers. In this study, we therefore perform some robustness analyses to understand to what extent pairs (or dyads) are formed on the basis of homophily.

\subsubsection{Overview of the data used in this study}

The analyses presented in this thesis are conducted using the data from two large-scale longitudinal studies the so-called Secondary Education Student Cohorts, conducted among students in the first grade of secondary school in either 1989/ 90 or 1999/ 00 . Both studies were carried out in the Netherlands by Statistics Netherlands and the Groningen Institute for Educational Research (GION) (Driessen \& Van der Werf, 1992; Kuyper, Lubbers, \& Van der Werf, 2003; Statistics Netherlands, 1991).

Chapter 2 addresses the influence of individual, family, and school factors on early schoolleaving. We use the VOCL'89 study which consists of 19,254 students from a random sample of 108 schools, who started secondary school in 1989/ 90, and whose educational career has been followed since then. This makes it possible not only to determine the educational level at any given time, but also to see whether students repeated classes or dropped out, or whether they transferred to a higher or lower track of education. Furthermore, students were tested on school performance and non-verbal intelligence in the first year of secondary education. Parents of the students received a questionnaire at the start of the survey, with the aim of collecting information about the families and the pupils. Data include the parental educational level, occupational level, cultural participation, and parental support in their children's education career. All students who had ever attended pre-vocational education (VMBO) are selected from the initial VOCL'89 population. Thus, even students who started secondary education in one of the two higher tracks (i.e. the pre-college track HAVO or pre-university track VWO), but later moved down to the lower track are also included in our sample. This results in a total of 10,749 students. In chapter 3 we use a unique dataset created by matching survey and administrative information on young individuals to explore the underlying mechanism between how social bonding may explain the relationship between early school-leaving and juvenile delinquency before and after leaving school. The basic sample is formed by the VOCL'99. This survey consists of 19,391 students from a random sample of almost 400 schools who were in the first grade of secondary school in 1999/2000. The cohort is shown to be representative for 12 year-old students in the Netherlands (Kuyper \& Van der Werf, 2003). The educational careers of these students were followed up annually by matching the 
cohort to the national educational register until the year 2010/ 11. These data were then matched to the basic pupils register which is kept by DUO (Dienst Uitvoering Onderwijs, i.e. the body that administers student grants and loans on behalf of the Dutch Ministry of Education) enabling us to follow the education career of VOCL'g9 survey respondents from 1999/ OO to 2008/ O9 and gather information about which grade the students were enrolled in during each successive year. We can therefore determine the education level attained at any time, to see for example whether the students had to repeat classes, and crucially whether they dropped out of school altogether. Furthermore, general ability tests were administered at the start of the survey giving us a good measure of school performance levels at the start of secondary school. A written questionnaire was also given to the parents of the surveyed students with the aim of collecting information about their families. To obtain information about potential delinquent behavior of our students, the individuals in VOCL'99 were linked to data on all crime suspects in the Netherlands between 1996 and 2007. This information was extracted from the Suspects Identification System (HKS) which is updated annually by the National Police Services Agency. A suspect is a person who has been charged with a crime. The aim of this chapter is to gain a better understanding of the mechanisms underlying the relationship between early school-leaving and delinquent behavior among juveniles both before and after leaving school. Therefore we focus only on the students in our sample who were no longer enrolled in education in school year 2008/09, since we need measures of delinquency both before and after leaving school for this population. This leaves us with 7,588 students who had left school with or without a basic qualification for our analysis.

For chapter 4 we again use the VOCL'99 dataset as a basic sample. For this study, we use tests measuring achievement motivation as well as the Five Factor Personality Inventory. Achievement Motivation was measured in January 2000 using the Academic Achievement Motivation Test (Hermans, 1970) and assesses a student's motivation to perform well in school. Personality was assessed in that same year with the Five Factor Personality Inventory (FFPI) developed by Hendriks, Kuyper, Offringa \& Van Der Werf (2008). The instrument has been tested nationally and internationally and has proven to be a reliable and valid measure to assess the Big Five Personality Traits (Hendriks et al., 2008). The FFPI yields a person's scores on Openness to Experience, Conscientiousness, Extraversion, Agreeableness, and Emotional Stability. From our initial sample of 19,391 students, we removed those who had died, were seriously ill or had moved abroad within the 1999/ 002010/ 11 period. Moreover, we excluded students who had missing values on our key variables. This leaves 14,230 students for our analyses.

The aim of Chapter 5 is to assess the impact of peer relations on early school-leaving. We again use the VOCL'99 as basic sample for this study. In addition, we use data from a sociometric questionnaire, conducted in January 2000 within the NWO research program '(Social-) Psychological factors as determinants of educational attainment'. As part of the sociometric questionnaire, students were asked to nominate classmates whom they liked best (maximum 3 nominations). For each nomination, the student was asked to report the surname and the 
first initial of the nominee. From these data, we were able to calculate both popularity (number of nominations received) and friendship (number of nominations given) for each student that had participated in the study. From our initial sample we excluded students who had died, were seriously ill or had moved abroad in the period between 1999/ 00 and 2010/ 11. In addition, we excluded students in classes that had response rates below 80 percent on the sociometric questionnaire. This leaves 10,898 students for our analyses. 


\section{The role of family resources, school composition and background characteristics in early school-leaving in lower secondary education ${ }^{3)}$}

\subsection{Introduction}

Early school-leaving has severe consequences for the life course of individual people, as well as a negative impact on society as a whole. It increases the risk of unemployment and low-paid jobs (Beckers \& Traag, 2005a), and also correlates with higher levels of delinquency. At the same time, growing concerns about the future supply of sufficiently skilled workers resulted in the Lisbon goal of reducing the proportion of early schoolleavers in all EU countries. For the Netherlands, the policy goal is to reduce the share of early school-leavers to 8 percent in 20104). To combat early school-leaving, we need more insight into the underlying factors that cause pupils to leave school prematurely. Notwithstanding the extensive research in this area, there are still significant blind spots. In this contribution, we shall improve current knowledge on early school-leaving in three ways. First, we use a comprehensive model, taking into account family resources, school composition factors5), and background characteristics simultaneously. Secondly, we apply this model to longitudinal panel data that provide independent variables measured at age

\footnotetext{
This chapter is published in Irish educational studies 30(1), T. Traag \& Van der Velden, R. (2011). Early school-leaving in the Netherlands: The role of family resources, school composition and background characteristics in early school-leaving in lower secondary education.

4) In 2000, 15.5 percent of all Dutch 18-to-24 -year-olds were considered early school-leavers; by 2006 this rate had decreased to 12.9 percent (Ministry of Education 2006). This is lower than the average of 25 percent in all $25 \mathrm{EU}$ countries, but higher than for example in Finland (7.9\%) and or Sweden (8.6\%). In Ireland, the percentage of early school leavers was $12.3 \%$ in 2006.

5) Apart from individual and environmental factors, other factors such as the economic climate can also affect early school-leaving, pushing and/or pulling young people from school into the labor market. However we do not discuss these factors in this contribution.
} 
twelve, well before early school-leaving took place. And thirdly, instead of comparing just two groups - dropouts and those who stay in education - we differentiate more, by distinguishing subgroups of early school-leavers. This further distinction between students with a lower and those with a full upper secondary qualification is necessary because a lower secondary qualification is no longer regarded as sufficient to enter the labor market (OECD, 2007).

Dutch secondary education starts at age 12, when pupils have to choose between three different tracks (see figure 1.1.1 in chapter 1 for an overview of the whole system). This contribution focuses on those pupils who started secondary education in the lowest track: pre-vocational secondary education (VMBO), which we shall refer to as lower secondary education. This lowest track accounts for about 55 percent of all enrolments at the start of secondary education. The other two tracks (pre-college education or HAVO, and preuniversity education or VWO) are the academic tracks that specifically prepare for higher education. The reason for focusing on the lowest track of secondary education is that early school-leaving is rarely a problem in the two other tracks. Our two research questions are:

1. What family resources, school composition factors and background characteristics influence the risk of early school-leaving?

2. Do the effects family resources, school composition factors and background characteristics differ between the subgroups of early school-leavers?

Our results show that cognitive capacities and motivation are important factors in the prevention of early school-leaving, especially for boys. Surprisingly, we found no significant effects for having an ethnic minority background after controlling for parental resources. With respect to the differentiation between groups of school-leavers, we found that the effects of all characteristics are always stronger for the dropout group than for the other two groups, suggesting that the underlying dimension is a continuum rather than a distinction between two or three totally different groups. Section 2.2 of this contribution elaborates the theoretical framework. In section 2.3 we describe our data and the variables used in our analyses. Section 2.4 gives a description of the findings, and section 2.5 contains the conclusions.

\subsection{Theoretical framework}

Human Capital theory focuses mainly on individual decisions to invest in education, and is very useful in explaining mechanisms in early school-leaving. The decision to leave education can be regarded as a rational choice (Becker, 1964; Boudon, 1974), in which costs and benefits may be constrained by social-structural variables. An important mechanism is what Breen and Goldthorpe (1997) call 'relative risk aversion'; i.e. young people want to 
acquire a level of education that will allow them to attain a class position at least as good as that of their family of origin, so investments in education are constrained by social class (O'Brien, 2003; Shavit \& Blossfeld, 1993). A lack of relevant family resources in this perspective is regarded as a lack of human capital (and as such, as a deficit).

In this contribution we do not intend to test the Human Capital approach as such, but we shall use it to make inferences on the processes underlying early school-leaving. We will distinguish three groups of explanatory factors ${ }^{6}$ : family resources, school composition factors and background characteristics.

\subsubsection{Family-related factors explaining early school-leaving}

Differences in school success not only relate to differences in individual characteristics, but also to differences in background. To understand how social origin leads to educational inequalities, we distinguish between different kinds of family resources (De Graaf \& De Graaf, 2002). These different resources determine the relative costs and benefits of staying in education. We distinguish the following four types of family resources: economic capital, human capital, social capital and cultural capital.

Let us look at the family's economic capital first. Parents with sufficient financial resources can provide their children with material goods they need in order to perform well at school; books and other learning materials, for example (Coleman, 1988; De Graaf, 1986). Parental income depends strongly on whether parents have paid work, and if so in what occupational group. Australian research has shown that school dropouts were more often from families where the father had a manual rather than a professional occupation, and where family income was low (Lamb, 1994). In Ireland 33 percent of children who come from families where the father is unemployed or low skilled did not continue school after the Junior Leaving Certification (National Youth Council of Ireland, 2001).

A family's human capital is defined as the cognitively stimulating environment it provides, and is measured in terms of the parents' education level. Parents with higher education are more likely to have greater knowledge of the school system and to view higher education as the preferred option for their children (Lamb, 1994; Rumberger, 1983).

Cultural capital is an important factor in explaining intergenerational transmission of inequality (Bourdieu \& Passeron, 1977; DiMaggio, 1982). Children of parents with high levels of cultural capital are better able to adjust to the dominant culture in schools than children of parents with less cultural capital. Children from the cultural elite are therefore more successful in school than children of culturally deprived parents, irrespective of their cognitive skills (De Graaf \& De Graaf, 2002).

Lastly, the family's social capital. Among other things, this concerns the relationship between parents and children. An effective transmission of resources from parent to child

6) Although the separation of some of the factors mentioned is quite artificial in some cases, we used this structure for the sake of clarity. 
requires sufficient interaction within the family (Coleman, 1988). Children from singleparent families have less social interaction, as only one parent is available. This is also true for children in large families, where children need to share interaction time with other siblings. This means that children in single-parent families and children in large families benefit less from their parents' resources, increasing the probability of leaving school early (Bhrolcháin, Chappell, Diamond, \& Jameson, 2000; Heard, 2004; McLanahan \& Sandefur, 1994; Nord \& West, 2001). Based on the above we expect to find negative effects of economic, human, social and cultural capital on early school-leaving.

Ethnic background can be seen as a separate dimension in resources. Ethnic minorities may lack specific resources that are necessary to succeed in life. Most importantly, in the context of the Netherlands, they lack human capital since second generation migrants attain lower educational levels than natives in the Netherlands. In addition to that, preschool participation rates are lower among second generation immigrants' children. Preschool participation is especially important among these groups because it is at this young age that linguistics competences are developed (Geerdes, 2009). Speaking the language of the host country is an important ingredient for educational success.

\subsubsection{Effect of school composition}

Effects of school composition are of particular importance, as they are the principal mechanism for governments to combat the problem of early school-leaving (Audas \& Willms, 2001). Schools tend to differ strongly in terms of performance and early schoolleaving. One major characteristic affecting performance and school careers is the proportion of children from ethnic minorities in a school. Studies in the Netherlands have revealed a clear relationship between a school's racial mix and the educational performance of its students (Van der Slik, Geert, \& De Bot, 2005; Van der Werf, Lubbers, \& Kuyper, 2002). Two main mechanisms underlie this relationship. First, average language skills in schools with large proportions of ethnic minorities are lower, as many students come from immigrant families who have not lived in the country long. Secondly, in these schools students have access to fewer cultural resources from their peers as most of them are from a lower social background. Van der Werf, Lubbers and Kuyper (2002) showed that students in urban areas are less successful than students in non-urban areas.

The Dutch education system is highly stratified and consists of three different educational tracks. Some secondary schools offer only one or two tracks, others offer all three. An interesting school characteristic in this respect is whether students attend a school which also offers the upper academic tracks. Based on Human Capital theory, we would expect students in heterogeneous schools not only to learn from their teachers, but also from their co-students. In heterogeneous schools, weaker students can learn from and be stimulated by stronger ones, thus reducing their chances of leaving school early. 
Summing up, we expect to find a positive effect for attending a school with a large share of ethnic minorities, as well as a positive effect for attending a school in an urban area. Also, we expect attending a heterogeneous school to have a negative effect on the risk of leaving school early.

\subsubsection{Background characteristics}

The most important individual factor in educational success is the students' cognitive abilities. Early school-leavers show lower levels of cognitive ability and perform less well in school compared to other students (Alexander et al., 2001; Audas \& Willms, 2001; Cairns, Cairns, \& Neckerman, 1989; Ensminger \& Slusarcick, 1992). In addition to differences in cognitive abilities, dropouts also do not work to their full potential (Barrington \& Hendricks, 1989) and show a lack of aspiration as well as motivation (Alexander, Entwisle, \& Horsey, 1997; Audas \& Willms, 2001). Recent studies on differential selection between boys and girls have shown that low-ability boys are selected out of university-bound programs early on (Baucal, Pavlovic-Babic, \& Willms, 2006).

In the Netherlands, relatively more boys than girls attend special education, boys perform less well in school, and significantly fewer boys than girls enter higher education (Marks \& Fleming, 1999; Rumberger, 1995; Veendrick, Tavecchio, \& Doornenbal, 2004)7). It is not clear whether this lower performance by boys is caused by lower cognitive abilities or whether the effects of cognitive abilities are stronger for boys than for girls.

The second individual factor is participation and identification. Participating in school leads to identification (Beekhoven, 2004; Voelkl, 1995). If students identify with their school, participation is strengthened and students enjoy going to school. A lack of identification with the school results in a decrease in participation and an aversion to school, thus increasing the risk of early school-leaving (Alexander et al., 1997; Audas \& Willms, 2001; Marks, 1998).

Based on the previous findings described above, we expect to find positive effects of being a boy, negative effects for cognitive ability and motivational aspects, as well as negative effects for the degree to which students like their school. Also, we expect to find a significant interaction effect of gender and cognitive ability.

\subsubsection{Breakdown into subgroups of early school-leavers}

This contribution distinguishes subgroups of early school-leavers. The reason for this breakdown is that we expect that school-leavers with no diploma at all differ from school-

7) However, this effect of gender is not found in all studies (Barrington and Hendricks 1989). 
leavers who did attain a diploma below the level of upper secondary education. We expect differences with respect to their characteristics, as well as to their opportunities in later life, as they have attained different levels of education. Therefore we anticipate that the effects will remain in the same direction, but be stronger for dropouts than for those who attained a qualification, albeit it a low one. Our analyses assess whether our independent variables influence the risk of early school-leaving and compare these effects for each group of (early) school-leavers to the group of students that attained at least an upper secondary qualification.

\subsection{Data and methodology}

For this analysis we use a large representative longitudinal survey carried out in the Netherlands by Statistics Netherlands and the Groningen Institute for Educational Research (Driessen \& Van der Werf, 1992; Statistics Netherlands, 1991). This survey, the so-called Secondary Education Student Cohort 1989 (VOCl'89) consists of 19,254 students from a random sample of 108 schools, who started secondary school in 1989/ 90, and whose educational career has been followed since then ${ }^{8}$. This makes it possible not only to determine the educational level at any given time, but also to see whether students repeated classes or dropped out, or whether they transferred to a higher or lower track of education. Furthermore, students were tested on school performance and non-verbal intelligence in the first year of secondary education. Parents of the students received a questionnaire at the start of the survey, with the aim of collecting information about the families and the pupils. Driessen and Van Der Werf (1992) tested the representativeness of the sample both at the level of the schoola) and of the individual student ${ }^{10}$. On the whole, the survey can be regarded as nationally representative for all students in the first year of secondary education in 1989/ 90. More specific information about the cohort study in general and missing data analyses can be found in the VOCL reports (Driessen \& Van der Werf, 1992; Statistics Netherlands, 1991).

\footnotetext{
8) The data collection for VOCL is largely based on registry data of enrolment in subsidized education. Therefore, panel attrition and measurement error are not of major concerns.

9) At the school level, analyses were carried out on the number of students in the first year, the size of the municipality, region and denomination. Large schools (over 206 students in year one) were underrepresented in the sample while schools with 56 to 65 students were slightly overrepresented. The largest municipalities were also underrepresented, as well as the Amsterdam region and the whole of the province North Holland. This was caused by the relatively large proportion of schools in Amsterdam that refused to participate in the study.

10) At the individual level, analyses were carried out on the representativeness of the sample based on the educational tracks provided in the school, gender, school recommendation, availability of parental data from the parental questionnaire, availability of data on ethnicity, the number of students with special needs, the educational and occupational level of the parents and the participation in school performance tests. These analyses showed that the total number of students in pre-vocational secondary education (VMBO) in the sample was consistent with the total population in the school year $1999 / \sim 00$. Students with missing data on ethnicity, parental occupation and parental education were shown to have lower scores on the school recommendation test and the scale for school perception, although these differences were not significant.
} 


\subsubsection{Population}

All students who had ever attended lower secondary education (VMBO) were selected from the initial VOCL'89 population. Thus, even students who started secondary education in one of the two higher tracks (i.e. pre-college education HAVO or pre-university education VWO), but later moved down to the lower track were also included in our sample. This resulted in a total of approximately 10 thousand students in lower secondary education (VMBO). These students were then divided into our subgroups of early school-leavers, based on their highest achieved level of education. The VOCL study covers only subsidized") full-time education, so students who entered part-time education are no longer monitored. However, as one of the tracks in senior secondary vocational education (MBO) consists of apprenticeship training combined with school, and leads to a qualification at upper secondary level, we decided to form an extra subgroup of students of whom we know that left full-time education but entered one of these programs. However, as we do not know whether they successfully completed this education, our dependent variable is divided in the following four groups:

- students with no diploma at all (“dropouts") ( $N=1,208)$;

- students with only a lower secondary education diploma (VMBO: 'low qualified') (N=3,409);

- students who successfully attained a diploma in lower secondary education and then entered an apprenticeship training ('apprentices') $(\mathrm{N}=1,034)$;

- students with a full upper secondary qualification (ISCED 3, 3b and 3 c long or above, i.e. senior cycle of secondary level and higher in the Irish case), $(\mathrm{N}=4,828)$.

Table 2.3.1 presents an overview of all independent variables we use in our analysis. See the appendix for a more detailed description of our variables.

\subsubsection{Statistical modeling}

Our analyses involve the breakdown of the total effect of individual, family and school characteristics on early school-leaving into two sources of variation: differences at the individual level and differences between schools. To deal with this, we use random coefficient or multilevel models. The basic idea of multilevel analysis is that data with a nested structure are not adequately represented by the probabilistic model of multiple regression analysis, but should be analyzed in a hierarchical linear model or random coefficient model (Goldstein, 1995; Snijders \& Bosker, 1999). We use a multinomial logistic model to take account of the fact that our dependent variable has four categories. Our

\footnotetext{
1) As all private education is excluded from the VOCL data collection, students may in fact have attained an upper secondary level qualification while this was not included in our data. There are no reliable figures on the number of students in private education in the Netherlands, although Regioplan (2007) estimated that there were about 34 private schools in the Netherlands with about 1,00o students overall, including primary education. Therefore we do not consider this shortcoming of our data design to cause bias in our results.
} 


\subsubsection{Overview of variables used in the analysis}

\begin{tabular}{|c|c|c|}
\hline Variable & Range & Notes \\
\hline \multicolumn{3}{|c|}{ Demographic individual characteristics } \\
\hline \multicolumn{3}{|l|}{ Sex: males } \\
\hline \multicolumn{3}{|l|}{ Ethnicity: ethnic minority } \\
\hline \multicolumn{3}{|l|}{ Cognitive capacities } \\
\hline Nonverbal intelligence ${ }^{1)}$ & $0-1$ & $\begin{array}{l}\text { Consists of subtests for verbal-linguistic-, mathematical-and visual-spatial } \\
\text { intelligence (Van Dijk \& Tellegen, 1994). The construct has a validity of .84. }\end{array}$ \\
\hline School performance ${ }^{1)}$ & $0-1$ & $\begin{array}{l}\text { Consists of three subtests: Dutch language, mathematics and information } \\
\text { processing). }\end{array}$ \\
\hline School recommendation ${ }^{11}$ & $5-9$ & $\begin{array}{l}\text { The recommended track, as given by the teacher in the final grade of primary } \\
\text { education. Scale based on Bosker, Hofman and Van der Velden (1985). }\end{array}$ \\
\hline \multicolumn{3}{|l|}{ Participation and identification } \\
\hline School motivation ${ }^{1)}$ & $0-1$ & $\begin{array}{l}\text { Was measured using the following two statements presented to the students: 'I like } \\
\text { to do my homework well, even if I find it difficult' and 'I don't try to do my best at } \\
\text { school' (reversed). }\end{array}$ \\
\hline School perception ${ }^{1)}$ & $0-1$ & $\begin{array}{l}\text { Based on a scale with } 11 \text { items on how students perceived the school ("I like going to } \\
\text { school") their teachers ("My teachers are always fair") etcetera. It measures the } \\
\text { degree to which a student likes school, and is used as a proxy for identification with } \\
\text { school. }\end{array}$ \\
\hline \multicolumn{3}{|l|}{ Economic capital } \\
\hline Social classa & & Based on the occupation of the breadwinner in the household. \\
\hline \multicolumn{3}{|l|}{ Human capital } \\
\hline Parental education ${ }^{1)}$ & $6-19$ & Scale based on Bosker, Hofman and Van der Velden (1985). \\
\hline \multicolumn{3}{|l|}{ Cultural capital } \\
\hline Cultural participation ${ }^{1)}$ & $0-1$ & Extent to which the parents visited museums, concerts and the theatre. \\
\hline Parents reading books ${ }^{1)}$ & $0-1$ & Number of books read by the parents per month \\
\hline \multicolumn{3}{|l|}{ Social capital } \\
\hline Parental support ${ }^{11}$ & $0-1$ & $\begin{array}{l}\text { Prevalence of parents having discussions about school, having discussions about } \\
\text { school performance and giving compliments about school performance. }\end{array}$ \\
\hline \multicolumn{3}{|c|}{$\begin{array}{l}\text { Family typea: single parent versus } \\
\text { two-parent household } \\
\text { Number of children in the family }{ }^{1)}\end{array}$} \\
\hline \multicolumn{3}{|l|}{ School level } \\
\hline$\%$ of ethnic minorities & & This proportion is measured as the deviation from the population mean \\
\hline Municipality & & Based on number of addresses per $\mathrm{km}^{2}$ \\
\hline School heterogeneity & & $\begin{array}{l}\text { Does the school provide only the lowest track, or does it also provide one or both } \\
\text { tracks in upper secondary education? }\end{array}$ \\
\hline
\end{tabular}

Notes: All scale variables were centered on the population mean.

1) Measured at age 12 .

model has a hierarchical structure in which individuals $i$ are nested in schools $j$. In this model $t$ denotes the reference category: students who attained a diploma in upper secondary education. For each of the remaining $t-1$ categories $s$, the two-level random intercept model specified is:

$\log \left(\frac{\pi_{i j}^{s}}{\left.\pi_{i j}^{t}\right)}\right)=\beta_{0}^{s}+\beta_{1}^{s} X_{j}+u_{j}^{s}$

where $u_{j}^{s}$ is a school-level random effect, assumed to be normally distributed with mean $\mathrm{O}$ and variance $\mathrm{s}_{\mathrm{u}}{ }^{2 \mathrm{~s}}$. 


\subsection{Empirical results}

Since the main aim of the contribution is to analyze characteristics that influence early school-leaving, we compare each of the three types of early school-leavers to those who did attain a full upper secondary education qualification (see table 2.4.1). However, the table also shows whether effects differ significantly between adjacent groups.

Our analyses show an elevated risk for boys to leave school early. Boys are almost twice as likely to leave school with a low or no qualification. Also, boys are about 2.5 times more likely to continue in an apprenticeship program. This large effect is mainly a result of the fact that many of these programs include engineering and technology and are predominately male-oriented. For ethnicity, we find a negative effect, but only when considering students who left after attaining a diploma in lower secondary education. This is quite surprising, as most studies find a higher risk for students from ethnic minorities to leave school early (Marks \& Fleming, 1999; Rumberger, 1995; Wit \& Dekkers, 1997). However, they usually do not take into account other characteristics of the students, the family, and the school simultaneously as we do in this model.

With respect to cognitive capacities, high school performance, recommended track, positive motivation, and positive school perception, all these factors significantly decrease the risk of leaving school early. The only exception is our measurement of intelligence. Students who scored lower on our test for non-verbal intelligence do not have a higher risk of leaving school early. Note that given the interaction term with gender, the estimates in the table present the effects for girls. The interaction effects of gender by cognitive capacities also show significant differences between boys and girls. School performance and motivation affect boys more than girls with respect to their risk of leaving school early. Our theory that effects are strongest for dropouts compared to those with low qualification does not hold for all measures of cognitive ability. We found stronger effects for both performance and motivation, but weaker effects for recommendation. Those who continue education in an apprenticeship program are shown to be quite a distinctive group with respect to cognitive ability. Although they show significantly lower levels of school performance than the reference group, they are quite similar to the other groups. However, they did not receive a significantly lower school recommendation, and they do not perceive school differently than the reference group. And although they show a significantly negative effect for motivation, this is only significant at the .05 level.

In general, students from low social classes (i.e. the reference group, non-employed parents) are more at risk of dropping out of school than all other social groups. For students with self-employed parents without employees the risk of dropping out seems to be the 


\subsubsection{Individual and school-level influences on early school-leaving from lower secondary education: logit effects and odds ratios}

\begin{tabular}{|c|c|c|c|c|c|c|}
\hline & \multicolumn{2}{|l|}{ No diploma at all } & \multicolumn{2}{|l|}{$\begin{array}{l}\text { Lower secondary } \\
\text { education only }\end{array}$} & \multicolumn{2}{|c|}{$\begin{array}{l}\text { Part-time apprenticeship } \\
\text { program }\end{array}$} \\
\hline & Logit & Odds ratio & Logit & Odds ratio & Logit & Odds ratio \\
\hline Intercept & $-1.214^{* *}$ & -.297 & -.092 & -.913 & $-1.529^{* *}$ & -.217 \\
\hline \multicolumn{7}{|l|}{ Sex } \\
\hline $\begin{array}{l}\text { Male } \\
\text { Female (ref). }\end{array}$ & $.612^{* *}$ & -1.845 & $.588^{* * * *}$ & -1.800 & $.896^{* *}$ & -2.449 \\
\hline \multicolumn{7}{|l|}{ Ethnicity } \\
\hline \multicolumn{7}{|l|}{ Native (ref). } \\
\hline Foreign & .037 & -1.037 & $-.184^{*}$ & -.832 & .031 & -1.031 \\
\hline Intelligence & -.198 & -.820 & -.021 & -.979 & .185 & -1.203 \\
\hline School performance & $-2.176^{* *}$ & -.113 & $-1.221^{* *}$ & -.295 & $-1.773^{* *}$ & -.170 \\
\hline School recommendation & $-.331^{* *}$ & -.718 & $-.642^{* *}$ & -.527 & -.077 & -.927 \\
\hline School motivation & $-1.126^{* *}$ & -.324 & $-.459^{* *}$ & -.632 & $-.468^{*}$ & -.626 \\
\hline School perception & $-.432^{*}$ & -.649 & $-.466^{* *}$ & -.628 & -.355 & -.701 \\
\hline \multicolumn{7}{|l|}{ Social class } \\
\hline Manual laborers & $-.713^{* *}$ & -.490 & $-.212^{* *}$ & -.809 & $-.290^{* *}$ & -.748 \\
\hline Self-employed, no employees & $-1.110^{* *}$ & -.330 & $-.648^{* *}$ & -.523 & $-.764^{* *}$ & -.466 \\
\hline Self-employed, with employees & $-.833^{* *}$ & -.435 & $-.371^{* *}$ & -.690 & $-.800^{* *}$ & -.449 \\
\hline Skilled blue-collar workers & $-.709^{* *}$ & -.492 & $-.281^{* *}$ & -.755 & -.237 & -.789 \\
\hline Office workers & $-.784^{* *}$ & -.457 & $-.408^{* *}$ & -.665 & $-.432^{* *}$ & -.649 \\
\hline Professionals & $-.744^{* *}$ & -.475 & $-.649^{* *}$ & -.523 & $-.331^{*}$ & -.718 \\
\hline \multicolumn{7}{|l|}{ Unemployed (ref). } \\
\hline Parental education & $-.071^{* *}$ & -.931 & $-.061^{* *}$ & -.941 & $-.037^{* *}$ & -.964 \\
\hline Cultural participation & $-.406^{* *}$ & -.667 & $-.343^{* *}$ & -.710 & .058 & -1.060 \\
\hline Reading books & .139 & -1.149 & -.035 & -.966 & .054 & -1.056 \\
\hline Parental support & $-.656^{* *}$ & -.519 & $-.447^{* *}$ & -.639 & $-.375^{* *}$ & -.687 \\
\hline \multicolumn{7}{|l|}{ Family type } \\
\hline $\begin{array}{l}\text { Single parent } \\
\text { Two parents (ref). }\end{array}$ & $.263^{* *}$ & -1.300 & $.210^{*}$ & -1.234 & $-.344^{* *}$ & -.709 \\
\hline \multicolumn{7}{|l|}{ Number of children in the family } \\
\hline \multirow{2}{*}{\multicolumn{7}{|c|}{ Two or three children (ref.) }} \\
\hline & & & & & & \\
\hline Four children & $.633^{* *}$ & -1.883 & $.387^{* *}$ & -1.472 & .133 & -1.142 \\
\hline$\%$ of foreign students & $.013^{*}$ & -1.013 & .008 & -1.008 & .003 & -1.003 \\
\hline \multicolumn{7}{|l|}{ Municipality } \\
\hline Very high & .162 & -1.176 & -.201 & -.818 & -.055 & -.946 \\
\hline High & $.381^{*}$ & -1.464 & .152 & -1.164 & .295 & -1.343 \\
\hline \multicolumn{7}{|l|}{ Moderately high (ref.) } \\
\hline Low & $-.358^{*}$ & -.699 & $-.344^{* *}$ & -.709 & -.103 & -.902 \\
\hline Very low & -.347 & -.706 & -.293 & -.746 & -.251 & -.778 \\
\hline \multicolumn{7}{|l|}{ School heterogeneity } \\
\hline \multicolumn{7}{|c|}{ Includes no higher education than VMBO (ref.) } \\
\hline Includes higher levels of education & $-.303^{*}$ & -.739 & $-.232^{*}$ & -.793 & -.120 & -.887 \\
\hline Sex*intelligence & -.205 & -.814 & .130 & -1.139 & -.464 & -.629 \\
\hline Sex*school performance & $-1.036^{* *}$ & -.355 & $-1.082^{* *}$ & -.339 & -.251 & -.778 \\
\hline Sex*school recommendation & -.079 & -.924 & .117 & -1.124 & $-.393^{* *}$ & -.675 \\
\hline Sex*school motivation & $-.750^{* *}$ & -.472 & $-.454^{* *}$ & -.635 & -.438 & -.645 \\
\hline Sex*school perception & .221 & -1.247 & .178 & -1.195 & .476 & -1.609 \\
\hline-2 log likelihood & 18,128 & & 15,876 & & 15,471 & \\
\hline
\end{tabular}

Source: VOCL'89.

Notes: ${ }^{* *} p<=.01 ;{ }^{*} p<=.05$ with reference category $=$ left full-time education with a full upper secondary qualification; bold $p<=.01 ;$ italic $p<=.05$ with reference category = adjacent group; ref. = reference category. 
smallest. This could be caused by the fact that these students want to take over their parents' business in the future, giving them a clear goal in life. Effects for social class are significantly stronger when considering the risk of leaving school without a diploma ('dropouts') compared to those who leave school after attaining a diploma in lower secondary education ('low-qualified'). Parental education also shows a significant relationship to the risk of dropping out. For every additional year of parental education, the risk of dropping out of school decreases by approximately 7 percent, although the effect is somewhat smaller for the apprenticeship group.

Cultural participation is negatively linked to the relative risk of dropping out of school or acquiring a low level diploma: having parents who frequently visit museums, concerts and the theatre decreases early school-leaving for these two categories, but we find no difference for the group who moved into apprenticeship programs. Parental reading behavior showed no significant effect on dropping out.

The amount of available social capital is important in explaining dropout behavior. Pupils with very supportive parents are up to 50 percent less likely to drop out of school compared to pupils with totally unsupportive parents. At the same time, the family composition and the number of children in a family are also of importance. Children from single-parent families and children in families with four or more children are more at risk of dropping out. However, growing up as an only child also significantly increases the risk of dropping out. This contradicts the assumption that having fewer children increases the transmission of social capital, therefore decreasing the risk of early school-leaving. It may be the case that parents with only one child have more opportunities to continue to work full-time, therefore effectively decreasing the available time per child compared to two-child families. Unfortunately, we were unable to test this hypothesis with our data. The results are different for the group of apprentices. Growing up with a single parent correlates negatively with being in apprenticeship training, while there is no effect of number of siblings.

Relatively large numbers of students from ethnic minorities in a school increase the risk of dropping out, after controlling for the individual effect of being a minority student. Students at an entirely 'black' school are more likely to drop out than those in an entirely 'white' school. In general, a 10 percent decrease in the share of students from ethnic minorities in a school results in a 13 percent decrease of the dropout risk. Degree of urbanization of the region in which the school is located only partly correlates with the dropout risk. Students in extremely urban regions are about 1.5 times more at risk of dropping out than students in moderately urban regions. However, dropout risks in regions with a very low and a very high degree of urbanization do not differ significantly from the risks in moderately urban regions, although this may well be caused by a relatively small number of observations of schools in non-urban regions. Students in lower secondary education attending a school that also provides higher tracks of secondary education are less at risk of dropping out of school or attaining only a low level diploma. 
So instead of being deterred by being in a more academic environment, students in lower levels of education appear to be encouraged to stay in school as a result of the more academic climate ${ }^{12}$.

\subsection{Conclusion and discussion}

In this contribution we used an elaborate multilevel model, consisting of individual and family-based characteristics on the first level and school-level factors on the second level, to explain early school-leaving. Most of our hypotheses on factors explaining early schoolleaving were confirmed in this study, supporting findings in previous studies on early school-leaving. One important mechanism driving early school-leaving is related to individual abilities and preferences. The student's cognitive abilities and school performance affect the cost of further investment in schooling while the student's motivation will affect the willingness to make such investments. The family resources constitute a second major mechanism. We found clear evidence that the different forms of family capital (economic, human, social and cultural) affect the chances of early schoolleaving. While a part of these effects can be interpreted as affecting the costs of investing in education (more resources lower the costs), another part must be interpreted as affecting the relative benefits of investment in education (the returns to education are perceived to be higher for students from higher social classes). Finally we also found evidence that school composition factors have an effect on early school-leaving. Although we have taken up only a limited number of school characteristics in our analysis, the results clearly show that schools differ systematically in early school-leaving: schools with high proportions of ethnic minorities show higher dropout rates, while schools that offer higher tracks show lower dropout rates in the low track than schools that only offer the low track. However in future research the influence of the school should be further elaborated on, by adding variables on school climate and school ethos in order to better understand why some schools produce more successful students than others.

This study has advanced the knowledge on who leaves school early and why in at least three important ways. First, we used an integrated model composed of individual characteristics such as cognitive abilities, family resources (economic, human, cultural and social capital) and school-level variables. By using such an elaborate model we were able to identify better what characteristics explain early school-leaving. An important finding was the stronger effects of cognitive abilities and school motivation on early

12) This finding is very much in line with school effectiveness research showing a multiplier effect where students in schools with a high concentration of lower track or lower performing students experience an additional negative effect across a range of outcomes. 
school-leaving for boys compared to girls ${ }^{13)}$. The results also underline the importance of family resources, especially in terms of cultural and social capital. A surprising result compared to previous research is the fact that this study found no significant effects for the risk of dropping out of school for students from ethnic minorities when controlling for parental resources like social class and parental education. In fact, when considering the risk of leaving school after graduating from lower secondary education, ethnic minority students are less likely to leave school altogether. One explanation could be that these students are more motivated than native students. Goldsmith (2004) showed that black and Latino students have high occupational expectations, educational aspirations, and concrete attitudes compared to white students, which may serve as a protective factor against early school-leaving. Another study, by Johnson, Crosnou and Elder (2001), showed that African American adolescents are more actively engaged in classroom and school activities. Thus these students may compensate the fact that they relatively more often stem from lower social backgrounds by higher levels of motivation and school perception. A second advancement on previous studies is the differentiation between groups of early school-leavers. Most studies divide early school-leavers into two groups, based on whether they attained a diploma or not. In this study we distinguished four groups of schoolleavers, separating 'real' dropouts and early school-leavers who left school after attaining a diploma in lower secondary education from those who continued education either parttime of full-time. In this distinction dropouts can be regarded as the lowest end of a scale of school success ranging from dropout, via leaving education after attaining a diploma in lower secondary education, moving on to an apprenticeship track, to obtaining a full upper secondary qualification. The results show that the effects of all characteristics are always stronger for the dropout group than for the other two groups, suggesting that the underlying dimension is a continuum rather than a distinction between two or three totally different groups.

Finally, we used longitudinal data on a cohort of pupils in the first year of secondary education with a multitude of individual, family, and school characteristics that were measured when students were still in the first year. This makes the direction of causality in our findings more plausible. As education is compulsory until the age of sixteen, we can assume that the data relating to the explanatory factors were measured at least three years before the event of early school-leaving. This makes our findings especially valuable; as it means that we can start combating early school-leaving in an early stage, focusing on students who lack motivation and a positive school perception, students with poor cognitive abilities and students in underprivileged families.

Although this chapter focuses on processes underlying early school-leaving in the Netherlands, many of the issues examined in the chapter and the findings will apply to other educational contexts within Western society as well. This especially holds true for

13) These findings are in line with previous results found in Serbia (Baucal et al. 2006). 
the gender, social background, motivational and cultural capital effects. Moreover there are two important lessons to be learned from the Dutch context.

One is the importance of a system of apprenticeship or some equivalent like the technical education provided by the vocational and community schools in Ireland. In the Dutch context the apprenticeship system seems to be an important safety net for - mainly male students who otherwise would have dropped out. Boys have a much higher risk of dropping out than girls and the provision of such a safety net is an important means to combat early school-leaving.

Another important lesson to be taken for other countries is to not solely focus on those who leave school without any diploma, but also set out policies for those that leave school immediately after the school-leaving age was reached, having attained very little qualification. Not only do they suffer the disadvantage of being low educated, but they more often also come from disadvantaged backgrounds as was shown in our analyses.

\subsection{Appendix Measuring background variables, resources and control variables}

Ethnic background is measured by the country of birth of both the respondent and one of his or her parents. Someone is considered to belong to an ethnic minority if either the respondent or his or her parents were born in one of the non-Western countries listed in the Employmentof Minorities (Promotion) Act (Wet SAMEN).

The school recommendation is based on the recommendation that students were given by the primary school concerning the type of secondary education for which they were best suited. In the final year of primary education most children complete a test (CITO-toets) which is comparable to the SAT. Based on this test and his/her own observations the primary school teacher will then give advice for the type of secondary education most suitable for the student. This advice was coded on a scale developed by Bosker, Hofman, and Van der Velden (1985) expressing the progress towards the top of the educational system. We then subtracted the population mean from the individual school recommendation score.

School performance was based on the total score in three tests (Dutch, mathematics andthe ability to process information), which were taken halfway during first grade. Each of the tests consisted of 20 multiple-choice questions. The values of Cronbach's alpha for 
the thre etests were $.76, .84$ and .77 , respectively. The total score was expressed on a scale from 0 to 1 . We then subtracted the population mean from the individual school performance score.

Non-verbal intelligence was measured using two tests. The first sub-test (PSB-3) measured the ability to reason and the second sub-test (PSB-8) the ability to abstract. Both subtestscontained 40 items. The values of Cronbach's alpha were .82 and .90, respectively. The numbers of correct items from both sub-tests were added together and this total sum was transformed to a scale with a minimum value of $o$ and a maximum value of 1 . We then subtracted the population mean from the individual non-verbal intelligence score.

school motivation was measured using the following two statements presented to the student: 'I like to do my homework well, even if I find it difficult' and 'I don't try to do my best at school' (reversed). The average of both items was taken. The value of Cronbach's alpha was .45. The total score was transformed to a scale from o to 1 . We then subtracted thepopulation mean from the individual school motivation score.

School perception was based on a scale with 11 items on how students perceived the school ('I like going to school'), their teachers ('My teachers are always fair') etcetera. It measures thedegree to which a student likes school, and is used as a proxy for identification with school. The value of Cronbach's alpha for this scale was .75. The scores on this scale range from o to 1. We then subtracted the population mean from the individual school motivation score.

Two indicators determined the social background of the school-leavers, the educational level of the parents and the social class of the parents. The educational level of the parents was determined according to the Standard Education Classification 1978 (Statistics Netherlands, 1987). The average educational level of both parents was used. The different levels were then converted to the average number of years of education according to the above-mentioned scale by Bosker, Hofman, and Van der Velden (1985). The following values were assigned: six years (primary education, ISCED 0-1), 10 years (secondary education, lower level, ISCED 2), 14 years (secondary education, higher level, ISCED 3), 17 years (tertiary education, first phase, ISCED 5 bachelor) and 19 years (tertiary education, second phase, ISCED 5 master or ISCED6). We then subtracted the population mean from the individual parental educational level.

The social class of the parents was based on information about the type of work and the occupation of the main breadwinner in the family. The following categories were distinguished:(1) not employed; (2) manual laborers; (3) self-employed without employees; (4) self-employed with employees; (5) skilled blue-collar workers; (6) office workers; and (7) professionals.

The cultural resources of the parents were measured according to their degree of cultural participation and their reading behavior. The items used in determining the position on the scale for cultural participation concerned the extent to which the parents visited museums, concerts and the theatre. The value of Cronbach's alpha for this scale was .88. The items used in determining the position on the scale for reading behavior concerned 
the number of books read by the parents per month. The value of Cronbach's alpha for this scale was .40. The scores on both scales were converted to values between $\mathrm{o}$ and 1 .

The amount of parental educational support was based on questions to both parents about having discussions about school, having discussions about school performance and giving compliments about school performance. These items were combined to provide a scale with a minimum value of $\mathrm{o}$ and a maximum value of 1. The value of Cronbach's alpha was .81. For these four variables we subtracted the population mean from the individual score.

The type of family was derived from the questionnaire sent out to parents during the first secondary school year. If parents indicated that there was no second parent or caretakerpresent in the family, the family is considered to be single parent household. In the same questionnaire parents were asked how many children were in the family, including the child in the sample.

The school's heterogeneity is divided into two groups: schools where there are only students on the lower secondary education level (i.e. VMBO) and schools that also consist of students from higher levels of secondary education (HAVO and VWO).

The percentage of students from ethnic minorities is computed by dividing the total number of ethnic minorities in the sample in the school by the total number of students in that school. Thus this figure is based on a total of 19,524 students in the initial sample. Then the deviation of the population mean was computed and used in the analysis.

The degree of urbanization is based on the number of addresses per $\mathrm{km}^{2}$ in the region. If there are 2,500 addresses or more, the urbanization rate is very high. Regions with 1,500 to 2,500 addresses are considered highly urbanized, while regions with 1,000 to 1,500 are considered moderately urbanized. Regions with 500 to 1,000 addresses have a low urbanization rate. Regions with less than 500 addresses are very low urbanized. 


\section{Social Bonding, Early School- Leaving, and Delinquency ${ }^{14)}$}

\subsection{Introduction}

Social control was introduced as a theoretical framework to explain the causes of delinquency among juveniles (Hirschi, 1969). Its basic contention is that the quality and strength of social bonds that youths form, for example with their school, should be strong predictors of their likelihood of becoming criminally active or not. It is now, however relatively widely accepted that social control alone cannot explain youth delinquency and the importance of a person's capacity for self-control must also be taken into consideration. This is perhaps best summed up by Gottfredson and Hirschi (1990) when they state that: "Combining the two ideas thus merely recognizes the simultaneous existence of social and individual restraints on behavior" (pp. 87-88). The implication of this change in perspective is significant since it can now be asserted that for given levels of social bonding, we may observe very different behavioral outcomes - such as offending and early school-leaving - which actually result from differences in individual propensity for self-control. So far there have been surprisingly few attempts to distinguish and measure the importance of these two possible channels to explain participation in risky behavior by youths.

In this chapter we therefore propose to investigate how successful social bonding theory is at predicting juvenile delinquency and early school-leaving. To account for the influence of self-control capacity we adopt a simple dynamic approach which assumes that past involvement in risky behavior reduces individual restraints for future participation in risky behavior. We test these hypotheses empirically by first constructing four measures of school social bonding (i.e. attachment to other students, commitment to school performance, belief in school rules, and school performance) from a large survey of secondary school pupils. This is then matched to micro-data containing information on both education and offending for these individuals from adolescence to early adulthood.

\footnotetext{
14) This chapter is published as a ROA Research Memorandum, T. Traag, Marie, O., \& Van Der Velden, R. K. W. (2010). Social Bonding, Early School-leaving, and Delinquency. ROA Research Memorandum no. 14.
} 
We also have detailed family background characteristics to control for non-school related bonding factors which may simultaneously affect delinquency and early school-leaving. The nature of our data enables us to consider a dynamic setting which estimates the impact of social bonds on sequential participation in risky behavior: delinquency before leaving school; leaving school with no qualification; and delinquency after leaving school. We also analyze how sensitive our results are to the inclusion of participation in one of these behaviors in the past, and how our social bonds estimates differ across youths who were involved or not previously. This approach allows us to disentangle the importance of social and individual restraints on risky behavior. Our main finding is that school performance is consistently the most important social bond protecting against participation in any of our three risky behavior outcomes. It is also the only bonding measure which remains significant throughout once we account for family background and previous behavioral patterns. Lastly, we also find significant differences in the importance of school performance levels in predicting early school-leaving and whether a student was arrested before leaving school or not.

The rest of the chapter is structured as follows: Section 3.2 presents a short literature review and sets up the theoretical framework forming the basis for our empirical analysis. Section 3.3 describes the data used for this study. Section 3.4 gives some descriptive statistics and sets up the modeling strategy. Section 3.5 reports and discusses our results. The final section contains concluding remarks.

\subsection{Literature review and theoretical framework}

Hirschi (1969) argued that delinquency among adolescents could be predicted by looking at the strength and quality of the bonds they formed with, among other social institutions, their schools. In his theory, later labeled Social Bonding Theory, Hirschi defined four main categories of social bonds (Burfeind \& Bartusch, 2010; Hirschi, 1969). The first is attachment, defining the quality of the bond between students and their school; it refers to the emotional ties to teachers and school officials. The second is commitment, which refers to the desire to succeed and the degree of commitment to academic pursuits. The third is involvement, which refers to school performance, attendance and attentiveness in the classroom, which we shall further refer to as performance. The fourth and last element is belief, which refers to believing that school rules are fair and are enforced evenly. 
A number of studies have found evidence that a lack of social bonding is directly associated with delinquent behavior (Gottfredson \& Hirschi, 1990; Jenkins, 1995; Krohn \& Massey, 1980; Thornberry, Moore, \& Christenson, 1985). Other studies applied Hirschi's theory to other forms of illicit behavior, such as drug and alcohol abuse (Akers \& Lee, 1999; Eitle \& Eitle, 2007; Ketterlinus \& Lamb, 1994), ethical rule breaking (Sims, 2002). More related to our research, Jenkins $(1995,1997)$ considered the effect of school bonding and delinquency at school and Jarjoura (1993) the impact of dropping out of school on future offending. Here we shall combine these two approaches to measure how the impact of social bonds on risky behavior evolves with an individual's past involvement in such activities.

Developmental criminologists claim that offenders who display delinquent behavior in the early stages of their life course are the ones most likely to become persistent offenders showing consistent patterns of delinquency. However, not all young offenders become lifetime criminals. In her developmental taxonomy, Moffitt (1993) makes a distinction between life-course-persistent and adolescence-limited antisocial behavior, arguing that adolescents start antisocial behavior because they are attracted by the independence and autonomy of peers who displayed problematic behavior in early life. They may nevertheless still be bonded enough to their parents, their school and other social institutions to stop engaging in risky behavior when they enter adulthood. This developmental approach from the criminology literature is of interest here as it highlights the importance of adopting a dynamic approach to understand delinquency.

In this chapter we investigate the persistence of antisocial behavior from adolescence into early adulthood while keeping track of how Hirschi's four elements of social bonding influence this behavior. The focus here is on school bonds which we argue will also reflect bonding strength to other social institution, such as work, later in life. We also want to distinguish these from non-school related bonding to the family and do this by accounting for a large number of individual characteristics as described in the next section.

This study considers two forms of risky behavior, juvenile delinquency and early schoolleaving. First, we analyze how delinquency while still in school is influenced by social bonding, as measured by four elements attachment to other students, commitment to school performance, belief in school rules, and school performance. Second, we analyze how social bonding affects early school-leaving and how this relationship may be affected by prior delinquent behavior. Third, we estimate the impact of social bonding on offending after having left school. We consider how the effect of the four social bonds may change with delinquent behavior while at school and/or the decision to drop out without a qualification at the level of secondary education. We assume throughout that decreased social bonding increases the likelihood of our three risky behavior outcome measures, but crucially hypothesize that this relationship may change over time, and especially once we take into account previous decisions to participate in such activities.

Following Gottfredson and Hirschi's (1990) argument about the relevance of self-control, we might anticipate that social bonding is not as strong a predictor of adult offending compared to early delinquency and school-leaving. This is assuming that participation in 
risky behavior in the past decreases one's self-control which in turn increases opportunities for future delinquency. Therefore, we expect to find significantly smaller negative effects of social bonding for early delinquents as well as for early school-leavers. A strong effect of past risky behavior would, however, suggest that gradual depreciation of self-control capacity (e.g. patience propensity) is crucial to understanding educational and criminal participation decisions of young adults. We also want to assert whether 'returns' to our measures of social bonds are different for individuals with past participation in risky behavior, as this may have important policy implications.

\subsection{Data}

\subsubsection{Student sample}

We shall use a unique dataset created by matching survey and administrative information on young individuals to explore the underlying mechanism between how social bonding may explain the relationship between early school-leaving and juvenile delinquency before and after leaving school. The basic sample is formed by a large representative longitudinal survey of Dutch youths carried out by Statistics Netherlands (CBS) and the Groningen Institute for Educational Research (GION). This survey, the Secondary Education pupil Cohort 1999 (VOCL'99), consists of 19,391 students from a random sample of almost 400 schools who were in the first grade of secondary school in 1999/ 00.

To facilitate the matching of survey information with administrative data, Statistics Netherlands provides all respondents with a unique identification number that is linked to the social security number. This enables us to match our cohort to the basic pupils register which is kept by DUO (Dienst Uitvoering Onderwijs, i.e. the body that administers student grants and loans on behalf of the Dutch Ministry of Education) and thus follow the education career of VOCL'99 survey respondents from 1999/ O0 to 2008/ O9 and gather information about which grade the students were enrolled in during each successive year. We can therefore determine the education level attained at any time, to see for example whether the students had to repeat classes, and crucially whether they dropped out of school altogether.

Furthermore, general ability tests were administered at the time of the survey giving us a good measure of school performance levels at the start of secondary school. A written questionnaire was also given to the parents of the surveyed students with the aim of collecting information about their families. 
In this chapter we want to gain a better understanding of the mechanisms underlying the relationship between early school-leaving and delinquent behavior among juveniles both before and after leaving school. Therefore we shall focus only on the students in our sample who were no longer enrolled in education in school year 2008/ 09, since we shall have measures of delinquency both before and after leaving school for this population. This leaves us with 7,588 students who had left school with or without a basic qualification for our analysis ${ }^{15}$.

\subsubsection{Delinquency information}

To obtain information about potential delinquent behavior of our students, the individuals in VOCL' 99 were linked to data on all crime suspects in the Netherlands between 1996 and 2007. This information was extracted from the Suspects Identification System (HKS) which is updated annually by the National Police Services Agency. A suspect is a person who has been charged with a crime. A person can be charged once or several times a year and one summons may include various offences. The data refer to suspects of criminal offences which does not automatically mean that this person is convicted. However, an estimated 90 percent of suspects are found guilty at a later stage or are offered a settlement ${ }^{16)}$ and more importantly, those who were found not to be guilty were removed from the registration (Blom, Oudhof, Bijl, \& Bakker, 2005). An individual is therefore considered to have participated in delinquent behavior if he/she was arrested at least once in a certain year.

\subsubsection{The Dutch education system}

The Dutch education system is highly stratified (see figure 1.1.1 in chapter 1 for an overview). To measure low education achievement we use the 1993 Dutch Ministry of Education definition of the minimum level of education a person should acquire to be successful on the labor market: the 'basic qualification' ('startkwalificatie' in Dutch). This concept does not amount to an actual certificate, but is widely used for political and research purposes to identify youths with low education achievement. Students who leave school without a diploma from upper secondary vocational education (MBO) or upper secondary general

\footnotetext{
15) Students who had died (66), were seriously ill (22) or had moved abroad in the 1999/ 00-2008/ 09 period (254) were removed from the sample. In some cases the link to the social security number could not be made and therefore the respondent could not be given an identification number. These respondents were also removed from the sample (24). Lastly, we excluded all students born before 1986 or after 1987 (832). These were students who had either skipped a grade in primary school or repeated more than one grade by the time of the survey and were thus either older or younger than could be expected for a cohort of first graders

16) A settlement can prevent prosecution, if certain conditions set by the police or the Public Prosecutor's Department are met, e.g. payment of a fine. Data on various types of crimes, such as economic and environment offences and social security fraud are usually not entered into the HKS and are therefore underrepresented in the figures.
} 
education (HAVO or VWO), as well as those who attain lower secondary general education (VMBO) are defined as early school-leavers. Research has shown that people without a basic qualification are on average much more likely to be unemployed and receive significantly lower wages (Allen \& Meng, 2010). In our analysis we shall therefore consider early school-leavers to be individuals who did not obtain a basic qualification before they left school.

\subsubsection{Measurement of social bonds}

The data used for this chapter were not originally collected with the intention of measuring nor testing Hirschi's social bonding theory. Therefore, constructs of the four elements of social bonding had to be based on the available information contained in the questionnaire administered in January 2000 while students were in first grade of secondary school (aged 12 to 13 years old). Several studies have tried to capture the elements of the social bond and many have criticized Hirschi's initial conceptualization. One important criticism came from Krohn and Massey (1980) who argue that Hirschi's distinction between commitment and involvement is unclear. In their opinion the temporal dimension of school involvement (i.e. time used to do homework and investing time in school) should be conceptualized as commitment, causing them to construct only three elements of the social bond. A second issue they raised was that Hirschi employed test scores as a measure of attachment to school making the concept ambiguous. In this study we conceptualize all four social bonds largely based on the original works of Hirschi but with a number of alterations to take into account past criticism. Table 3.3.1 describes how our measures generally compare to the original concepts.

\subsubsection{Conceptualization of the Four Elements of Social Bonding}

\begin{tabular}{lll}
\hline & Original concept by Hirschi & Concept as used in this chapter \\
\hline Attachment & $\begin{array}{l}\text { The quality of the bond between students } \\
\text { and their school which refers to the emotional } \\
\text { ties to teachers and school officials }\end{array}$ & $\begin{array}{l}\text { The quality of the bond between students and their } \\
\text { classmates }\end{array}$ \\
Commitment & $\begin{array}{l}\text { The desire to succeed and the degree of } \\
\text { commitment to academic pursuits }\end{array}$ & $\begin{array}{l}\text { The desire to succeed and the degree of } \\
\text { commitment to academic pursuits }\end{array}$ \\
Belief & $\begin{array}{l}\text { Believing that school rules are fair and evenly } \\
\text { enforced }\end{array}$ & $\begin{array}{l}\text { Believing that teachers treat all students fairly } \\
\text { School performance, attendance and } \\
\text { attentiveness in the classroom }\end{array}$
\end{tabular}


Our measures of the four elements of social bonding were constructed using the following information:

- Attachment (Cronbach's alpha $=.81$ ) is a ten-item index indicating the responses to questions such as: "In our class students are nice to each other" and "In our class there is a pleasant atmosphere".

- Commitment (Cronbach's alpha $=.74$ ) is an nine-item index indicating the responses to questions like: "I study much better at home when I'm worried about failing" and "I always try to do my homework as well as possible".

- Belief (Cronbach's alpha $=.62$ ) is a two-item index indicating the responses to the following questions: "In our class teachers treat you fairly" and "In our class teachers are really interested in the students".

- Performance is an index based on three subtests taken in the first months of secondary school that measure the students' aptitude in arithmetic/mathematics, text comprehension and information processing skills.

The indexes and scores for the four elements were all normalized to a scale with a minimum of $\mathrm{o}$ and a maximum of 1. See table 3.6.1 in the appendix for a full list of items used.

\subsubsection{Risky behavior outcomes}

We have three measures of the risky behavior youths may become involved in:

1. Crime before school-leaving is a dummy variable indicating whether the student had been arrested by the police before the date he or she left school.

2. Early school-leaving is a dummy variable indicating whether a student left school without a basic qualification. Young people who leave education without a basic qualification are labeled early school-leavers.

3. Crime after school-leaving is a dummy variable indicating whether the student was arrested by the police on or after the date of leaving school.

\subsubsection{Personal characteristics}

The personal background variables available in the VOCL'99 survey include gender, ethnicity, age at leaving school, parental religion, and parental marital status at the start of secondary school. We also have information on parental education level, parental reading behavior as a proxy for cultural activity from the 2000 parental questionnaire, and parental income in 2005 from the Annual Income Registry kept by Statistics Netherlands based on information from the Dutch Tax Administration. Some of these 
characteristics are missing for certain survey participants if parents did not answer all the questions. For these individuals we shall therefore include dummies to capture potential selection in responding to the survey.

\subsection{Descriptives and modeling}

\subsubsection{Descriptive statistics}

Table 3.4.1 shows the distribution of the four social bond elements and of the background variables for the total sample as well as for students who were and those were not involved in one of the three risky behaviors of interest. The results generally support the assumption that low social bonding correlates with higher levels of juvenile delinquency and early school-leaving. However, there are some striking differences between delinquency before and delinquency after leaving school. While attachment, commitment, belief, and performance are all inversely related to delinquency before school-leaving, for delinquency after leaving school we only observe a significant negative relationship with school attachment and school performance. Early school-leaving is negatively linked to all four elements of social bonding except school commitment; early school-leavers have significantly lower scores on school attachment, belief and performance than those who left school with a basic qualification.

Table 3.4.1 also shows the distribution of our background variables for the individuals in our samples who did and who did not display one of our three measures of risky behavior and their respective differences (the $\Delta$ columns). Levels of criminal participation and early school-leaving are quite high because this is a sub-sample of the original student population who left education relatively young. As in most of the literature, here too we see that males and students with foreign born parents are significantly more at risk of being delinquents as well as being early school-leavers. Parental religion and marital status also account for some of the differences in participation in risky behavior. There is also a significant negative relationship between levels of parental education, income, and reading behavior with our three outcomes of interest.

The last row of table 3.4.1 reports the differences in average age when leaving school between individuals who participated in risky behavior those who did not. Our early school leavers are slightly older and we expect this to be driven by the impact of repeating classes on the likelihood of obtaining a basic qualification. Interpreting the difference in 


\subsubsection{Distribution of Social Bond elements, background variables and indicators of juvenile delinquency and early school-leaving}

\begin{tabular}{|c|c|c|c|c|c|c|c|c|c|c|}
\hline & \multirow[t]{2}{*}{ Total } & \multicolumn{3}{|c|}{$\begin{array}{l}\text { Committed crime before } \\
\text { school-leaving? }\end{array}$} & \multicolumn{3}{|c|}{$\begin{array}{l}\text { Left school without a basic } \\
\text { qualification? }\end{array}$} & \multicolumn{3}{|c|}{$\begin{array}{l}\text { Committed crime after } \\
\text { school-leaving? }\end{array}$} \\
\hline & & No & Yes & $\Delta$ & No & Yes & $\Delta$ & No & Yes & $\Delta$ \\
\hline Total & 7,588 & 88.6 & 11.4 & & 59.1 & 37.0 & & 91.9 & 8.1 & \\
\hline \multicolumn{11}{|l|}{ Hirschi's Social Bond elements } \\
\hline Mean School attachment (0-100) & 64.6 & 64.8 & 62.4 & $-2.4^{* *}$ & 65.6 & 62.7 & $-2.9^{* *}$ & 64.8 & 61.9 & $-2.9^{* *}$ \\
\hline Mean School commitment (0-100) & 66.3 & 66.4 & 65.8 & -.6 & 66.8 & 65.6 & $-1.2^{* *}$ & 66.4 & 66.1 & -.3 \\
\hline Mean School belief (0-100) & 66.1 & 66.5 & 62.9 & $-3.6^{* *}$ & 66.8 & 64.9 & $-1.9^{* *}$ & 66.3 & 64.3 & -2.0 \\
\hline Mean School performance (0-100) & 64.6 & 51.4 & 43.9 & $-7.6^{* *}$ & 55.1 & 42.6 & $-12.5^{* *}$ & 64.8 & 61.9 & $-2.9^{* *}$ \\
\hline \multicolumn{11}{|l|}{ Background variables } \\
\hline Male & 48.1 & 43.7 & 82.2 & $38.5^{* *}$ & 47.4 & 54.4 & $7.0^{* *}$ & 45.1 & 81.5 & $36.4^{* *}$ \\
\hline Foreign & 15.3 & 13.6 & 28.2 & $14.6^{* *}$ & 13.2 & 2.3 & $-1.9^{* *}$ & 14.5 & 24.3 & $9.8^{* *}$ \\
\hline Mean age left education & 18.7 & 18.7 & 18.9 & $.2^{* *}$ & 19.0 & 18.2 & $-.8^{* *}$ & 18.8 & 17.3 & $-1.5^{* *}$ \\
\hline \multicolumn{11}{|l|}{ Parental religion } \\
\hline No religion & 4.3 & 39.1 & 49.5 & $1.4^{* *}$ & 38.3 & 47.7 & $9.4^{* *}$ & 38.8 & 57.4 & $18.6^{* *}$ \\
\hline Catholic & 28.9 & 29.6 & 22.8 & $-6.9^{* *}$ & 32.6 & 25.9 & $-6.7^{* *}$ & 29.5 & 21.6 & $-7.9^{* *}$ \\
\hline Protestant & 25.1 & 26.1 & 17.5 & $-8.6^{* *}$ & 3.6 & 19.1 & $15.5^{* *}$ & 26.2 & 12.6 & $-13.6^{* *}$ \\
\hline Other Catholic religions & 1.7 & 1.7 & 1.6 & -.1 & 1.7 & 1.9 & .2 & 1.7 & 1.6 & -.1 \\
\hline Muslim & 3.2 & 2.6 & 7.5 & 4.9 & 2.5 & 4.7 & $2.2^{* *}$ & 3.0 & 5.8 & $2.8^{* *}$ \\
\hline Hindu & .5 & .5 & 1.2 & $.7^{* *}$ & .6 & .6 & .0 & .5 & .6 & .1 \\
\hline Other religions & .3 & .4 & .0 & -4.0 & .5 & .1 & -.4 & .3 & .3 & .0 \\
\hline \multicolumn{11}{|l|}{ Parental marital status } \\
\hline Married & 87.9 & 88.6 & 82.0 & $-6.7^{* *}$ & 95.6 & 84.9 & -1.7 & 88.3 & 82.8 & $-5.5^{* *}$ \\
\hline Cohabiting & 3.5 & 3.3 & 4.6 & 1.3 & 3.1 & 4.4 & 1.3 & 3.3 & 5.3 & $2.0^{* *}$ \\
\hline Never married & 1.3 & 1.1 & 2.9 & $1.8^{* *}$ & 1.0 & 1.9 & .9 & 1.2 & 2.6 & $1.4^{* *}$ \\
\hline Widowed & 1.1 & 1.0 & 1.6 & .6 & 1.0 & 1.2 & .2 & 1.1 & 1.0 & -.1 \\
\hline Divorced & 5.9 & 5.9 & 8.9 & $3.0^{* *}$ & 5.9 & 7.6 & $1.7^{* *}$ & 6.1 & 8.3 & 2.2 \\
\hline Mean parental education (0-100) & 52.6 & 53.5 & 44.9 & $-8.6^{* *}$ & 56.4 & 45.4 & $-11.0^{* *}$ & 53.4 & 41.5 & $-11.9^{* *}$ \\
\hline Parental reading behavior $(0-100)$ & 14.0 & 14.2 & 12.1 & $-2.1^{* *}$ & 14.7 & 12.6 & $-2.1^{* *}$ & 14.1 & 12.3 & $-1.8^{* *}$ \\
\hline Mean parental Mean income (log) & 1.1 & 1.1 & 1.0 & $-.1^{* *}$ & 1.2 & 1.0 & $-.2^{* *}$ & 1.1 & 1.0 & $-.1^{* *}$ \\
\hline
\end{tabular}

Source: VOCL'99.

Notes: ${ }^{* *} p<=0.01^{*} p<=0.05$

age at school-leaving for the two delinquency measures is much more complex: because all our students are from the same age cohorts, we have by construction more or less time to observe an arrest before or after leaving school, depending on the age they did so. This is just one of the issues we shall address in our modeling strategy which we turn to now.

\subsubsection{Modeling strategy}

We can start our analysis by estimating the following simple logistic regression equation, where $\beta_{0}$ is a constant, and $u$ an error term: 
RiskyBehaviour $_{\mathrm{i}}=\beta_{0}+\beta_{1}$ Attachment $_{\mathrm{i}}+\beta_{2}$ Commitment $_{\mathrm{i}}+\beta_{3}$ Belief $_{\mathrm{i}}+\beta_{4}$ Involvement $_{\mathrm{i}}+$ $\beta_{5}$ AgeleftSchool $_{\mathrm{i}}+u_{\mathrm{i}}$

For each individual $i$ we have three different dummies for participation or not in RiskyBehaviour (i.e. delinquency before school-leaving, leaving school without basic qualification, and delinquency after school-leaving). As AgeLeftSchoo/ will mechanically increase the chances of observing more or less pre or post school-leaving delinquency, we control for this in equation (1) and all other specifications. The key coefficients here are the four ß's which are estimates of the impact of the four measures of social bonds on the likelihood of participation in the three risky behaviors concerned. The descriptive statistics in table 3.4.1 showed that individual and family characteristics affect both school bonding and risky behavior participation. We therefore estimate:

$$
\begin{aligned}
\text { RiskyBehaviour }_{\mathrm{i}}= & \beta_{0}+\beta_{1} \text { Attachment }_{\mathrm{i}}+\beta_{2} \text { Commitment }_{\mathrm{i}}+\beta_{3} \text { Belief }_{\mathrm{i}}+\beta_{4} \text { Involvement }_{\mathrm{i}}+ \\
& \beta_{5} \text { AgeLeftSchool } \\
\mathrm{i} & +\beta_{6} \text { SocioEconomicBackground }_{\mathrm{i}}+u_{\mathrm{i}}
\end{aligned}
$$

in which we also include all the background variables we have available to obtain Bs which take into account possible simultaneous associations (which appear relevant from the correlations reported in table 3.6.2 in the appendix). This is also important to rid our estimates of the impact of family bonding as much as possible, considering our focus on school social bonding factors. The models we shall estimate will be more dynamic in nature and also control for the effect of past participation in risky behavior on future participation in risky behavior.

$$
\begin{aligned}
\text { RiskyBehaviour }_{\mathrm{i}}= & \beta_{0}+\beta_{1} \text { Attachment }_{\mathrm{i}}+\beta_{2} \text { Commitment }_{\mathrm{i}}+\beta_{3} \text { Belief }_{\mathrm{i}}+\beta_{4} \text { Involvement }_{\mathrm{i}}+ \\
& \beta_{5} \text { AgeLeftSchool }{ }_{\mathrm{i}}+\beta_{6} \text { SocioEconomicBackground }_{\mathrm{i}}+ \\
& \beta_{7} \text { PastRiskyBehaviour } \mathrm{i}_{\mathrm{i}}+u_{\mathrm{i}}
\end{aligned}
$$

This will give us estimates of our four social bonding measures for the likelihood of being an early school leaver by whether or not the individual was criminally active before dropping out. We adopt the same approach to estimate the impact of school attachment, commitment, belief, and performance on crime after leaving school controlling first for crime before leaving school and then also for leaving school without a basic qualification. Our last models consider the addition of interactions between the four social bond measures and past participation in risky behavior.

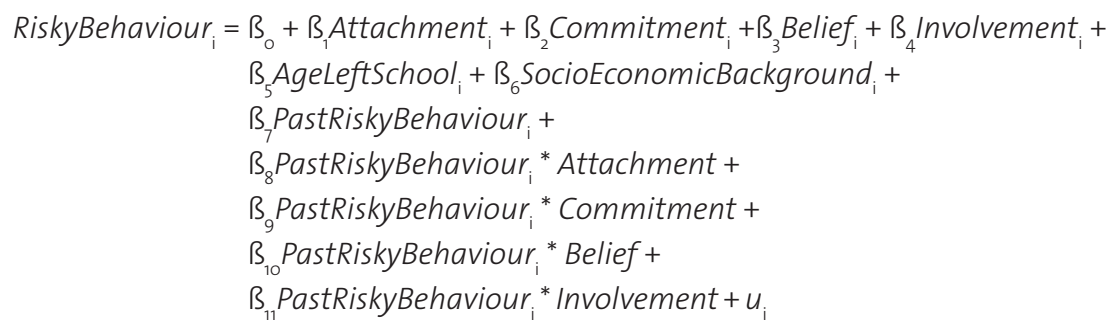


This specification will give us estimates of the impact of the four social bonding measures on early school-leaving specifically for individuals who were criminally active before dropping out. We shall do the same for crime after leaving school with interaction of the social bond measures with being arrested before leaving school and/or leaving without a basic qualification. We expect these modeling strategies to enable us to estimate the returns to differences in strength of social bonding in explaining risky behavior participation when levels of individual self-control are deteriorating as proxied by past risky behavior participation.

\subsection{Results}

\subsubsection{Effects of social bonding on juvenile delinquency and early school-leaving}

The simple model described by equation (1) above is reported for our three outcomes: crime before school-leaving, early school-leaving, and crime after school-leaving in columns (1), (3), and (6) of table 3.5.1. The estimated ß's suggest that differences in school performance have the strongest negative influence on the likelihood of participating in all types of risky behavior. For example, in column (1), a unit change in this social bonding measure results in a 2.1 percent reduction in the chances of committing a crime before leaving school. We also see that higher levels of school belief are linked to lower probabilities of arrest before leaving school and of dropping out without a basic qualification.

Lastly, we observe that school attachment reduces the chance of completing school without a basic qualification. The results are almost unchanged, if somewhat mitigated, once we include controls for background variable in columns (2), (4), and (7). The main difference is that the coefficient on attachment to other students is halved and no longer significantly explains differences in crime after school-leaving.

Inclusion of participation in past risky behaviors significantly predicts early school-leaving, column (5), and crime after school-leaving, columns (8) and (9). The estimates of the social bond impacts become relatively smaller. As might be expected, higher school performance makes it much less likely that students drop out without a basic qualification. Perhaps less obvious is the observation that lower levels of this bonding measure are a strong predictor of crime after school-leaving, even after controlling for dropping out and having committed an offence in the past. 


\subsubsection{Logistic regression effects of the four elements of Social Bonding on crime before school- leaving, early school-leaving and crime after school-leaving}

\begin{tabular}{|c|c|c|c|c|c|c|c|c|c|}
\hline & \multicolumn{2}{|c|}{$\begin{array}{l}\text { Committed crime } \\
\text { before school- } \\
\text { leaving? }\end{array}$} & \multicolumn{3}{|c|}{$\begin{array}{l}\text { Left school without a basic } \\
\text { qualification? }\end{array}$} & \multicolumn{4}{|c|}{ Committed crime after school-leaving? } \\
\hline & $(1)$ & $(2)$ & (3) & $(4)$ & $(5)$ & $(6)$ & (7) & $(8)$ & (9) \\
\hline School attachment (0-100) & -.004 & .002 & $-.008^{* *}$ & $-.005^{*}$ & $-.005^{*}$ & $-.010^{* *}$ & -.005 & -.006 & -.006 \\
\hline School commitment (0-100) & .001 & -.005 & -.001 & -.004 & -.004 & .004 & -.001 & .000 & .000 \\
\hline School belief (0-100) & $-.008^{* *}$ & $-.007^{* *}$ & $-.003^{*}$ & -.002 & -.002 & .000 & .000 & .002 & .002 \\
\hline School performance $(0-100)$ & $-.021^{* *}$ & $-.015^{* *}$ & $-.042^{* *}$ & $-.037^{* *}$ & $-.037^{* *}$ & $-.026^{* *}$ & $-.020^{* *}$ & $-.017^{* *}$ & $-.011^{* *}$ \\
\hline Age at leaving school & $.067^{* *}$ & $.079^{* *}$ & $-.383^{* *}$ & $-.388^{* *}$ & $-.395^{* *}$ & $-.583^{* *}$ & $-.611^{* *}$ & $-.655^{* *}$ & $-.585^{* *}$ \\
\hline Controls for background variables ${ }^{11}$ & no & yes & no & yes & yes & no & yes & yes & yes \\
\hline Crime before school-leaving & & & & & $.620^{* *}$ & & & $1.374^{* *}$ & $1.290^{* *}$ \\
\hline Early School-leaving & & & & & & & & & $.793^{* *}$ \\
\hline Nagelkerke $\mathrm{R}_{2}$ & $3.9 \%$ & $19.7 \%$ & $21.6 \%$ & $26.3 \%$ & $27.0 \%$ & $18.8 \%$ & $31.3 \%$ & $34.8 \%$ & $36.1 \%$ \\
\hline
\end{tabular}

Source: VOCL'99.

Notes: ${ }^{* *} \mathrm{p}<=.01,{ }^{*} \mathrm{p}<=.05$; log odds ratios reported; sample size is 7,588 for all models

1) Controlled for gender, ethnicity, parental religion, parental marital status, parental education, parental reading behaviour, parental income and missing values.

In general we can conclude from the results reported in table 3.5.1 that social bonding is negatively linked to both delinquency before and after school-leaving and the risk of early school-leaving. However, not all elements of social bonding have proven to be of equal importance and our more stringent modeling specifications suggest that school performance is the one that matters in the end. Our results also make it clear that past risky behavior is a very strong predictor of future risky behavior and give credence to theories that highlight individual as well as social restraint factors.

\subsubsection{Interaction effects}

To measure whether the 'returns' to our measures of social bonds differ from past participation in risky behavior we now turn to models which include interaction terms between the elements of social bonding and the first two risky behavior events we observe (i.e. arrested before school-leaving and early school-leaving). This is presented in table 3.5.2 for both the risk of being an early school-leaver in column (2) and the risk of being arrested after school-leaving columns (4) to (6). In columns (1) and (3) we also present the results from the full model estimated in table 3.5.1 for comparison.

The most striking result here is the significant interaction of crime while at school and school performance. The main effect for school performance (i.e. -.040) represents the 


\subsubsection{Logistic regression effects for predicting the interaction effect of the four elements of Social Bonding on crime before school-leaving, early school-leaving and crime after school-leaving (unstandardized coefficients)}

\begin{tabular}{|c|c|c|c|c|c|c|}
\hline & \multicolumn{2}{|c|}{ Early school-leaving } & \multicolumn{4}{|c|}{ Crime after school-leaving } \\
\hline & $(1)$ & $(2)$ & (3) & (4) & (5) & (6) \\
\hline School attachment (0-100) & $-.005^{*}$ & -.004 & -.006 & -.007 & .002 & .001 \\
\hline School commitment (0-100) & -.004 & $-.005^{*}$ & .000 & -.002 & .006 & .004 \\
\hline School belief (0-100) & -.002 & -.002 & .002 & .001 & -.001 & -.002 \\
\hline School performance $(0-100)$ & $-.037^{* *}$ & $-.040^{* *}$ & $-.011^{* *}$ & $-.013^{* *}$ & $-.019^{* *}$ & $-.020^{* *}$ \\
\hline Age leaving school & $-.395^{* *}$ & $-.401^{* *}$ & $-.585^{* *}$ & $-.588^{* *}$ & $-.594^{* *}$ & $-.597^{* *}$ \\
\hline Controls for background variables & yes & yes & yes & yes & yes & yes \\
\hline Crime before school-leaving & $.620^{* *}$ & -.642 & $1.290^{* *}$ & .324 & $1.280^{* *}$ & .325 \\
\hline Early School-leaving & & & $.793^{* *}$ & $.774^{* *}$ & 1.154 & 1.216 \\
\hline Crime before ${ }^{*}$ School attachment & & -.009 & & .003 & & .003 \\
\hline Crime before*School commitment & & .010 & & .005 & & .006 \\
\hline Crime before*School belief & & .001 & & .002 & & .002 \\
\hline Crime before*School performance & & $.024^{* *}$ & & .007 & & .006 \\
\hline Early School-leaving*School attachment & & & & & -.011 & -.011 \\
\hline Early School-leaving*School commitment & & & & & -.009 & -.009 \\
\hline Early School-leaving*School belief & & & & & .005 & .005 \\
\hline Early School-leaving*School performance & & & & & $.012^{*}$ & .012 \\
\hline Nagelkerke $\mathrm{R}_{2}$ & $27.0 \%$ & $27.5 \%$ & $36.1 \%$ & $36.1 \%$ & $36.2 \%$ & $36.3 \%$ \\
\hline
\end{tabular}

Source: VOCL'99.

Notes: ${ }^{* *} \mathrm{p}<=0.01,{ }^{*} \mathrm{p}<=0.05$; log odds ratios reported; sample size is 7,588 for all models

protective effect of this social bond for students who had not been arrested. The interaction term (.024) indicates that the protective effect of school performance for students who had been arrested before leaving school is much smaller, namely $-.040+.024=-.016$.

The interaction effect is depicted in Figure 3.5.3, showing the mean probability of leaving school early by school performance level for students who did commit an offence versus those who did not. The figure shows that although the probability of being an early school-leaver when having a low school performance score is about equal, this probability decreases much more rapidly for pupils who had not been arrested before leaving school and remains much lower compared to students who had been arrested. This indicates that although school performance has a very negative impact on early school-leaving for all individuals, it is a much weaker predictor of dropout behavior for those who committed an offence while still enrolled in school. In other words, early criminal involvement appears to reduce strongly the effect of good educational performance as a social bond preventing early school-leaving. 


\subsubsection{Probability fuction of the effect of School Involvement on early school-leaving by crime before school-leaving}

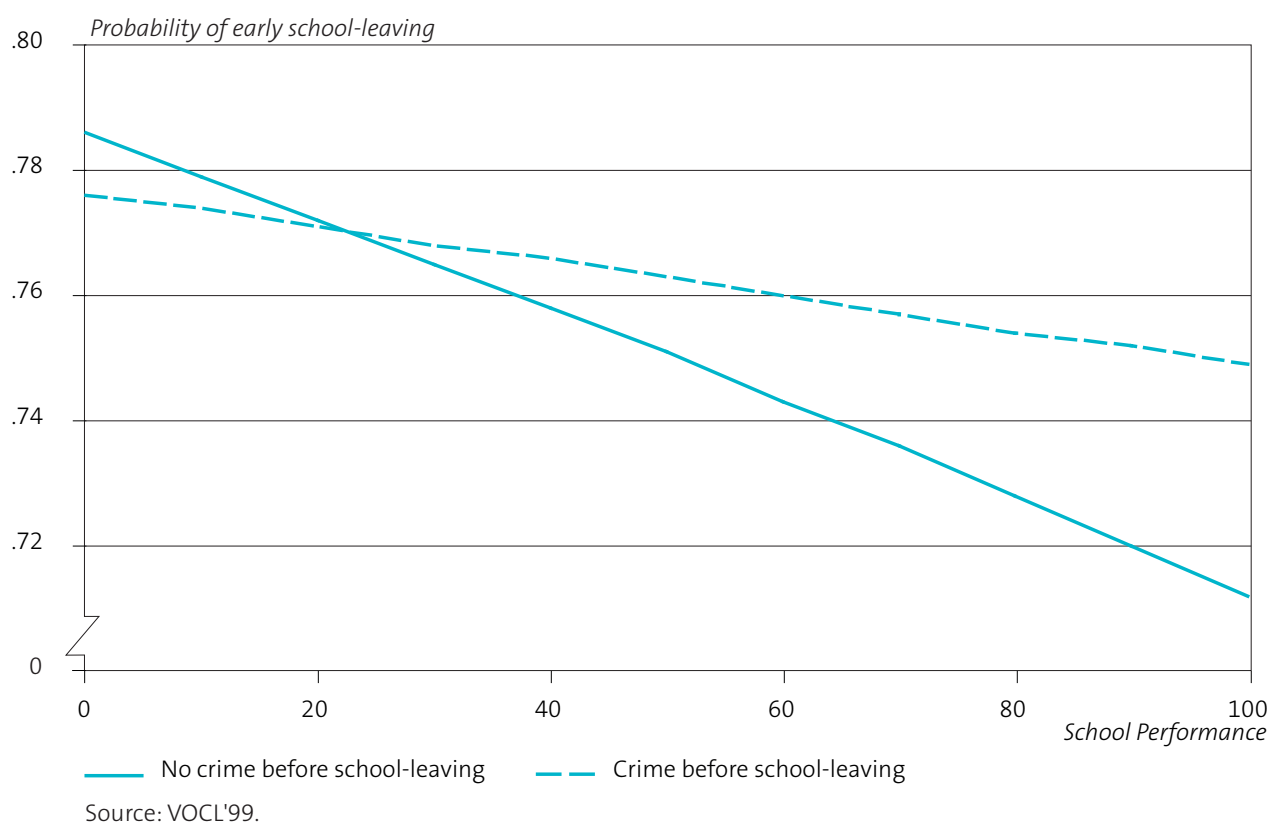

Source: VOCL'99.

In column (4) we include interaction effects for the social bonds with criminal activity before school-leaving to explain future offending behavior. In column (5) we remove these interactions and add the interactions between the four social bonds and early schoolleaving. The results in column (5) show a significant interaction effect indicating that the risk of being arrested after school is much less influenced by school performance for early school-leavers than for those who attained a basic qualification. However, this coefficient is only marginally significant, and is no longer significant when we also consider crime before school-leaving. Lastly, we combine both sets of interactions in column (6) to explain crime after school-leaving. The results suggest that there are no significant differences in the 'returns' to social bonds across groups with distinct experiences in past risky behavior, since none of our interaction terms is significant (although they point in the right direction, i.e. lower returns for students who had engaged in past risky behavior). 


\subsection{Conclusion}

In this chapter we have attempted to measure the extent to which social and self-control theories can predict participation in risky behavior. In our analyses, we found support for Hirschi's (1969) theory that social bonding is an important protective factor for both delinquencies before and after school-leaving and the risk of dropping out without a basic qualification. However, not all elements of social bonding have proven to be of equal importance. In general we can say that it is mainly school performance that matters. At the same time our results make it clear that past risky behavior is a very strong predictor of future risky behavior and give credence to theories that highlight individual as well as social restraint factors. This is in line with Gottfredson and Hirschi's (1990) argument on the importance of capacity for self-control as an explanation of why some individuals engage in risky behavior while others do not. So yes, both social bonding theory and the general theory of crime help us to understand better how young people become young offenders, leave school under qualified and become adult criminals.

The question remains how best to interpret these findings to prevent adolescents from lapsing from one form of risky behavior into another. They primarily suggest that increasing school performance levels could significantly decrease risky behavior. Targeting the poorest performers at an early age should therefore be advocated, as this would appear to be the most efficient means to reduce their sequential participation in all forms of risky behavior. This conclusion is mitigated, however, by the findings from the interaction specifications we considered; these show that the returns to higher school performance levels are less important for students who had been arrested while still at school compared to those for pupils who had not been involved in criminal activity. This would suggest that investment in the improvement of school performance to reduce adolescent risky behavior should be coupled with policies preventing risky behavior of children and young adolescents in order to increase their self-control and the returns to school bonding. 


\subsection{Appendix}

\subsubsection{Item listing for Social Bonds}

N

Min

Max

Mean

Sd

School Attachment

In our class students help each other

7,104

7,102

In our class students treat each other fairly

In our class there is a pleasant atmosphere

In our class students are accepted as they are

The atmosphere at my school is pleasant

7,116

In our class students trust each other

7,063

I get along very well with my classmates

7,115

like the classmates in this school better than my classmates

in primary school

7,123

like the teachers in this school better than my teachers in primary school

School Commitment

I always study much harder if I'm worried about my report

I study much better at home if I'm worried about failing

I find it very important to get a good report

When I study I demand a lot from myself

I always try to do my homework as well as possible

I always keep trying until I succeed

I always tell my parents about good grades immediately

I study much harder if I have a test

I would very much like to be the best in my class

School Belief

In our class teachers treat you fairly

In our class teachers are really interested in the students

School Involvement

Based on test scores on three sub-tests taken in de first months of secondary school that measure the students aptitude in arithmetic/mathematics, text comprehension and information processing skills 


\subsubsection{OLS regressions for predicting the four elements of Social Bonding (standardized coefficients)}

School Attachment School Commit- School Belief School Performance

ment

Male

Ethnic minority

Parental religion: Catholic

Parental religion: Protestant

Parental religion: Other

Parental marital status: Never Married

Parental marital status: Divorced

Average parental education level (scale 0-1)

Parental reading behavior (scale $0-1$ )

Parental income in 2005 (log)

Controls for missing values

$\mathrm{R}^{2}$
$-.058$

$-.023$

.006

$.030^{*}$

$-.030^{*}$

$-.011$

$-.029^{*}$

$.032^{* *}$

$.029 *$

.021

yes

.036
$-.001$

$.075^{* *}$

$-.021$

$-.096^{* *}$

$.070^{* *}$

$-.001$

$-.048^{* *}$

$.045^{* *}$

$-.021$

.013

yes

.029
$-.032^{* *}$

$-.038^{* *}$

$-.004$

$-.006$

$-.003$

$-.011$

$-.030^{*}$

$-.031^{*}$

$-.006$

.004

yes

.008
$-.016$

$-.047^{* *}$

$.038^{* *}$

$.045^{* *}$

.004

$-.010$

.014

$.199^{* *}$

$.081^{* *}$

$.046^{* *}$

yes

.089

Source: VOCL'99

Notes: ${ }^{* *} p<=.01 .{ }^{*} p<=.05$; sample size is 7,588 . 



\section{The effects of Cognitive and Non-Cognitive Skills on early school-leaving ${ }^{17)}$}

\subsection{Introduction}

Over the past decades, a large number of studies have shown differences in Cognitive Skills to be important predictors for educational failure, i.e. early school-leaving. Early school-leavers show lower levels of Cognitive Skills and perform less well in school compared to other students (Alexander et al., 2001; Audas \& Willms, 2001; Cairns et al., 1989; Chamorro-Premuzic \& Furnham, 2006; Ensminger \& Slusarcick, 1992; Furnham, 2008; Heckman \& Rubinstein, 2001; Traag \& Van der Velden, 2011). Although differences in Cognitive Skills are one of the strongest predictors of school failure, other factors play a role as well. One of these factors is the Non-Cognitive Skills. This was already recognized by one of the pioneers in intelligence testing, Alfred Binet, who stated that: 'A child, even if intelligent, will learn little in class if he never listens, if he spends his time in playing tricks, in giggling, in playing truant' (Binet, Simon, \& Kite, 1916 p.254). Eysenck (1947) introduced the first paradigm for consistently studying the impact of Personality Traits on academic performance (Petrides, Chamorro-Premuzic, Frederickson, \& Furnham, 2005). Later, other models for the measurement of Personality Traits, such as the Five Factor Personality Inventory FFPI (McCrae \& Paul T. Costa, 1997) emerged.

In recent years more and more attention has been given to the importance of NonCognitive Skills in explaining individual differences in educational success as well as labor market outcomes. Heckman, Stixrud and Urzua (2006) showed that both Cognitive and Non-Cognitive Skills determine social and economic success. However, they also found

\footnotetext{
7) This chapter is published as a ROA Research Memorandum, T. Traag, \& Van Der Velden, R. K. W. (2011). The effects of cognitive and non-cognitive skills on early school-leaving. ROA Research Memorandum no. 5. We would like to thank Angela Lee Duckworth, Jannes de Vries, Martin Humburg, and Christoph Meng for their helpful comments.
} 
evidence that Non-Cognitive Skills may be as important as or even more important than Cognitive Skills in explaining labor market outcomes such as wage levels, employment chances or occupational choice. In that same study, Heckman et al. also evaluated the impact of both risk behavior and schooling decisions. They showed that while Cognitive Skills were the most important factor in the decision to drop out of school, Non-Cognitive Skills were especially important in explaining who attained the General Education Diploma (GED)18) after dropping out of school and who did not. This confirmed the hypothesis of an earlier study by Heckman and Rubinstein, which showed that while GED receivers had equally high scores on achievement tests as those who attained a high school diploma, they had lower levels of Non-Cognitive Skills (Heckman \& Rubinstein, 2001).

In most studies investigating the impact of Cognitive and Non-Cognitive Skills on educational achievement, both categories of skills are treated as additive factors in explaining educational and labor market outcomes. In other words, many of these studies aim to show that Non-Cognitive Skills play a role after controlling for Cognitive Skills. But there is a complex interplay between the two factors as well, that is often overlooked. In 1964, Vroom developed the Expectancy theory in his study on the motivations for decisionmaking. According to Vroom (1964), performance is a multiplicative function of both ability and motivation:

Performance $=f$ (ability $\times$ motivation)

From this formula it follows that, while ability affects performance, the impact of ability is dependent on a person's motivation level and vice versa. For those with low motivation, increases in ability will result in smaller increases in performance than for those who are highly motivated. And conversely, for those with low ability, an increase in the motivation levels will have less impact on the performance level than for the ones with high ability (Vroom, 1964: p. 203).

The aim of this chapter is to gain a better understanding of the process of early schoolleaving by studying the interplay between Cognitive and Non-Cognitive Skills. We will use a unique dataset that enables us to overcome the shortcomings of many studies which struggle with contemporaneous measures of educational outcomes and measures of Cognitive and Non-Cognitive Skills. By measuring both skill types at the age of twelve and observing subsequent early school-leaving, we are able to ensure a credible claim for causality. Also, we will contribute to the existing literature by explicitly looking at the interaction effects between Cognitive and Non-Cognitive Skills. We shall apply Vroom's formula to predict individual differences in early school-leaving risks, but also extend his formula by broadening motivation to include a wider array of Non-Cognitive Skills, using both measures of Achievement Motivation in school as well as Personality Traits based on

18) The GED can be attained after taking a test in five subject areas. Only individuals who do not have a high school diploma can take the GED test. 
the FFPI (McCrae \& Paul T. Costa, 1997). This approach will help us to get an insight into how and why some adolescents are unable to obtain a full upper secondary qualification and thus become early school-leavers.

The results show that while Cognitive Skills are the most important predictor of early school-leaving, Non-Cognitive Skills also have a notable impact on the risk of becoming an early school-leaver. We find that Conscientiousness and Agreeableness protect against early school-leaving, while Openness to Experience increases this risk. In addition, we find that the protective effect of Conscientiousness holds specifically for students with low levels of Cognitive Skills, while the protective effect of Agreeableness holds specifically for students with medium-level Cognitive Skills. Openness to Experience, on the other hand, decreases the protective effect of Cognitive Skills, especially for students with high levels of Cognitive Skills.

The chapter is structured as follows: section 4.2 presents a literature review on NonCognitive Skills as predictors of school success. Next, in Section 4.3 we describe the data used for this study and our modeling strategy. In section 4, we report our results. Lastly, section 4.5 contains concluding remarks.

\subsection{Non-Cognitive Skills as predictors of school success}

\subsubsection{Personality Traits}

Although Cognitive Skills have been shown to be an important factor in explaining individual differences in school success, as well as in health and work outcomes (Furnham, 2008), differences in Cognitive Skills alone are insufficient to fully explain why an individual succeeds or fails in school (Chamorro-Premuzic \& Furnham, 2006; Heckman \& Rubinstein, 2001). This has led to a new body of research on non-cognitive predictors for school success, especially the Big Five Personality dimensions. O'Connor and Paunonen (2007) offer two broad justifications for using Personality Traits to predict school success. First, Personality affects a person's habits, which in turn can influence school success (Rothstein, Paunonen, Rush, \& King, 1994). Second, while Cognitive Skills reflect what a person is able to accomplish, thePersonality Traits reflect what they will do and how they will use these abilities (Chamorro-Premuzic \& Furnham, 2003b). 
The Five-Factor Model of Personality (McCrae \& Paul T. Costa, 1997) differentiates Personality factors that reside at the highest level of the Personality hierarchy, encompassing the entire domain of lower level Personality Traits: Openness to Experience, Conscientiousness, Extraversion, Agreeableness and Emotional Stability. There has been extensive research on the direct relationship between Personality Traits and school success (see Chamorro-Premuzic \& Furnham, 2005 for a literature review).

Openness to Experience is characterized by 'intellectence' (acquired Cognitive Skills) and unconventionality (imaginative, autonomous and nonconforming) (Judge, Higgins, Thoresen, \& Barrick, 1999). The study by Ackerman and Heggestad (1997) showed Openness to Experience to have a positive relationship with school success, even when controlling for intelligence. However, more recent studies have not been able to replicate these results. One explanation could be that the creative and imaginative nature of these students is disadvantageous in academic settings, especially when reproduction of curricular content is the main requirement (Fruyt \& Mervielde, 1996).

Conscientiousness manifests itself in a number of facets, like the will to achieve, dependability and orderliness, and has consistently been found to predict academic achievement throughout the life course (Fruyt \& Mervielde, 1996; Poropat, 2009). Some authors have speculated that Conscientiousness may affect academic performance beyond ability, and even compensate for poor intellectual ability (Chamorro-Premuzic \& Furnham, 2003a).

Extraversion is a rather broad construct that consists of sociability as well as social orientation, dominance and assertiveness. Research among young children has shown a positive relationship between Extraversion and school success, while evidence among adolescents and adults has shown a negative effect (Chamorro-Premuzic \& Furnham, 2003a). These conflicting results have been attributed to the difference between the sociable environment of primary schools as opposed to the more formal atmosphere of secondary and higher education (Matthews, Zeidner, \& Roberts, 2006). With respect to a possible interaction effect, the study by Petrides et al. (2005) showed differential effects of Extraversion between low and high ability boys: for low ability boys, Extraversion had a detrimental effect on school success, while for high ability boys Extraversion had no effect. One possible explanation is that those with low ability will need to invest a lot of time and effort in their educational career in order to succeed. However, extraverts tend to be pleasure-seeking and outgoing, making them less likely to spend time on their education in favor of extra-curricular activities.

Agreeable people are trustable and caring as well as likable. No direct significant effects of agreeableness on educational success have been found, although some antisocial Personality Traits associated with low Agreeableness may have detrimental effects (Matthews et al., 2006).

Emotional Stability generally refers to a lack of positive psychological adjustment. Evidence on how and why neuroticism affects school success is inconclusive. A study by McKenzie 
and Tindell (1993) showed neuroticism to be correlated with low achievement only for students with a weak superego, indicating that self-control and focusing of motivation compensate for negative emotionality (Matthews et al., 2006).

\subsubsection{Achievement Motivation}

Motivational differences are assumed to be partly reflected by differences in Personality Traits, specifically Conscientiousness. However, whereas Personality Traits describe a person's characteristics in all kinds of situations, constructs from the tradition of Achievement Motivation research are specifically designed to describe differences between individuals in a learning and achievement-related setting (Steinmayr \& Spinath, 2008). Traditionally, Achievement Motivation was thought to simply reflect the balance between striving for success on the one hand and the fear of failure on the other, while later research showed that motivation could be understood as (a) the choice to make an effort, (b) an assessment of the level of effort to be invested, and (c) the choice to persist at this level (Matthews et al., 2006). Cognitive Skills and Achievement Motivation are not isolated concepts. In fact it seems reasonable to assume that Cognitive Skills, Achievement Motivation and Personality Traits develop along mutually causal lines, where successful performance in certain tasks increases interest and thus increases Achievement Motivation (Ackerman \& Heggestad, 1997: p. 239). In their study of the economics and psychology of Personality Traits, Borghans, Duckworth, Heckman and Ter Weel (2008) stress that discerning between measures of Cognitive Skills, Achievement Motivation and Personality is complicated since the measurement of these concepts is affected by factors such as the respondent's motivation to perform well, test anxiety and differences in Personality, i.e. openness, curiosity and perseverance.For one, this means that there is overlap between Achievement Motivation and Conscientiousness. However, the complex interplay between these Traits is not the focus of this study. Therefore we estimate the effect of Achievement Motivation and Personality Traits on school success in two separate models.

\subsubsection{Hypotheses}

In this chapter, we explore how Achievement Motivation and Personality affect early school-leaving when controlling for Cognitive Skills. Based on our literature review we assume the following hypotheses:

1. Achievement Motivation significantly decreases the risk of early school-leaving.

2. Personality Traits can significantly predict the risk of leaving school early. Based on previous findings in the literature we expect to find significant negative effects for Conscientiousness and Openness to Experience and a positive effect for Extraversion. 
Based on previous studies, we do not expect to find any significant effects for Agreeableness and Emotional Stability.

As was assumed by Vroom (1964), the relationship between performance, ability and motivation is a multiplicative function, assuming that the impact of ability is dependent on a person's motivation level and vice versa. This implies interaction effects between Cognitive and Non-Cognitive Skills on early school-leaving. Based on this assumption of a multiplicative relationship between performance, ability and motivation, we assume that the impact of Achievement Motivation is stronger for high ability students than for low ability students:

3. There is a significant negative interaction effect between Cognitive and Non-Cognitive Skills on the risk of early school-leaving.

Based on previous findings, we expect to find negative effects for Conscientiousness and Openness to Experience and a positive effect of Extraversion. In concordance with Vroom's assumption of a multiplicative relationship between Cognitive and Non-Cognitive Skills we therefore expect that:

4. There is a significant negative interaction effect of Conscientiousness and Openness to Experience with Cognitive Skills on early school-leaving, and a positive interaction effect for Extraversion with Cognitive Skills. Again we do not expect to find any significant interaction effects for Agreeableness and Emotional Stability.

\subsection{Research design}

For this study we use a large representative longitudinal survey of Dutch youth carried out by Statistics Netherlands (CBS) and the Groningen Institute for Educational Research (GION). This survey, the Secondary Education Pupil Cohort 1999 (VOCL'99), consists of 19,391 students from a random sample of 126 schools who were in the first grade of secondary education (age 12) in 1999/2000 (Van Berkel, 1999). The cohort is shown to be representative for 12 year-old students in the Netherlands (Kuyper \& Van der Werf, 2003). The educational careers of these students were followed up annually by matching the cohort to the national educational register until the year 2010/ 11. The register data provide information on the school type, grade and examination results. We can therefore determine the educational level attained at any time. Furthermore, an achievement test was administered during the first year of the study, providing us with a good measure of the Cognitive Skills at the start of secondary school. In addition, tests were conducted on Achievement Motivation and Personality. A written questionnaire was also given to the parents of the surveyed students with the aim of collecting information about the family 
background of the pupils like socioeconomic background and parenting styles (Kuyper et al., 2003).

From our initial sample of 19,391 students, we removed those who had died, were seriously ill19) or had moved abroad within the 1999/ 00-2010/ 11 periods (473 students). Moreover, we excluded students who had missing values on our key variables: Cognitive Skills, Achievement Motivation or Personality Traits (4,688). This left 14,230 students for our analyses. In this sample, 53.4 percent started education in the pre-vocational track, 49.4 percent was male and the average score on the test measuring Cognitive Skills was .59. In the original sample, 56.5 percent started in pre-vocational education, 50 percent was male and the average score on the Cognitive Skills test was .57. So in general we can say that the selected sample is biased somewhat towards a sample of more highly skilled students, slightly more often being female. The risk of becoming an early school-leaver is highest for those who started their education career in the pre-vocational track. About one third of these students do not attain a full upper secondary qualification. For those who started in the general tracks preparing for vocational colleges or universities, the risk is much lower (see table 4.3.1). Only 8 percent of the students who started in the precollege track did not attain a full upper secondary qualification. For students who started in the pre-university track, only 5 percent left school early. Since we observe less low

\subsubsection{Descriptives for early school-leaving by education level in 1st grade of secondary education (row percentages in brackets)}

\begin{tabular}{|c|c|c|c|c|}
\hline \multirow[t]{2}{*}{ Level first year in secondary education } & \multirow[t]{2}{*}{ Total population } & \multirow{2}{*}{$\begin{array}{l}\text { Total early school- } \\
\text { leavers }\end{array}$} & \multicolumn{2}{|l|}{ Diploma status } \\
\hline & & & No diploma at all & $\begin{array}{l}\text { Pre-vocational } \\
\text { education or } \\
\text { vocational assistant }\end{array}$ \\
\hline Total & 14,230 & $\begin{array}{l}2,879 \\
\quad(20.2 \%)\end{array}$ & $\begin{array}{l}362 \\
(2.5 \%)\end{array}$ & $\begin{array}{l}2,444 \\
(17.2 \%)\end{array}$ \\
\hline Pre-vocational track & 7,591 & $\begin{array}{l}245 \\
(32.3 \%)\end{array}$ & $\begin{array}{l}288 \\
(3.8 \%)\end{array}$ & $\begin{array}{l}2,093 \\
(28.5 \%)\end{array}$ \\
\hline Pre-college track & 3,004 & $\begin{array}{l}251 \\
\quad(8.4 \%)\end{array}$ & $\begin{array}{l}37 \\
(1.2 \%)\end{array}$ & $\begin{array}{l}212 \\
(7.1 \%)\end{array}$ \\
\hline Pre-university track & 3,635 & $\begin{array}{l}178 \\
(4.9 \%)\end{array}$ & $\begin{array}{l}37 \\
(1.0 \%)\end{array}$ & $\begin{array}{l}139 \\
(3.9 \%)\end{array}$ \\
\hline
\end{tabular}

Source: VOCL'99

\footnotetext{
19) A total of 31 students were removed from the sample due to serious illness in the beginning of their educational career, that prevented them from attending education for long periods of time. In the Netherlands, health problems are viewed as an important predictor for early school-leaving (Researchcentrum voor Onderwijs en Arbeidsmarkt, 2011), but this refers mainly to mental health problems like behavioral disturbances. These students are still included in the sample. A previous study on the impact of physical health problems on early school-leaving showed only very limited effects, and only for students in pre-university education (Van Heesch, Bosma, Traag, \& Otten, 2011). Therefore we do not expect to find any bias in our results based on this selection.
} 
educated students in our sample, and consequently those with higher Cognitive Skills, we expect our estimates to be somewhat underestimated.

\subsubsection{Measuring early school-leaving}

The Dutch education system is highly stratified (see figure 1.1.1 in chapter 1). After six years of primary education, students enter secondary education at the age of 12. Here they have to choose between three tracks: one preparing for university education (VWO, duration 6 years), one preparing for a college for higher vocational education (HAVO, duration 5 years) and one track preparing for vocational education at the upper secondary level (VMBO, duration 4 years). Track placement takes place on the basis of a nationwide test, called CITO-test, at the end of primary education and the advice of the primary school teacher. Subsequently, depending on the track chosen, students can either leave education or enter one of three upper secondary vocational tracks, higher vocational education, or university. In the Dutch education system, compulsory education starts at age five (although most children start at age 4) and lasts until the age of 16. Since 2007, Dutch youths are obliged to learn or to work until the age of 18 or until completion of a full upper secondary (ISCED 3) qualification ('kwalificatieplicht'). Those who have not attained this minimum education level at age 18 are required to either resume education or work until the age of 27 ('leerwerkplicht', officially adopted in 2009).

In this chapter, an early school-leaver is defined as a student who was no longer enrolled in education in September 2010 (2010/ 11 school year) and who did not have a full upper secondary qualification (see figure 1.1.1). This definition is in line with the international definition of early school-leaving used by the OECD and Eurostat. In our sub-sample, 2,060 (18.9 percent) students had not attained this minimum level of education.

\subsubsection{Independent variables}

Cognitive Skills were measured using a test developed by the Cito-group (the Dutch equivalent of Educational Testing Services) which was administered in January 2000, four months after entry into secondary education. This test is a sub-test of the test used at the end of primary education to determine track placement. The test consisted of three subtests for text comprehension, arithmetic and information processing(see (Lubbers, 2004), for a detailed description of the testing procedure). Each test has 20 multiplechoice items. For comparability purposes, this and all other scale variables used were rescaled so that the lowest score was 0 and the highest score was 1.

Achievement Motivation was also measured in January 2000 using the Academic Achievement Motivation Test (Hermans, 1970) and assesses a student's motivation to perform well in school. The scale consists of 9 items indicating the responses to questions 
like: "I do my homework much better when I'm worried about failing" and "I always try to do my homework as well as possible". Previous studies have shown Achievement Motivation to be a key predictor of school success (Hustinx, Kuyper, Van der Werf, \& Dijkstra, 2009; Kuyper, Dijkstra, Buunk, \& Werf, 2011; Kuyper, Van der Werf, \& Lubbers, 2000).

Personality was assessed one year later (February 2001), when the students were in grade 2 of secondary education, with the Five Factor Personality Inventory (FFPI) developed by Hendriks, Kuyper, Offringa \& Van der Werf (2008). The instrument has been tested nationally and internationally and has proven to be a reliable and valid measure to assess the Big Five Personality Traits (Hendriks et al., 2008; Hendriks, Perugini, Angleitner, Ostendorf, Johnson, Fruyt, Hřebíčková, Kreitler, Murakami, Bratko, Conner, Nagy, Rodgríguez-Fornells, \& Ruisel, 2003). The FFPI yields a person's scores on Openness to Experience, Conscientiousness, Extraversion, Agreeableness and Emotional Stability. Responses were given on a five-point scale ranging from $1=$ not at all applicable to $5=$ entirely applicable. A person's 'compatible anchored factor scores' were computed using the FFPI scoring software. Compatible anchored factor scores are standardized scores anchored at the scale mid point. They are computed as weighted linear combinations of a person's 100 item responses, using item weights established in the Dutch norm sample (Hendriks et al., 2008). As indicated above, the scores were rescaled so that the lowest score was $\mathrm{o}$ and the highest score was 1.

The VOCL'99 data comprise a number of socioeconomic background variables that have been shown in earlier research to affect school success: gender, migrant status, parental educational level${ }^{20}$, and parental income ${ }^{21)}$ (Bhrolcháin et al., 2000; De Graaf, 1986; Heard, 2004; Lamb, 1994; McLanahan \& Sandefur, 1994; Nord \& West, 2001; Rumberger, 1983, 1987; Traag \& Van der Velden, 2011). Some of these characteristics are missing for certain students in the survey if parents did not answer all questions. For these individuals we replaced the missing value by the population average and included characteristic missing dummies to capture potential selection in responding to the survey. In addition, we shall control for the education level of the class in 1st grade, using two dummies for pre-college track and pre-university track with the pre-vocational track as the reference category.

\footnotetext{
20) Parental education was collected in the parental questionnaire during school year 1999/ oo. For both parents (if available) the highest education level was recoded into the number of years of schooling needed to obtain this level (Bosker, Van Der Velden, \& Hofman, 1985) varying from 6 (primary education) to 19 years (university education) of schooling. To reflect the parental educational level the mean of the father and the mother was taken.

21) Parental income is measured as the log of the mean personal income of both the father and the mother (if available) in 2004 and was taken from the Annual Income Registry kept by Statistics Netherlands and based on information from the Dutch Tax Administration. It includes income from labor as well as social security benefits and other sources of income. For single parent households, only the income of the resident parent was used. Parents with zero or negative income (124 cases from the initial population) were recoded to having zero income. In cases where the income could not be matched (702 cases from the initial population), the income was replaced by the population mean.
} 


\subsection{Results}

\subsubsection{Descriptive results}

Table 4.4.1 presents the differences in Cognitive and Non-Cognitive Skills of early schoolleavers versus those who attained the minimum education level (regular school-leavers). The first important finding from this table is that there is a clear positive relationship between Cognitive Skills and early school-leaving, as could be expected. The differences between the two groups are also depicted in figure 4.4.2. While early school-leavers on average perform less well in school compared to those who attained the minimum education level $\left(t=47.137^{* *}\right)$, the graph also shows that there is some overlap in Cognitive Skills between the two groups, indicating that a significant proportion of our early schoolleavers have sufficient skills, but do not manage to attain a certain level of education. In Dutch literature, this distinction between those who cannot and those we will not attain a full upper secondary qualification is often referred to as the 'classical at-risk student' and the 'resigner'(Allen \& Meng, 2010): the classical at-risk student is the student that lacks sufficient Cognitive Skills to attain a certain level, while the resigner is the student that is able to attain a certain level of education based on cognitive ability, yet makes the decision to resign from education nevertheless. This is exactly the group where Non-Cognitive Skills may be expected to guide the decision to invest in further schooling or not.

\subsubsection{Mean test scores on Cognitive Skills, Achievement Motivation and Personality Traits by early school-leaving}

\begin{tabular}{lcccc}
\hline & Total & Early school-leaver & Regular school-leaver & T-test \\
\hline Cognitive Skills & & & & \\
& 0.59 & 0.45 & & $47.137^{* *}$ \\
Non-Cognitive Skills & & & & \\
Achievement Motivation & 0.62 & 0.61 & 0.63 & $4.967^{* *}$ \\
& & & & 1.370 \\
Openness to Experience & 0.41 & 0.41 & 0.41 & $4.629^{* *}$ \\
Conscientiousness & 0.55 & 0.54 & 0.55 & $7.869^{* *}$ \\
Extraversion & 0.65 & 0.64 & 0.66 & $7.176^{* *}$ \\
Agreeableness & 0.64 & 0.62 & 0.68 & \\
Emotional stability & 0.67 & 0.66 & 11,351 & \\
N & 14,230 & 2,879 & & \\
\hline
\end{tabular}

Source: VOCL'99.

Notes: ${ }^{* *}=p<.01^{*}=p<.05$ 


\subsubsection{Distribution of Cognitive Skills and Achievement Motivation by early school-leaving}
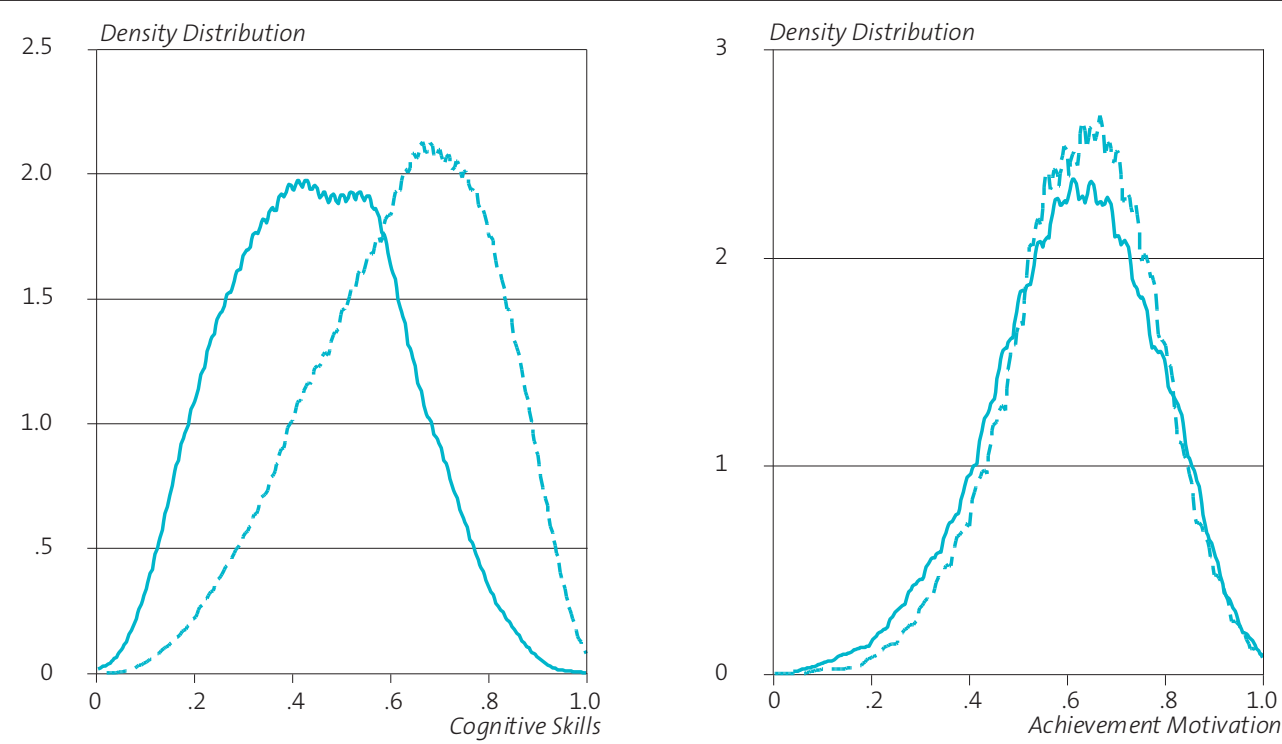

Early school-leaver - Attained at least basic vocational education

Source: VOCL'99.

Although in most cases we also find significant differences between early and regular school-leavers in the area of Non-Cognitive Skills, these differences are quite small compared to the differences in Cognitive Skills. For Achievement Motivation, Extraversion, Agreeableness and Emotional Stability, we find that the regular school-leavers have on average somewhat higher scores than the early school-leavers, but for Conscientiousness and Openness to Experience, the two distributions almost completely overlap (see figure 4.4.3). This is not fully in line with our expectations, as we expected to find higher levels of Conscientiousness and Openness to Experience among regular school-leavers and lower levels of Extraversion among early school-leavers. 


\subsubsection{Distribution of scores on Personality Traits by early school-leaving}
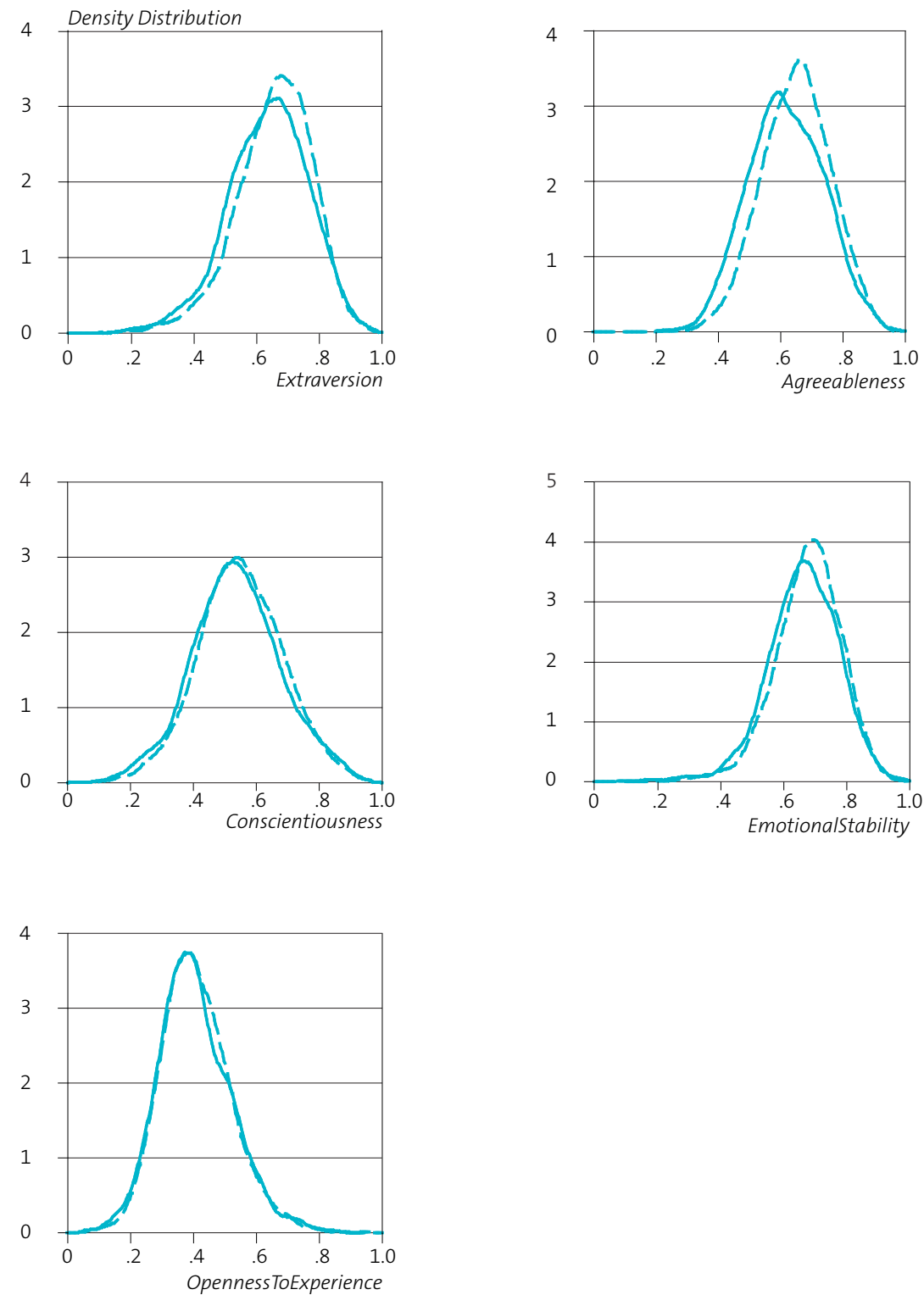

Early school-leaver

_ _ Attained at least basic vocational education

Source: VOCL'99. 


\subsubsection{Logistic regression analyses}

To explore how Cognitive and Non-Cognitive Skills affect the risk of early school-leaving directly and indirectly we now turn to a logistic model. We shall estimate a series of logistic regression models that estimate the propensity that an individual $i$ is an early school-leaver (ESL). In our first model (equation 1), we estimate the effect of our Cognitive Skills measure:

$E S L_{\mathrm{i}}=\beta_{\mathrm{o}}+\beta_{1}$ CognitiveSkills $\mathrm{i}_{\mathrm{i}}+u_{\mathrm{i}}$

Where $E S L_{i}$ indicates whether individual $i$ is an early school-leaver, Cognitiveskills is a vector of Cognitive Skills, and $u_{i}$ the idiosyncratic error term. In the second model, we add our measure of Achievement Motivation:

$E S L_{\mathrm{i}}=\beta_{0}+\beta_{1}$ CognitiveSkills $s_{\mathrm{i}}+\beta_{2}$ AchievementMotivation $+u_{\mathrm{i}}$

In the third model, we add a vector Socio-EconomicBackground ${ }_{i}$ to the equation with controls for the education level of the class in the 1st grade of secondary education, gender, migrant status, parental education, parental income and parental communication as well as dummies for missing values.

$$
\begin{aligned}
E S L_{i}= & \beta_{0}+\beta_{1} \text { CognitiveSkills }_{\mathrm{i}}+\beta_{2} \text { AchievementMotivation }+ \\
& \beta_{3} \text { SocioEconomicBackground }+u_{i}
\end{aligned}
$$

Lastly, we add the interaction term between Cognitive Skills and Achievement Motivation to the model.

$$
\begin{aligned}
& E S L_{i}= \beta_{0}+\beta_{1} \text { CognitiveSkills } s_{i}+\beta_{2} \text { AchievementMotivation }+ \\
& \beta_{3} \text { SocioEconomicBackground }{ }_{i}+\beta_{4} \text { CognitiveSkills }_{i}^{*}{ }^{*} \text { AchievementMotivation } \\
& i
\end{aligned}
$$

As indicated earlier, we shall run separate analyses for the Personality Traits as these are partly correlated with Achievement Motivation. We start with a model in which we have a vector for CognitiveSkills, and a vector BigFive, representing the different Personality Traits (Openness to Experience, Conscientiousness, Extraversion, Agreeableness, and Emotional Stability):

$$
E S L_{i}=\beta_{0}+\beta_{1} \text { CognitiveSkills }_{i}+\beta_{2} \text { BigFive }_{i}+u_{i}
$$

Again, we add some control variables to control for differences in socio-economic background and other controls as well as dummies for missing values:

$$
E S L_{\mathrm{i}}=\beta_{0}+\beta_{1} \text { CognitiveSkills }_{\mathrm{i}}+\beta_{2} \text { BigFive }_{\mathrm{i}}+\beta_{3} \text { SocioEconomicBackground }_{\mathrm{i}} \mathrm{u}_{\mathrm{i}}
$$


In the final model, we add interaction terms between Cognitive Skills and Personality Traits ${ }^{22)}$ :

$$
\begin{aligned}
E S L_{i}= & \beta_{0}+\beta_{1} \text { CognitiveSkills }_{\mathrm{i}}+\beta_{2} \text { BigFive }_{\mathrm{i}}+\beta_{3} \text { SocioEconomicBackground }_{\mathrm{i}} \mathrm{u}_{\mathrm{i}}+ \\
& \beta_{4} \text { CognitiveSkills }_{\mathrm{i}}{ }^{*} \text { BigFive }_{\mathrm{i}}
\end{aligned}
$$

\subsubsection{The effect of Achievement Motivation on early school-leaving}

Table 4.4.4 presents the results for the first set of analyses. In Model 1, we estimate the risk of becoming an early school-leaver based on one's Cognitive Skills. As the results show, there is a significant negative effect of Cognitive Skills, indicating that the higher a student scored on the performance test in the first grade of secondary education, the lower the risk to become an early school-leaver. For students with a mean score on Cognitive Skills, the probability of becoming an early school-leaver is:

$$
\frac{1}{1+e^{\left.-\left(.59^{*}-5.105\right)+1.363\right)}}=.163
$$

For students who are one standard deviation (.19) above or below the mean, the probability of becoming an early school-leaver equals:

$$
\frac{1}{1+e^{\left.-\left((.59-.19)^{*}-5.105\right)+1.363\right)}}=.343 \text { or } \frac{1}{1+e^{-\left(\left((.59+.19)^{*}-5.105\right)+1.363\right)}}=.068
$$

In (2), we add Achievement Motivation to the model. This model confirms what we had already seen from our descriptive results. We can note that a high score on Achievement Motivation decreases the risk of becoming an early school-lever $\left(B=-352^{* *}\right)$. Another important finding from this model is that the effects for Cognitive Skills hardy change after adding Achievement Motivation to the model. This indicates that the effect of Cognitive Skills on early school-leaving is not caused by differences in Achievement Motivation. Adding controls for (socioeconomic) background hardly affects the estimate for Achievement Motivation, but it does have an impact on the estimate for the Cognitive Skills (3). Including controls for education level at age 1223) and for parental background clearly reduces the impact of Cognitive Skills.

In (4), we include the interaction term between Cognitive Skills and Achievement Motivation. As stated in the hypothesis, we expected a negative interaction effect between Cognitive and Non-Cognitive Skills on early school-leaving. However, the interaction term is not significant.

\footnotetext{
22) Borghans et al. (2008) suggest that in some cases the relationship between non-cognitive skills and outcomes may be curvilinear. Inclusion of quadratic functions of our resulted in non-significant estimates, and were therefore not included in the models presented in this chapter.

23) In a separate analysis, we tested if the effects found in this analysis using dummies for educational level at age 12 are comparable to the effects found when performing separate models for each of the three groups. In this approach, our conclusions remained the same. These analyses can be requested from the corresponding author.
} 


\subsubsection{The impact of Personality Traits on early school-leaving}

In the second part of this analysis, we estimate the impact of Personality Traits on early school-leaving. When comparing model (1) with model (5) in table 4.4.6, we can conclude that adding Personality Traits to the model does not affect the direct effects of Cognitive Skills. The effect for Cognitive Skills remains virtually identical.

\subsubsection{Logistic regression of Cognitive Skills and Achievement motivation on the risk of early school- leaving}

(1)

$(2)$

(3)

$\begin{array}{cc}4.514^{* * *} & 4.601^{* * *} \\ -3.158^{* * *} & -3.354^{* * *} \\ -.314^{* *} & -.465\end{array}$

Achievement Motivation

$1.363^{* * *}$

$1.572^{* * *}$

$-5.087^{* * *}$

$-.352^{* *}$

$-.465$

Educational level at age 12

Pre-vocational track (ref.)

Pre-college track

Pre-university track

Sex

Male

Female (ref).

Migrant status

Migrant

Native Dutch (ref)

Parental education

Parental income

Parental communication

Controls for missing values

No

$-.826^{* * *}$
$-1.051^{* * *}$
$.462^{* * *}$
-.009
$-.081^{* * *}$
$-.265^{* * *}$
$-.511^{* * *}$

No

Yes

Cognitive Skills*Achievement Motivation

Log Likelihood

$-6,183.067$

$-6,18.006$

$-5,836.135$
$-.827^{* * *}$

$-1.052^{* * *}$

$.462^{* * *}$

$-.008$

$-.081^{* * *}$

$-.265^{* * *}$

$-.511^{* * *}$

Yes

.322

Source: VOCL'99.

Notes: Sample size is 14,230 observations. ${ }^{* * *}=p<.01 .{ }^{* *}=p<.05 .{ }^{*}=p<.1$

In general we expected to find a negative relationship between Openness to Experience and early school-leaving since Openness to Experience is thought to reflect 'intellectence' and thus to have a positive effect on education outcomes above and beyond intelligence (Ackerman \& Heggestad, 1997). People who have higher scores on Openness to Experience tend to be open to new aesthetic, cultural, or intellectual experiences. People with low scores on openness tend to have more conventional, traditional interests. They prefer the plain, straightforward, and obvious over the complex, ambiguous, and subtle. Our model however shows a significant positive effect ( $\beta=.889^{* * *}$ ), indicating that high scores on Openness to Experience increase the risk of leaving school early instead of being a protective factor. 
The next trait, Conscientiousness, reflects the will to achieve, and the desire for dependability and orderliness. From our literature review, we expected to find a negative effect of conscientiousness on early school-leaving, which is confirmed by the results in our model $\left(\beta=-1.091^{* * *}\right)$.

Extraversion is the third factor, which reflects positive affect and sociability. Based on previous study results we expected to find a positive relationship between early schoolleaving and extraversion. However, our results show the opposite. High scores on Extraversion are related to lower probabilities of becoming an early school-leaver $\left(B=-.867^{* * *}\right)$. However, this effect becomes non-significant once controls have been added to the model (model 6).

Based on previous findings, we did not expect Agreeableness or likeability to have any direct effect on early school-leaving. From our study, however, we do find a significant negative effect. Thus, being likeable and being able to act in a cooperative manner decreases the probability of leaving school before a minimum level of education is attained. However, this effect becomes non-significant once controls have been added to the model (model 6).

Emotional Stability is the final Personality factor added to model 1 and reflects emotional instability and proneness to psychological distress on the lower bound, and predictability and consistency on the upper bound. In previous studies on the relationship between Personality

\subsubsection{Probability of early school-leaving by Cognitive Skills and Openness to Experience}

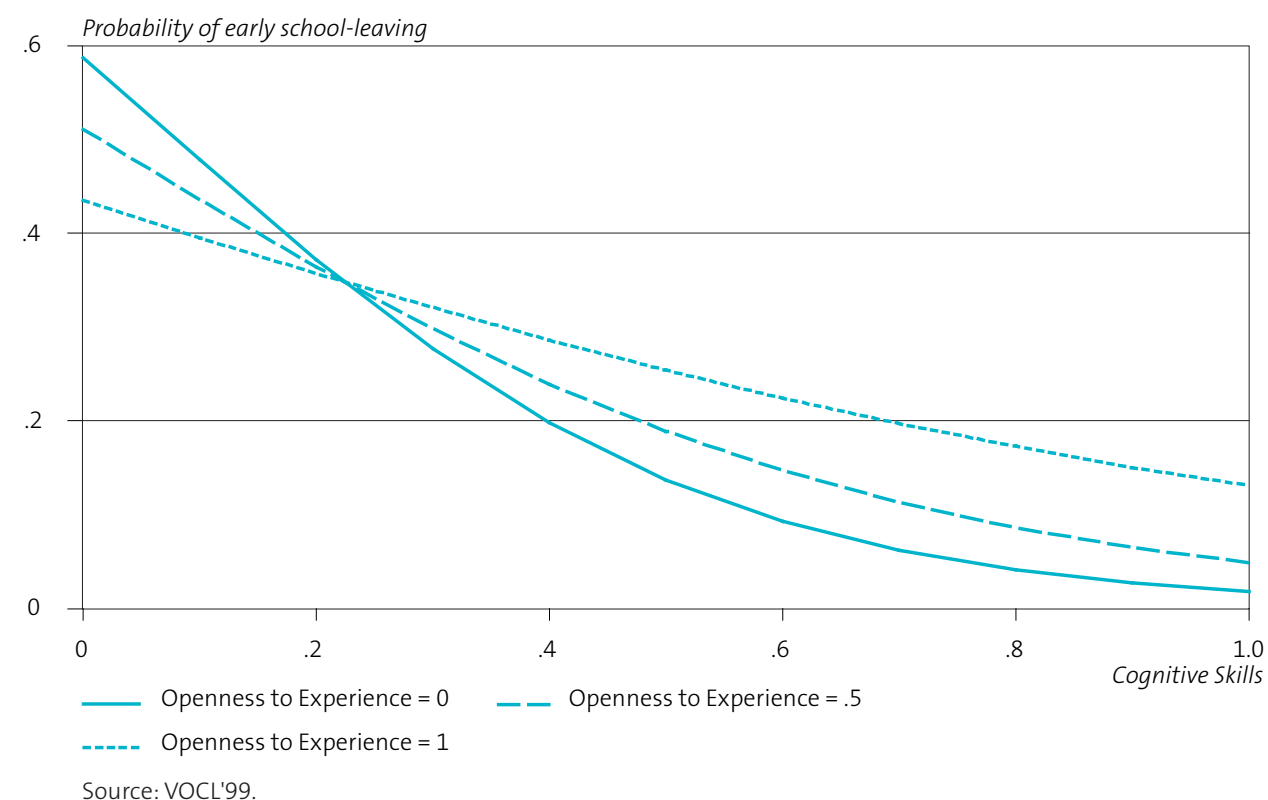

r. VOCL'99.

Note: All other variables in the model are kept at their means. 
and educational outcomes, no direct effects of Emotional Stability were found. In our study, we do find a significant positive effect for Emotional Stability $(B=.552)$, but this effect becomes very small and non-significant when controls are added to the model (model 6$)$.

We also tested the interaction effects between our five Personality Traits and Cognitive Skills (models 7a to 7e). Contrary to our hypothesis, but in line with the main effect, the interaction effect for Openness to Experienceis positive (model 7a). The graphical representation of the interaction effect is depicted in figure 4.4.5.

The graph shows that higher Cognitive Skills decrease the risk of becoming an early schoolleaver at all values of Openness to Experience. However, the impact of Cognitive Skills is

\subsubsection{Logistic regression of the interaction of Cognitive Skills and Personality Traits on the risk of early school-leaving}

\begin{tabular}{|c|c|c|c|c|c|c|c|c|}
\hline & (1) & (5) & (6) & (7a) & (7b) & $(7 c)$ & $(7 d)$ & (7e) \\
\hline \multicolumn{9}{|l|}{ Term } \\
\hline Constant & $1.363^{* * *}$ & $2.450^{* * *}$ & $5.062^{* * *}$ & $5.622^{* * *}$ & $4.127^{* * *}$ & $4.980^{* * *}$ & $4.335^{* *}$ & $4.715^{* * *}$ \\
\hline Cognitive Skills & $-5.105^{* * *}$ & $-5.139^{* * *}$ & $-3.275^{* * *}$ & $-4.376^{* * *}$ & $-1.330^{*}$ & $-3.105^{* * *}$ & $-1.681^{* * *}$ & $-2.530^{* * *}$ \\
\hline Openness to Experience & & $.889^{* * *}$ & $.758^{* * *}$ & -.613 & $.733^{* * *}$ & $.760^{* * *}$ & $.753^{* * *}$ & $.756^{* * *}$ \\
\hline Conscientiousness & & $-1.091^{* * *}$ & $-1.352^{* * *}$ & $-1.347^{* * *}$ & .403 & $-1.353^{* * *}$ & $-1.365^{* * *}$ & $-1.360^{* * *}$ \\
\hline Extraversion & & $-.867^{* * *}$ & -.269 & -.285 & -.278 & -.138 & -283 & -272 \\
\hline Agreeableness & & $-1.016^{* * *}$ & -.101 & -.084 & -.108 & -.103 & $1.125^{*}$ & -.105 \\
\hline Emotional stability & & $.552^{* *}$ & .145 & .137 & .09 & .146 & .138 & .689 \\
\hline \multicolumn{9}{|l|}{ Education level at age 12} \\
\hline Pre-college track & & & $-.835^{* * *}$ & $-.843^{* * *}$ & $-.839^{* * *}$ & -.834 & $-.839^{* * *}$ & $-.833^{* * *}$ \\
\hline Pre-university track & & & $-1.069^{* * *}$ & $-1.093^{* * *}$ & $-1.088^{* * *}$ & -1.067 & $-1.088^{* * *}$ & $-1.064^{* * *}$ \\
\hline \multicolumn{9}{|c|}{ 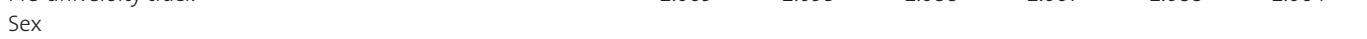 } \\
\hline Male & & & $.454^{* * *}$ & $.455^{* * *}$ & $.457^{* * *}$ & .454 & $.457^{* * *}$ & $.424^{* * *}$ \\
\hline \multicolumn{9}{|l|}{ Female (ref). } \\
\hline \multicolumn{9}{|l|}{ Migrant status } \\
\hline Migrant & & & .01 & .01 & .01 & .01 & .012 & .01 \\
\hline \multicolumn{9}{|l|}{ Native Dutch (ref). } \\
\hline Parental education & & & $-.083^{* * *}$ & $-.083^{* * *}$ & $-.084^{* * *}$ & $-.083^{* * *}$ & $-.084^{* * *}$ & $-.084^{* * *}$ \\
\hline Parental income & & & $-.275^{* * *}$ & $-.276^{* * *}$ & $-.272^{* * *}$ & $-.275^{* * *}$ & $-.275^{* * *}$ & $-.275^{* * *}$ \\
\hline Parental communication & & & $-.459^{* * *}$ & $-.465^{* * *}$ & $-.455^{* * *}$ & $-.459^{* * *}$ & $-.485^{* * *}$ & $-.461^{* * *}$ \\
\hline Controls for missing values & No & No & Yes & Yes & Yes & Yes & -.485 & Yes \\
\hline Cognitive Skills*Openness to Experience & & & & $2.744^{* * *}$ & & & & \\
\hline Cognitive Skills* Conscientiousness & & & & & $-3.571^{* * *}$ & & & \\
\hline Cognitive Skills* Extraversion & & & & & & -.271 & & \\
\hline Cognitive Skills*Agreeableness & & & & & & & $-2.585^{* *}$ & \\
\hline Cognitive Skills*Emotional Stability & & & & & & & & -1.128 \\
\hline Log Likelihood & $-6183,0672$ & $-6123,2497$ & $7-5794,84$ & 5792,07 & $-5788,04$ & $-5794,810$ & $4-5792,266$ & $7-5794,4038$ \\
\hline
\end{tabular}

Source: VOCL'99.

Notes: Sample size is 14,230 observations. ${ }^{* * *}=p<.01 .{ }^{* *}=p<.05 .{ }^{*}=p<.1$ 
stronger for students with lower scores on Openness to Experience as is reflected by the steeper angles. Thus, the protective effect of Cognitive Skills is strongest for students who are very conventional and traditional. At the same time, the graph shows that while Openness to Experience is negatively related to early school-leaving for those with low scores on Cognitive Skills (i.e. lower than approximately .25); this effect becomes positive for those with higher scores on Cognitive Skills. For those with high Cognitive Skills, students with high Openness to Experience are more likely to become an early school-leaver, while for those with low Cognitive Skills, high Openness to Experience protects against early schoolleaving. This finding is in line with the assumption made by De Fruyt and Mervielde (1996) that high Openness to Experience is actually disadvantageous when reproduction of curricular content is required. It seems to suggest that students with high Cognitive Skills as well as a high Openness to Experience become more frustrated by a setting of reproduction of curricular content. In the case of low Cognitive Skills, this education environment might still be interesting enough for students with a high Openness to Experience.

The interaction between Cognitive Skills and Conscientiousnessis negative (model $7 b$ ), which is exactly what we expected in our hypotheses. Figure 4.4 .7 shows the impact of Cognitive Skills on the risk of leaving school early for different values of Conscientiousness. For students with low Cognitive Skills, Conscientiousness has a strong protective effect against early school-leaving, while for students with higher than average Cognitive Skills;

\subsubsection{Probability of early school-leaving by Cognitive Skills and Conscientiousness}

8

Probability of early school-leaving

6

.4

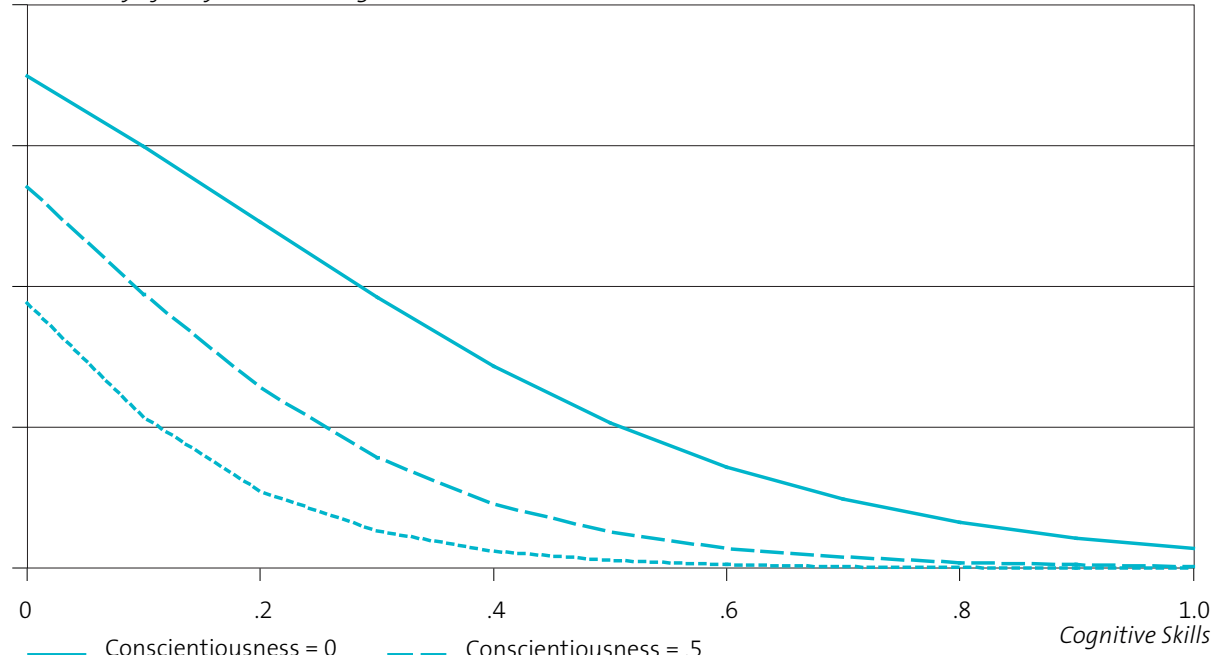

Conscientiousness $=1$

Source: VOCL'99.

Note: All other variables in the model are kept at their means. 
the difference in the probability of leaving school early is very small and no longer significant. Thus Conscientiousness can compensate for low ability, but within high ability groups, differences in Conscientiousness no longer play an important role.

For Agreeableness, we did not expect to find a significant interaction with Cognitive Skills (model 7d). However, our results show that this trait has a negative interaction with Cognitive Skills, indicating that the protective effect of Cognitive Skills is higher for students with high scores on Agreeableness. This effect is depicted in figure 4.4.8. We see that students with a low level of Agreeableness show a higher risk of becoming an early school-leaver compared to those who are more agreeable, but this effect is strongest for those with average Cognitive skills. For those with extremely high and extremely low Cognitive Skills, Agreeableness does not seem to affect the risk of becoming an early school-leaver. This might indicate that average skilled students who are agreeable and therefore probably more popular among peers have a lower risk of becoming an early school-leaver. This is confirmed by additional analyses (see Traag, Lubbers, \& Van Der Velden, 2012).

In our hypotheses, we expected to find a negative interaction effect for Extraversion. Although our results (model $7 c$ ) confirm this ( $B=-.271$ ), the effect is not significant. In model 7e we estimated the interaction between Emotional Stability and Cognitive Skills, which is negative but not significant.

\subsubsection{Probability of early school-leaving by Cognitive Skills and Agreeableness}

Probability of early school-leaving

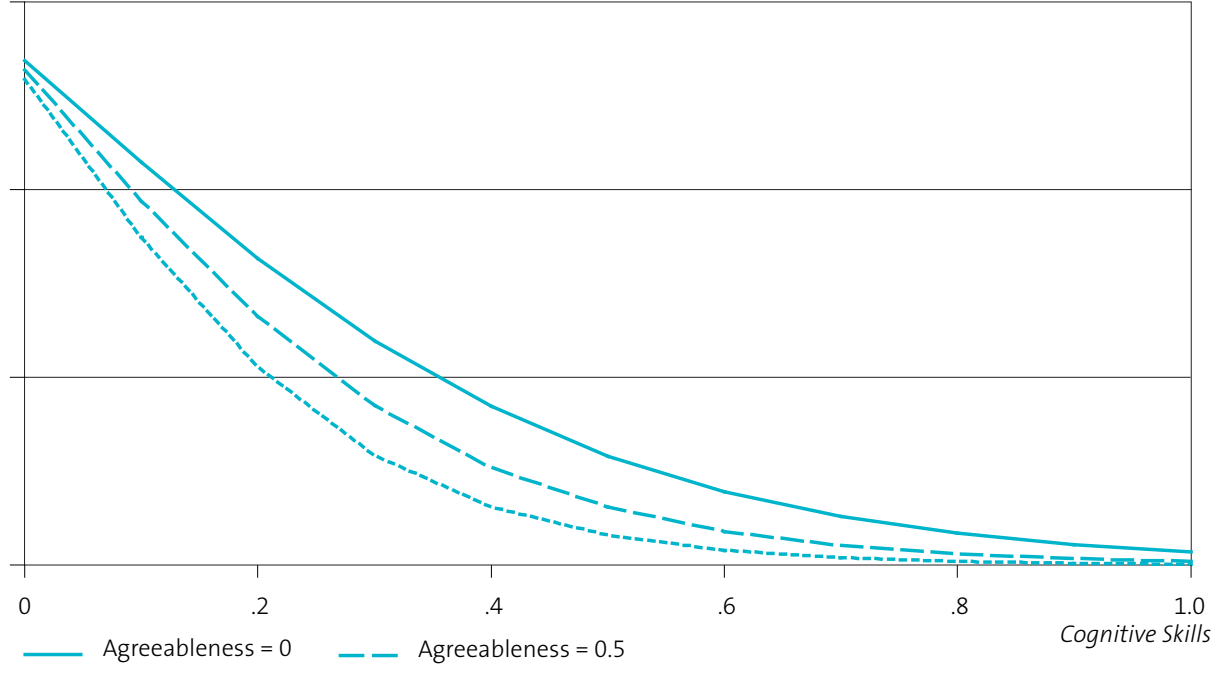

Source: VOCL'99.

Note: All other variables in the model are kept at their means. 


\subsection{Conclusion and discussion}

Early school-leavers are a very heterogeneous group, comprised of those who cannot attain an upper secondary qualification simply because they lack the cognitive ability, and those who have the ability but nevertheless decide not to invest in further schooling. This chapter aimed to investigate how Non-Cognitive Skills can explain individual differences in early school-leaving above and beyond the effect of Cognitive Skills. We wanted to see if differences in Non-Cognitive Skills could explain why adolescents with comparable Cognitive Skills show such different education outcomes. Our analyses provide some insight on how and why some students become early school-leavers, while others do not. Our results showed that Cognitive Skills measured at age 12 do indeed have a strong and direct effect on the risk of becoming an early school-leaver, and that this effect is hardly affected by any of the Non-Cognitive Skills that were added to the model. However, NonCognitive Skills also explain part of the individual differences in drop-out risk.

First, there is a direct impact of Achievement Motivation. We find that the higher the Achievement Motivation, the lower the risk of leaving school without a full upper secondary qualification. This result is in line with previous studies on the effect of motivation on school success (Alexander et al., 1997; Audas \& Willms, 2001; Traag \& Van der Velden, 2011). Achievement Motivation does not affect the impact of Cognitive Skills as was suggested by Vroom's Expectancy Theory (Vroom, 1964): we did not find a significant interaction effect of Achievement Motivation and Cognitive Skills on the risk of becoming an early school-leaver.

Second, we looked at the impact of Personality Traits as a predictor for early school-leaving. We found significant effects for three of the five Personality Traits on the risk of becoming an early school-leaver. We found a positive effect for Openness to Experience, indicating that it is a risk factor in early school-leaving. This is contrary to what we expected based on the study by Ackerman and Heggestad (1997). When looking at the interaction effect between Cognitive Skills and Openness to Experience, however, we found that the positive effect of the latter is only true for students with high Cognitive Skills. As De Fruyt and Mervielde (1996) suggested this could be because the creative and imaginative nature of these highly skilled students is disadvantageous in settings where reproduction is the main requirement. It is very likely that highly skilled students with higher scores on Openness to Experience comply with the education system as long as they have to and leave the system as soon as compulsory education ends. The reverse is true for low skilled students with a high score on Openness to Experience. For these students the education setting may still provide enough intellectual challenges to actually keep them in the system and obtain a full upper secondary qualification.

In general, being conscientious is a protective factor against early school-leaving. High scores on Conscientiousness decrease the probability of becoming an early school-leaver, 
which is in line with previous studies (Chamorro-Premuzic \& Furnham, 2003b; De Fruyt \& Mervielde, 1996; Poropat, 2009). But there is also an interaction effect with Cognitive Skills. The protective effect of Conscientiousness holds specifically for students with low Cognitive Skills. For those with high Cognitive Skills, there is hardly any effect of Conscientiousness. This is in line with findings by Chamorro-Premuzic and Furnham (2003a) that higher levels of Conscientiousness can compensate for poor intellectual ability.

For Agreeableness, we found a protective effect on early school-leaving but only for students with average Cognitive Skills. One possible explanation for this protective effects could be that Agreeableness is an important predictor for peer acceptance (Lubbers, Van der Werf, Kuyper, \& Offringa, 2006a), while peer acceptance is an important predictor for educational success (Hymel, Comfort, Schonert-Reichel, \& McDougall, 1996; Lubbers, Van der Werf, Snijders, Creemers, \& Kuyper, 2006b; Parker \& Asher, 1987; Wentzel, 2003). This is indeed what we find in additional analyses (Traag et al., 2012). We did not find any significant effects for Extraversion or Emotional Stability on early school-leaving, at least after controlling for background characteristics.

In general, we must conclude that Cognitive Skills are indeed an important predictor of early school-leaving. Some adolescents simply lack the Cognitive Skills to finish a certain level of education. However, Non-Cognitive Skills play an important role in explaining why some students choose to leave the education system in spite of the fact that they have the Cognitive Skills to obtain a full upper secondary qualification. For some, the education system just does not match their Personality, making it hard for them to comply with school rules and regulations and even making it less likely that they will stay in school after compulsory education. An important trait here appears to be Openness to Experience. Students that are very open to experience are viewed as very creative and imaginative, but Openness to Experience can also be a negative factor since it is strongly linked to risk behavior (Nicholson, Soaneb, Fenton-O'Creevy, \& Willmand, 2005). In their study on the impact of Personality on risk-taking, Nicholson and colleagues make a distinction between stimulation seekers, goal achievers, and risk adapters. Only the first group is truly risk seeking and may be of interest for further studies on early school-leaving because it may very well be precisely the group we previously defined as the 'resigners', a group of students that has the ability to achieve in education but who is in search of something else than conforming to conventional careers paths. 



\section{That's what friends are for? The impact of peer characteristics on early school-leaving ${ }^{24)}$}

\subsection{Introduction}

Early school-leaving has a lasting influence on an individual's life course. It increases the risk of unemployment and low-paid jobs (Beckers \& Traag, 2005a, 2005b; Rumberger, 1987), the risk of dependency on social security benefits, and it also correlates with higher levels of delinquency (Thornberry et al., 1985; Traag, Marie, \& Van Der Velden, 2010). The majority of the existing literature reflects an individual deficit model, focusing primarily on individual and family characteristics as the major causes of early schoolleaving (Hymel et al., 1996; Ream \& Rumberger, 2008), while ignoring the importance of peer relations for school engagement. In this chapter, we investigate whether peer relations influence a student's risk of early school-leaving. A large number of studies demonstrate the impact of peer relations on academic performance. Some argue that students who feel accepted by their peers are better able to meet academic challenges (Furrer \& Skinner, 2003; Lubbers et al., 2006b; Patrick, Ryan, \& Kaplan, 2007; Walters \& Bowen, 1997). Also, it is argued that the characteristics of peers influence academic performance, because students observe and model other students' learning styles (Bandura, 1977), evaluate their achievement by comparing it to others (specifically with friends, Lubbers, Van der Werf, \& Kuyper, 2009)and are rewarded for behavior that is valued by peers (Wentzel, 1996). Peer relations in classrooms have been associated with grades (Wentzel, 2003; Zettergren, 2003) 25), scores on achievement tests (Buhs \& Ladd,

\footnotetext{
24) This chapter is published as a ROA Research Memorandum, T. Traag, Lubbers, M.J. \& Van Der Velden, R. K. W. (2011). That's what friends are for? The impact of peer characteristics on early school-leaving. ROA Research Memorandum no. 6. We would like to thank Roxanne Korthals, Olivier Marie for their helpful comments.

25) For additional literature see Guldemond (1994), Ollendick, Weist, Borden, \& Greene (1992), Wentzel \& Caldwell (1997) and Wigfield, Eccles, \& Rodriguez
} (1998). 
2001) ${ }^{26)}$, and graduation rates (Risi, Gerhardstein, \& Kistner, 2003). Although academic performance is highly correlated with early school-leaving, studies on the relevance of peers for early school-leaving are rather limited. In this study, we want to contribute to the existing literature in three ways.

First of all, large-scale empirical research on the impact of peer characteristics on early school-leaving is rather limited. Cairns et al. (1989) used a prospective longitudinal study of 475 US students that included individual interviews to map social networks to identify affiliations with peers who were vulnerable to subsequent school drop-out. Their study showed that for both boys and girls in seventh grade, school drop-outs affiliated with peers who themselves later dropped out of school. However, Cairns and colleagues did not add any controls for academic and family factors. A study by Vitaro, Larocque, Janosz and Tremblay (2001) among Caucasian boys in Canada showed that while socioeconomic background and personal dispositions had a direct impact on high school drop-out, unpopularity/friendlessness (peer rejection) had no impact. However, association with deviant friends (i.e. friends, who were arrested by the police, were member of a gang and/or considering to leave school) did have a significant impact on high school drop-out. Peer deviance was measured by questions to respondents about exposure to deviant drop-out friends. Although this study does bring about some interesting results, generalization of the results may be limited since the study was conducted exclusively among white males. Also, the measurement of unpopularity/ friendlessness used was quite unconventional. In 2008, a study by Ream and Rumberger (2008) showed that the number of drop-out friends significantly increased the risk of school drop-out in twelfth grade, suggesting that friends act as a prototype for subsequent processes, influencing educational attainment and school drop-out. However, the measurement of peer relations and the measurement of peer characteristics in this study were rather limited. Peer drop-out was measured by students' responses to the question how many of their close friends had dropped out, yet no true peer relations were established, so they were unable to add any controls for other peer characteristics. Our first contribution to the current literature is that we will use a very unique dataset which allows us to better analyze how exposure to future early school-leavers increases one's own risk of early school-leaving above and beyond characteristics of both the student and their peers. We will use a large scale longitudinal panel study of almost 20 thousand Dutch students in the first grade of secondary education in 1999. We will focus on characteristics that predict a student's own risk of early school-leaving as well as the peer's future drop-out status. Peer relations were measured by asking students to nominate classmates whom they liked best. In the analysis we match individual characteristics with peer characteristics like gender, ethnicity, socio-economic background, cognitive and non-cognitive skills, and future ${ }^{26)}$ Also see Diehl, Lemerise, Caverly, Ramsay, \& Roberts (1998), Ladd, Kochenderfer, \& Coleman (1997), Vandell \& Hembree (1994) for literature on the
relationship between peers and achievement scores. 
drop-out status. In line with past research we expect that students who associate with future school-leavers are more likely to become an early school-leaver themselves. In addition, we expect that peers' school performance, achievement motivation and social class all have a positive impact on the probability of attaining a full upper secondary qualification.

Our second advancement is that relatively few studies have analyzed the relevance of the concepts of both popularity and number of friends for educational attainment at the same time (Farmer, Estell, Leung, Trott, Bishop, \& Cairns, 2003; Ream \& Rumberger, 2008; Vitaro et al., 2001). Moreover, these few studies produced mixed results. While some authors found additive effects (Diehl, Lemerise, Caverly, Ramsay, \& Roberts, 1998; Vandell \& Hembree, 1994), others found redundant relations. A possible explanation for these mixed results was given by Ladd et al. (1997), who suggested that patterns of association between number of friends, peer acceptance and outcome variables differ depending onthe outcome measures. We will distinguish between two -partially overlapping -peer groups, namely those who were nominated by our focal respondents as best liked classmates (non-reciprocal as well as reciprocal friends) and those who nominated our focal respondents (the peer group determining students' popularity). We then test whether the characteristics of these two groups affect the students' probability of early school-leaving.

Our third advancement on previous studies is that we address the complex issue of providing evidence of peer effects, above and beyond alternative processes that might explain peer similarity. Similarity may be a product of homophily, which refers to the tendency of people to associate with others who are very much like themselves. A large body of empirical evidence (see McPherson, Smith-Lovin, \& Cook, 2001) suggests that people initially select each other based on visible traits and then choose their friends from the resulting group of similar others (Lubbers et al., 2006b). Homophily is a pervasive organizing principle of social relationships. This makes it difficult to disentangle the causal direction between peer relations and the similarity between peers. In this study, we therefore performed some robustness analyses to understand to what extent pairs (or dyads) are formed on the basis of homophily. To do this, we performed an analysis of all possible dyads within classes. Specifically, we regressed the probability that a pair is in a friendship relation on the similarity between the students in the pair on a number of predictors of early school-leaving (Traag \& Van der Velden, 2011), such as cognitive skills, motivation and social class indicators. In a second step, we added the similarity in future school-leaving status as a predictor, to study whether having the same future schoolleaving status affects the probability of forming a friendship relation. If unobserved characteristics affect both the forming of a relationship and the risk of becoming an early school-leaver, adding the future school-leaving status will have a strong effect on the probability that this pair is in a friendship relationship. If this is not the case, then we can have more confidence in the causality of our results. A second explanation of dyadic similarity in early school-leaving and academic characteristics related to early school- 
leaving can be found in the practice in Dutch education to group children together in classes based on their cognitive skills, again making it more likely for children who are very much the same on a number of characteristics to have a friendship relation. This again, makes it harder to distinguish between the mere effect of selection and the true influence of peers. We use a random coefficient model that takes into account the clustering of our data into schools and classes and controlled for the track level.

The main findings are that friendship and popularity have additive effects. Having friends who later become early school-leavers as well as being popular among future early schoolleavers increases a student's own risk of becoming an early school-leaver. We will show that this is a mere effect of peer selection. Other characteristics of the peer group such as gender composition, ethnic composition, average cognitive and non-cognitive skills, and average socio-economic background have no effects on the risk of becoming an early school-leaver but some of these characteristics do play a role in peer selection.

This chapter is structured as follows. In section 5.2 we discuss our data and the variables used. This section also includes the analytical strategy and methodology used. In section 5.3 we discuss our results from the descriptive analyses and the random effect models. Section 5.4 concludes with a discussion of our findings and addresses some issues for future research.

\subsection{Data and study design}

Data were collected as part of the large-scale study "Secondary Education Pupil Cohort 1999" (VOCL'99), carried out by the Groningen Institute for Educational Research (GION) and Statistics Netherlands (CBS). The study followed a cohort of students who entered secondary education at the age of 12 until they leave full-time education. The initial sample consisted of 19,391 students in 825 classes from 126 schools who entered secondary education in the 1999/ OO school year. The sample is representative for schools and students in Dutch secondary education (Kuyper et al., 2003).

From our initial sample of 19,391 students we excluded students who had died, were seriously ill or had moved abroad in the period between 1999/ 00 and 2010/ 11 (473 students). In addition, we excluded students in classes that had response rates below 80 percent on the sociometric questionnaire ( 8,020 students). This left 10,898 students for our analyses. This selected sample differs a little bit from the initial cohort population. The average age of this sample is 12.5 years $(S D=.48)$ at the first measurement, $54.3 \%$ of this sample is female, $8.8 \%$ is first or second-generation non-western migrants, and 50.7 started education in pre-vocational education. In the unselected sample of 19,931 students, the average age is 12.6 years ( $\mathrm{SD}=.51), 50 \%$ is female, 11.5 is first or second generation nonwestern migrants, and $56.5 \%$ is in the pre-vocational track at age 12 . Since our selection is 
slightly biased towards students from higher educational tracks, females and native students, those less at risk of early school-leaving are overrepresented in this subsample. This will have a conservative effect on the results.

\subsubsection{Measures}

\subsubsection{Early school-leaving}

In this chapter, an early school-leaver is defined as a student who did not have a full upper secondary qualification in September 2010 (in the school year 2010/ 11). This is considered the minimum level of education a person should acquire to be successful on the labor market: the 'basic qualification' ('startkwalificatie' in Dutch) (OECD, 2007). This concept does not amount to an actual certificate, but is widely used for political and research purposes to identify youths with low education achievement. To aid understanding of the operationalization of early school-leaving, we will first shortly explain the Dutch education system, which is very stratified (for an overview, see figure 1.1.1 in chapter 1). After 8 years of primary education, students enter secondary education at the age of 12. Here they are placed in one of three tracks: one track preparing for university education (VWO, duration 6 years), one for higher vocational education (HAVO, duration 5 years), and one for vocational education at the upper secondary level (VMBO, duration 4 years). Track placement is decided on the basis of a nationwide CITO test at the end of primary education and the advice of the primary school teacher. A full upper secondary qualification is defined as a diploma from the pre-university track, the pre-college track, or a diploma at the level of at least upper secondary basic vocational education. This means that early

\subsubsection{Early school-leaving rates by track level in the first grade of Dutch secondary education and education level achieved in school year 2010/2011 (percentages in brackets)}

\begin{tabular}{|c|c|c|c|c|}
\hline \multirow{2}{*}{$\begin{array}{l}\text { Track level first grade in } \\
\text { secondary education }\end{array}$} & \multicolumn{2}{|c|}{ Diploma status 2010/ 11 } & \multirow{2}{*}{$\begin{array}{l}\begin{array}{l}\text { Total early school- } \\
\text { leavers }\end{array} \\
\text { Total }\end{array}$} & \multirow[t]{2}{*}{ Total population } \\
\hline & No diploma at all & $\begin{array}{l}\text { Pre-vocational } \\
\text { education or } \\
\text { vocational assistant }\end{array}$ & & \\
\hline Pre-vocational track & $\begin{array}{l}198 \\
(3.6)\end{array}$ & $\begin{array}{l}1,516 \\
(27.4)\end{array}$ & $\begin{array}{l}1,714 \\
(31.0)\end{array}$ & 5,524 \\
\hline Pre-college track & $\begin{array}{l}24 \\
(1.0)\end{array}$ & $\begin{array}{l}169 \\
(7.4)\end{array}$ & $\begin{array}{l}193 \\
(8.4)\end{array}$ & 2,296 \\
\hline Pre-university track & $\begin{array}{l}29 \\
(0.9)\end{array}$ & $\begin{array}{l}124 \\
(4.0)\end{array}$ & $\begin{array}{l}153 \\
(5.0)\end{array}$ & 3,078 \\
\hline Total & $\begin{array}{l}251 \\
(2.3)\end{array}$ & $\begin{array}{l}1,809 \\
(16.6)\end{array}$ & $\begin{array}{l}2,060 \\
(18.9)\end{array}$ & $\begin{array}{l}10,898 \\
(100.0)\end{array}$ \\
\hline
\end{tabular}

Source: VOCL'99. 
school-leavers are students who attained no diploma at all, or a diploma at the level of the pre-vocational track or at the level of vocational assistant in upper secondary education. In our sub-sample, 2,060 (18.9 percent) students had not attained this minimum level of education. The risk of becoming an early school-leaver is largest for those who started their educational career in the pre-vocational track (see table 5.2.1), 27.4 percent of these students did not attain a full upper secondary qualification. For those who started in the tracks preparing for vocational colleges or university, the risk is much smaller. Only 8.4 percent of students who started in the pre-college track and 5.0 percent of those who started in the pre-university track did not attain a full upper secondary qualification.

\subsubsection{Individual and family characteristics}

In our models we controlled for a number of characteristics that were shown in a previous study (Traag \& Van der Velden, 2011) to predict early school-leaving:

School performance ${ }^{27)}$ is a sub-test of the test used at the end of primary education to determine track placement. The test consists of three subtests for text comprehension, arithmetic and information processing (see (Lubbers, 2004), for a detailed description of the testing procedure). Each test has 20 multiple-choice items ${ }^{28)}$. For comparability purposes, this and all other scale variables used were rescaled so that the lowest score was $\mathrm{O}$ and the highest score was 1 .

School motivation was measured in January 2000 in the student questionnaire ${ }^{29)}$ using the Academic Achievement Motivation Test (Hermans, 1970) that assesses a student's motivation to perform well in school. The scale consists of 9 items ${ }^{30}$ indicating the responses to questions like: "I do my homework much better when I'm worried about failing" and "I always try to do my homework as well as possible". Previous studies have shown motivation to be a key predictor of academic attainment (Hustinx et al., 2009; Kuyper et al., 2011; Kuyper et al., 2000).

\footnotetext{
27) In January 2000 (four months after their entry into secondary education), the students completed a school performance test, a student questionnaire and a sociometric questionnaire while in their regular classes. They were assured that the information in the survey would be kept confidential. Students who were absent on the day the questionnaires were administered are treated as missing cases. The school performance test was developed by the Cito Group (the Dutch equivalent of Educational Testing Services). The test was taken in class, under the supervision of one or more teachers, mostly the class tutor, and took up two full periods. A total of 1,216 students did not participate in any of the tests, while 377 students filled out one or two. A total of 91.8 percent of the students participated in the school performance test.

28) The reliability of the total test is $\beta=.90$, which reflects the intercorrelation between the items incorporated in the scale. As a general rule of thumb, tests with $\beta>=.90$ are considered excellent; tests with $\beta>=.70$ are considered good while and $\beta$ below .50 is considered unacceptable.

29) The student questionnaire was also administered in class, mostly during the tutor class. The questionnaire contained questions on, among other things, school motivation, learning strategies, school well-being, class climate and truancy. Since most schools took the student questionnaire on the same day as the school performance test and the sociometric questionnaire, there is a high correlation between the non-response on these items. The overall response rate for the students questionnaire is 94 percent.

30) The reliability of the scale is .74, which can be considered a good, internally consistent scale.

31) To obtain information from the parents, a parental questionnaire was given to the students. Completed questionnaires could either be returned to the school or directly to Statistics Netherlands, again assuring confidentiality. The overall response rate for this questionnaire was 82 percent. The parental questionnaire had two aims. First, it was designed to measure variables in the home environment that affect school performance of the children, such as parenting styles, parental involvement, and aspirations. Second, the socio-economic status of the household was measured by asking questions on parental education and occupation.
} 
Parental education was collected in the parental questionnaire ${ }^{31)}$ during the school year 1999/ Oo. For both parents (if available) the highest education level wasrecoded into the number of years of schooling needed to obtain this level (Bosker et al., 1985) varying from 6 (primary education) to 19 years (university). To reflect the parental education level the mean of the father and the mother was taken.

Parental income is measured as the log of the mean personal income of both the father and the mother (if available) in 2004 and was taken from the Annual Income Registry kept by Statistics Netherlands based on information from the Dutch Tax Administration. It includes income from labor as well as social security benefits and other sources of income. For single parent households, only the income of the resident parent was used. Parents with zero or negative income (124 cases in the initial population) were recoded to having zero income ${ }^{32}$. Where the income could not be matched ( 702 cases in the initial population), the income was replaced by the population mean.

Parental communication is based on three questions ${ }^{33}$ to both parents in the parental questionnaire on talking to their child about school and their performance. It includes items such as "How often do you or your partner talk to your child about things your child learned in school?".

Gender is coded o for boys and 1 for girls.

Migrant status is based on the Municipal Population Registration (GBA) and is coded o for native Dutch and 1 for migrant. A respondent is defined as a 'migrant' if he/she was born abroad or at least one of his/her parents was born abroad.

Item non-response was replaced by the mean score of the sub-population in the same class. For each variable a dummy was included with value 1 if data were replaced and value o when data were not replaced.

\subsubsection{Peer group characteristics}

As part of the sociometric questionnaire, students were asked to nominate classmates whom they liked best (maximum 3 nominations). For each nomination, the student was asked to report the surname and the first initial of the nominee. This resulted in 38,041 nominations for 14,271 students. These names were then transformed into their corresponding identity numbers using an automated procedure. In a few cases, we were not able to match a nominee's name to an identification number for the following reasons. First, notwithstanding the request to only nominate children within their classes, some students nominated persons outside their classes. Secondly, some students did not fill in a full surname, but only used initials. These nominations could only be matched if the combination of initials was unique within that class. Thirdly, some students wrote things like "all boys in my class", or "none" instead of a name. These cases were coded as missing values.

\footnotetext{
32) Negative or zero incomes occur in those cases where parents are self-employed and made no profits or suffered losses during the observation period. 33) The reliability of the scale is .64 , which is considered a good internal consistency.
} 
Popularity. Popularity was operationalised as the number of times students were nominated by their classmates as 'best liked' (hence peer-reported). We estimate the effects of both being popular among future early school-leavers as well as being popular among future regular school-leavers. These variables were measured as the number of nominations received by future early school-leavers and future regular school-leavers, respectively. School-leaving status of peers was measured in the same way as for the focal respondents.

Number offriendships. A classmate is defined as a friend if the respondent nominated that person as 'best liked'. In most studies on the impact of friendship, only those dyads are classified as friends where the nomination is reciprocal. Studies using reciprocal nominations as a measure for friendship (Bukowski \& Hoza, 1993; Vandell \& Hembree, 1994) stress that the use of such a measure represents a conservative test of the hypothesis that peer acceptance and friendship are unique contributors to adjustment because of the inherent overlap in the measures. In the present study we will concentrate on an analysis that includes both reciprocal and non-reciprocal friends, because as only a maximum of three nominations could be given, requiring reciprocity would be a very strict measure of peer relations. However we repeated the analysis using only reciprocal friends. This analysis yielded the same substantive results ${ }^{34}$. To estimate the effects of having friends among future early school-leavers and future regular school-leavers, we include the number of future early school-leaving and future regular school-leaving friends in our models. Again, the school-leaving status of friends is measured in the same way as described earlier.

To control for characteristics of both nominated and nominating peers, we computed a number of variables that reflect the characteristics of the peer group. For performance, motivation, parental education, parental income, and parental communication, we calculated the mean score of the peer group. For gender, we used the percentage of males in the peer group and for migrant status, the percentage of migrants.

In the second part of our analyses, we test the impact of similarity among peers on the probability that one peer nominates the other, using the characteristics described above. For this procedure, we calculated a set of dummies indicating whether students were the same (1) or not (o) on gender, migrant status and school-leaving status. For continuous variables (i.e. school performance, school motivation, parental education, parental income, and parental communication), we first computed tertiles for both the focal student and the peer and then computed dummy variables indicating that they were in the same tertile (1) or not (0). We use these dummies to predict the probability that within a dyad one peer nominated the other.

34) As a robustness check, we replicated our study using only reciprocal friends. Of course, the distribution of these variables is much more skewed than in the less stringent sample, with 28.5 percent of all students having no friends at all compared to 7.2 percent for non-reciprocal friends. However, findings based on reciprocal friendships are very comparable to the findings in this study. The results of the robustness check are described in table 5.5 .1 in the appendix. 


\subsubsection{Descriptive statistics of explanatory variables, by school-leaving status (standard deviations given in brackets)}

\begin{tabular}{|c|c|c|c|c|c|c|}
\hline & \multicolumn{2}{|c|}{ Regular school-leavers } & \multicolumn{2}{|c|}{ Early school-leavers } & \multicolumn{2}{|l|}{ Total } \\
\hline \multicolumn{7}{|l|}{ Student characteristics } \\
\hline \multicolumn{7}{|l|}{ Gender } \\
\hline Male & 44.2 & & 51.9 & & 45.7 & \\
\hline Female & 55.8 & & 48.1 & & 54.3 & \\
\hline \multicolumn{7}{|l|}{ Migrant status } \\
\hline Migrant & 7.8 & & 13.0 & & 8.8 & \\
\hline Native & 92.2 & & 87.0 & & 91.2 & \\
\hline School performance & .6 & $(.177)$ & .5 & $(.167)$ & .6 & $(.187)$ \\
\hline School motivation & .6 & $(.145)$ & 6 & $(.165)$ & .6 & $(.150)$ \\
\hline Parental education & 14.2 & (3.148) & 12.2 & (3.358) & 13.8 & $(3.282)$ \\
\hline Parental income & 10.2 & $(.992)$ & 10.0 & $(1.122)$ & 10.2 & $(1.023)$ \\
\hline Parental communication & .5 & $(.162)$ & .5 & $(.175)$ & .5 & $(.165)$ \\
\hline \multicolumn{7}{|l|}{ Popularity } \\
\hline Number of nominations by regular school-leavers & 2.2 & $(1.581)$ & 1.5 & $(1.340)$ & 2.1 & $(1.562)$ \\
\hline Number of nominations by early school-leavers & .4 & $(.696)$ & .8 & $(.946)$ & .5 & $(.767)$ \\
\hline$\%$ Males & .4 & $(.470)$ & .5 & $(.476)$ & .4 & $(.472)$ \\
\hline$\%$ Migrants & .1 & $(.198)$ & .1 & $(.265)$ & .1 & $(.213)$ \\
\hline Average School performance & .6 & $(.237)$ & .4 & $(.219)$ & .5 & $(.241)$ \\
\hline Average School motivation & .6 & $(.206)$ & .5 & $(.231)$ & 6 & $(.212)$ \\
\hline Average Parental education & 12.8 & $(4.668)$ & 11.0 & $(4.818)$ & 12.5 & $(4.750)$ \\
\hline Average Parental income & 9.3 & $(3.007)$ & 8.8 & (3.324) & 9.2 & (3.074) \\
\hline Average Parental communication & .5 & $(.190)$ & .5 & $(.205)$ & .5 & (.193) \\
\hline \multicolumn{7}{|l|}{ Friends } \\
\hline Number of regular school-leaving friends & 2.2 & $(.966)$ & 1.7 & $(1.048)$ & 2.1 & $(1.007)$ \\
\hline Number of early school-leaving friends & .4 & $(.624)$ & .8 & $(.858)$ & .4 & $(.696)$ \\
\hline$\%$ Males & .4 & $(.470)$ & .5 & $(.469)$ & .4 & $(.470)$ \\
\hline$\%$ Migrants & .1 & $(.186)$ & .1 & $(.243)$ & .1 & (.199) \\
\hline Average School performance & .6 & $(.218)$ & .4 & $(.210)$ & 6 & $(.225)$ \\
\hline Average School motivation & .6 & $(.182)$ & 6 & $(.213)$ & 6 & $(.189)$ \\
\hline Average Parental education & 13.3 & $(4.160)$ & 11.4 & $(4.511)$ & 12.9 & (4.293) \\
\hline Average Parental income & 9.6 & $(2.607)$ & 9.1 & (3.085) & 9.5 & $(2.711)$ \\
\hline Average Parental communication & .5 & $(.168)$ & .5 & $(.190)$ & .5 & $(.173)$ \\
\hline \multicolumn{7}{|l|}{ School*class level } \\
\hline Degree of urbanization & 3.2 & $(1.232)$ & 3.4 & $(1.229)$ & 3.2 & $(1.235)$ \\
\hline Percentage of migrants & .1 & $(.131)$ & .1 & $(.185)$ & .1 & (.144) \\
\hline \multicolumn{7}{|l|}{ Heterogeneity } \\
\hline Only pre-vocational track & 14.0 & & 40.5 & & 19.0 & \\
\hline All tracks & 70.1 & & 55.1 & & 67.2 & \\
\hline Only pre-college and pre-university tracks & 12.7 & & 3.7 & & 11.0 & \\
\hline Only pre-university track & 3.2 & & .6 & & 2.7 & \\
\hline Class size & 22.4 & (6.598) & 19.6 & $(6.643)$ & 21.9 & (6.698) \\
\hline
\end{tabular}

Source: VOCL'99

Note: Sample size is 10,898 students

\subsubsection{Class-and school-level characteristics}

We also include a number of school-level predictors in our model that were shown to affect early school-leaving in our previous study (Traag \& Van der Velden, 2011). 
The school's heterogeneity is divided into four categories:

- schools that only provide the pre-vocational track,

- schools that provide all three tracks,

- schools that provide only the pre-college and the pre-university track,

- schools that provide only the pre-university track.

We will use three dummy variables to represent this variable; the first category serves as the reference category.

The percentage of migrant students is computed by dividing the total number of migrants in the sample in the school by the total number of students in the sample in that school. The degree of urbanization is based on the number of addresses per square $\mathrm{km}$ in the school region. For our analyses, this variable was coded (1) fewer than 500 addresses, (2) 500-1,000 addresses, (3) 1,000-1,500 addresses, (4) 1,500-2,500 addresses, and (5) 2,500 addresses or more. In addition, we control for the number of students within a class and the education track, with two dummies for the pre-college track and the pre-university track (pre-vocational track is the reference category). Table 5.2.2 gives the descriptive statistics of all variables used in the analyses while table 5.2.3 gives the zero-order correlations for the individual variables used in our models.

\subsubsection{Analytical strategy}

We estimated a series of random effect models that include individual, peer and class characteristics. The reason random effect models are chosen is that students are not

\subsubsection{Zero-order correlations analyses}

1.

Early school-leaving

2. Gender

3. Migrant status

4. School performance

5. School motivation

7. Parental income

8. Parental communication

9. Popularity

10. Friends

11. Popularity: Number of nominations by regular school-leavers

12. Popularity: Number of nominations by early school-leavers

13. Friends: Number of nominations by regular school-leavers

14. Friends: Number of nominations by early school-leavers
6. Parental education
.060

.071

$-.351$

$-.052$

$-.237$

$-.101$

$-.066$

$-.067$

$-.060$

$-.174$

.209

$-.222$

.245
2

Source: VOCL'99.

Notes: Correlations significant at the .01 level are reported in italics. 
randomly assigned to classes, as the composition of classes is partly based on students' cognitive skills. Therefore, we expect early school-leaving not only to differ on their individual characteristics, but also on class characteristics. Therefore, we used a random coefficient logit model that estimates the risk that a student ${ }_{i}$ in a class, will become an early school-leaver, allowing the intercept to have random effects among classes:

$$
\operatorname{logit}\left(p_{i j}(\text { dropout=1 })\right)=\beta_{o j}+\sum_{h=1}^{m} \beta_{1 h} S_{i j}+\sum_{h=1}^{m} \beta_{2 h} P_{i j}+\sum_{h=1}^{m} \beta_{3 h} F_{i j}+\sum_{h=1}^{m} \beta_{4 h} C_{i j} \text { with } \beta_{o j}=\beta_{o}+y_{i j}+u_{o j}
$$

where $S$ = student and family characteristics

$\mathrm{P}=$ characteristics of those who nominated the student

$\mathrm{F}=$ characteristics of those who were nominated by the student

$\mathrm{C}=$ characteristics of the class/school

As discussed above, the effect of peer characteristics might be caused by unobserved heterogeneity in the peer selection process instead of true peer influence. Therefore, we ran an additional random effect model (see Section 5.3.3) in which we estimated the probability that within all possible dyads $d$ within the classes in our sample, at least one of the two students will nominate the other, based on similarity on a number of characteristics by using model (2a). First we estimated the probability of at least one student selecting the other within dyad $d$ on the basis of similarity in a number of student and family characteristics. For dichotomous variables these are coded (1) if they were similar and (o) if they were not similar. For continuous variables we first computed tertiles for both the focal student and the peer and then computed dummy variables indicating that they were in the same tertile (1) or not (o). This model shows to what extent the similarity of personal and family characteristics affect a student's choice of peers. 


$$
\begin{aligned}
& \operatorname{logit}\left(p_{\text {ij/(peersimilarity=1) }}\right)=\beta_{\text {oj }}+\sum_{h=1}^{m} \gamma_{1 h} G_{d j}+\sum_{h=1}^{m} \gamma_{2 h} M S_{d j}+\sum_{h=1}^{m} \gamma_{3 h} S P_{d j}+\sum_{h=1}^{m} \gamma_{4 h} S M_{d j}+\sum_{h=1}^{m} \gamma_{5 h} P E_{d j}+ \\
& \sum_{h=1}^{m} \gamma_{6 h} P I_{d j}+\sum_{h=1}^{m} \gamma_{7 h} P C_{d j} \\
& \text { with } b_{\mathrm{oj}}=b_{\mathrm{o}}+\gamma_{\mathrm{i}}+u_{\mathrm{oj}} \\
& \text { where } \mathrm{G}=\text { gender } \\
& M S=\text { migrant status } \\
& \mathrm{SP}=\text { school performance } \\
& \mathrm{SM}=\text { school motivation } \\
& \mathrm{PE}=\text { parental education level } \\
& \mathrm{PI}=\text { parental income } \\
& P C=\text { parental communication }
\end{aligned}
$$

In the second model (2b) we added the similarity in school-leaving status to analyze whether this affects the predictive quality of our choice of peers model, by comparing the pseudo $R^{2}$ to the first model (model 2a).

$$
\begin{aligned}
& \operatorname{logit}\left(p_{\mathrm{ij} \text { (peersimilarity=1) }}\right)=\beta_{\mathrm{oj}}+\sum_{\mathrm{h}=1}^{m} \gamma_{1 \mathrm{~h}} \mathrm{G}_{\mathrm{dj}}+\sum_{\mathrm{h}=1}^{m} \gamma_{2 \mathrm{~h}} M S_{\mathrm{dj}}+\sum_{\mathrm{h}=1}^{m} \gamma_{3 \mathrm{~h}} \mathrm{SP} \mathrm{P}_{\mathrm{dj}}+\sum_{\mathrm{h}=1}^{m} \gamma_{4 \mathrm{~h}} \mathrm{SM} \mathrm{M}_{\mathrm{dj}}+\sum_{\mathrm{h}=1}^{m} \gamma_{5 \mathrm{~h}} \mathrm{PE} \mathrm{E}_{\mathrm{dj}}+ \\
& \sum_{h=1}^{m} \gamma_{6 h} P I_{d j}+\sum_{h=1}^{m} \gamma_{7 h} P C_{d j}+\sum_{h=1}^{m} \gamma_{8 h} S L S_{d j}
\end{aligned}
$$

where SLS = similarity in school-leaving status

\subsection{Results}

\subsubsection{Descriptive results}

The average rate of popularity among future regular school-leavers is 2.6 nominations. As shown in Figure 5.3.1, this is higher than the popularity among future early school-leavers, 
5.3.1 Average number of nominations received by school-leaving status in year 2010/2011

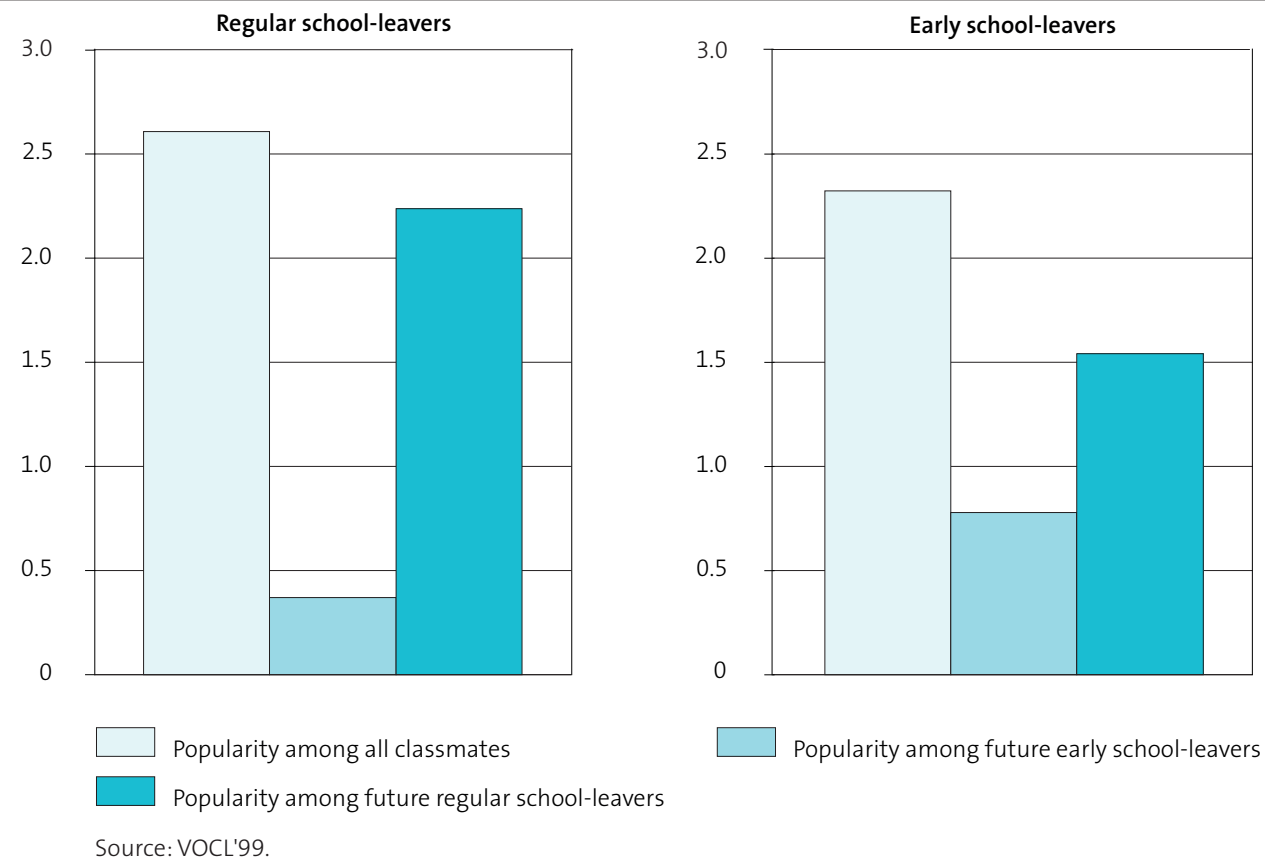

5.3.2 Average number of friends by school-leaving status in year 2010/2011

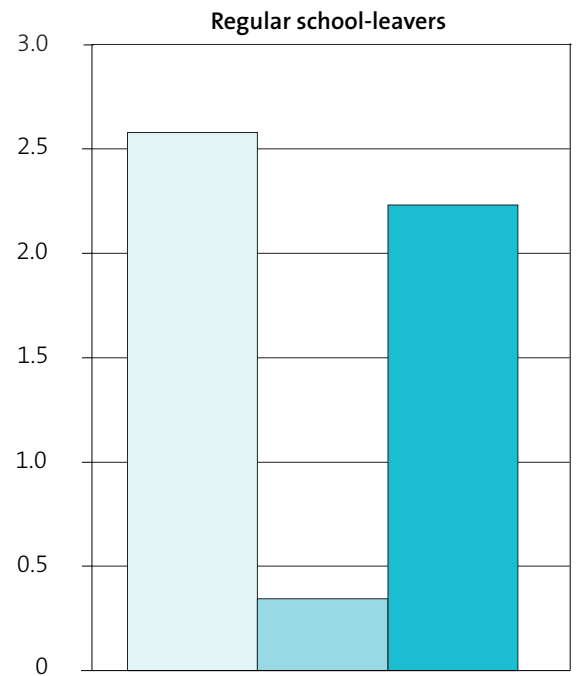

Friendship among all classmates

Friendship among future regular school-leavers

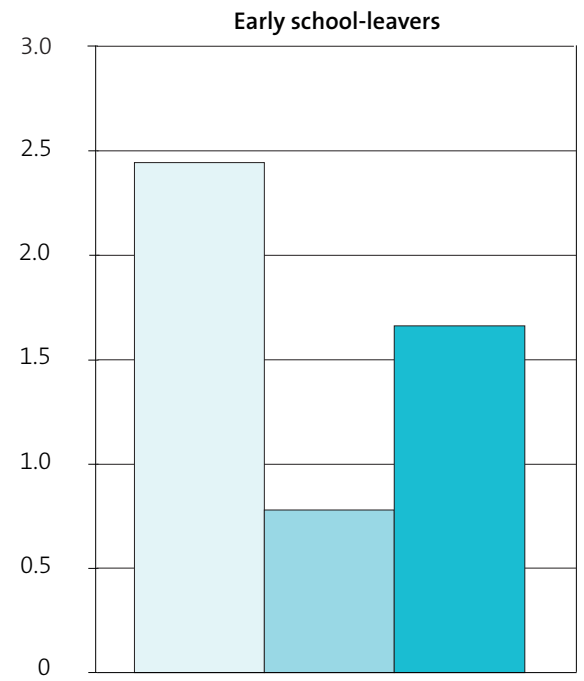

Friendship among early school-leavers

Source: VOCL'99. 
who received only 2.3 nominations. Popularity among future early school-leavers is slightly higher among future early school-leavers (.8) than among regular school-leavers (.4). Popularity among future regular school-leavers is higher for the future regular schoolleavers (2.2) than for the future early school-leavers (1.5).

Figure 5.3.2 shows an almost identical picture for friendship. Future early school-leavers have in general fewer friends (2.4) than future regular school-leavers (2.6). Future early school-leavers had significantly higher numbers of friends among other future early school-leavers (.8) than future regular school-leavers (.3). As can be expected, future regular school-leavers have more friends among other future regular school-leavers (2.2) compared to future early school-leavers (1.7). Thus we can conclude that there is indeed a relationship between a student's own future school-leaving status and their peers. Students that become early school-leavers more often tend to be related to peers with a similar school-leaving status.

\subsubsection{The impact of peer characteristics on early school-leaving}

To estimate the effect of peers on early school-leaving, we used our sample of 10,898 observations within 579 unique classes across 120 schools. To correct for the clustering of students in classes, we applied a random coefficient model that allows the constant to be random (see section 5.2.2). We ran a series of models, adding blocks of variables to the model while excluding others. Lastly, we ran a full model including characteristics of the individual, the friends, those who nominated our respondent and some class level predictors. We start with a model that contains only individual characteristics, serving as a baseline model that shows which variables predict the risk of early school-leaving. Table 5.3.3 shows the results.

As we have seen in our previous study (Traag \& Van der Velden, 2011), being male increases the risk of early school-leaving by 54 percent (logit $=.432^{* * *}$ ) while being a migrant decreases it by $\left.72\left(\operatorname{logit}=-.329^{* * *}\right)^{35}\right)$. School performance $\left(\right.$ logit $\left.=-2.818^{* * *}\right)$, school motivation (logit $\left.=-.478^{* *}\right)$, parental education (logit $\left.=-.088^{* * *}\right)$, parental income (logit $=$ $-.104^{* *}$ ), and parental communication (logit $=-.331^{*}$ ) all significantly reduce the risk of early school-leaving. To illustrate these effects: for school performance, the risk of becoming an early school-leaver is .723 for a reference person, i.e. native females in a prevocational track, with average scores on school performance, school motivation, parental education, parental income, and parental communication, who were in a school in an average urbanized region, with an average percentage of ethnic minorities, with an

\footnotetext{
35) Note that we only find such a protective effect of having a migrant background after controlling for parental characteristics and the percentage of migrant students at the school level. Without such controls the effect would have been positive (logit=.057; not reported in the model), indicating that migrant students have a higher chance to become an early school-leaver.
} 
average class size, and a school that only provides pre-vocational education. When school performance increases with one standard deviation, the risk of becoming early schoolleaver for this reference person is decreased to .612.

In addition, we find some effects of school and class characteristics. As expected, we find strong effects for the track level at age 12, with the pre-college and pre-university tracks showing significantly lower risks of becoming an early school-leaver. In addition, schools that provide other tracks of education than the pre-vocational one have lower early schoolleaving rates than schools that only provide the pre-vocational track. The degree of urbanization has a positive effect (logit $\left.=.092^{* * *}\right)$, indicating that the risk of leaving school early is higher in more urbanized areas. Also attending schools with a high percentage of migrant students increases the risk of early school-leaving $\left(\right.$ logit $\left.=.634^{* *}\right)$. Lastly, the size of the class has a small negative effect (logit $=-.003$ ) but this effect is not significant. However, based on the intraclass correlation, we can conclude that the variance explained at the school and class level is very small.

In model, 2 a characteristics of those who nominated the students are added to the model. The results show that the characteristics of those who nominated the focal student add only small effects to the risk of an individual becoming an early school-leaver beyond the individual characteristics of the student and our other control variables. Being popular among those who perform well in school as well as those with high educated parents has a negative effect, while being popular among those with high parental income increases the chance the chance to leave school early. However, these effects are only marginally significant $(p<.10)$.

In model $2 b$ we add popularity among future early school-leavers as well as popularity among future regular school-leavers to the model. This reduces all peer characteristics and causes them to become non-significant. Being popular among future regular schoolleavers reduces the risk of leaving school early by 12 percent $\left(\operatorname{logit}=-.131^{* * *}\right)$. At the same time, being popular among future early school-leavers increases the risk of becoming an early school-leaver oneself by 17 percent (logit $=.159^{* * *}$ ).

Model za estimates the risk of becoming an early school-leaver based on individual traits and the characteristics of friends. Again, we find that having friends with high educated parents decreases the risk of becoming an early school-leaver by 4 percent for every additional year of education of these parents and this effect is highly significant (logit = $\left.-.040^{* * *}\right)$. Again we find a small positive effect of this friend's parental income, but the effect is only significant at the $10 \%$ level. In model $3 b$ we add the school-leaving status of the friends as predictors to our model. Having many friends among regular school-leavers is negatively linked to becoming an early school-leaver, although the effect is not significant (logit $=-.012$ ). Having friends among future early school-leavers clearly increases the chance to become an early school-leaver oneself (logit $=.232^{* * *}$ ) as was expected.

In our last model, we added all variables for the individual, nominators, friends, and the school *class. Again, we find a significant negative effect of being popular among future regular school-leavers (logit $=-.120^{* * *}$ ) and a significant positive effect of popularity 


\subsubsection{Random effects logit model for the risk of early school-leaving dependent on individual and peer characteristics (logits are reported)}

\begin{tabular}{|c|c|c|c|c|c|}
\hline & $(2 a)$ & $(2 b)$ & $(3 a)$ & $(3 b)$ & $(4)$ \\
\hline \multicolumn{6}{|l|}{ Fixed effects } \\
\hline Intercept & $2.659^{* * *}$ & $3.065^{* * *}$ & $2.548^{* * *}$ & $2.409^{* * *}$ & $2.450^{* * *}$ \\
\hline \multicolumn{6}{|l|}{ Individual level predictors } \\
\hline \multicolumn{6}{|l|}{ Student characteristics } \\
\hline \multicolumn{6}{|l|}{ Gender } \\
\hline Male & $.307^{* * *}$ & $.311^{* * *}$ & $.419^{* * *}$ & $.428^{* * *}$ & $.348^{* *}$ \\
\hline \multicolumn{6}{|l|}{ Female (ref). } \\
\hline \multicolumn{6}{|l|}{ Migrant status } \\
\hline Migrant & $-.339^{* * *}$ & $-.340^{* * *}$ & $-.343^{* * *}$ & $-.333^{* * *}$ & $-343^{* * *}$ \\
\hline \multicolumn{6}{|l|}{ Native (ref). } \\
\hline School performance & $-2.630^{* * *}$ & $-2.594^{* * *}$ & $-2.791^{* * *}$ & $-2.745^{* * *}$ & $-2.625^{* * *}$ \\
\hline School motivation & $-.473^{* *}$ & $-.463^{* *}$ & $-.476^{* * *}$ & $-.464^{* *}$ & $-.459^{* *}$ \\
\hline Parental education & $-.085^{* * *}$ & $-.083^{* * *}$ & $-.085^{* * *}$ & $-.085^{* * *}$ & $-.082^{* * *}$ \\
\hline Parental income & $-.104^{* * *}$ & $-.101^{* * *}$ & $-.104^{* * *}$ & $-.099^{* * *}$ & $-.098^{* * *}$ \\
\hline Parental communication & $-.286^{*}$ & $-.276^{*}$ & $-.322^{*}$ & $-.300^{*}$ & $-.274^{*}$ \\
\hline \multicolumn{6}{|l|}{ Popularity } \\
\hline Percentage of males & .145 & .079 & & & .097 \\
\hline Percentage of migrants & .044 & .015 & & & .003 \\
\hline Average school performance & $-.487^{*}$ & -.136 & & & -.505 \\
\hline Average school motivation & .064 & .093 & & & .092 \\
\hline Average parental education & $-.024^{*}$ & -.017 & & & .000 \\
\hline Average parental income & $.044^{*}$ & .033 & & & .033 \\
\hline Average parental communication & -.376 & -.349 & & & -.429 \\
\hline Number of nominations by regular school-leavers & & $-.131^{* * *}$ & & & -.120 \\
\hline Number of nominations by early school-leavers & & $.159^{* * *}$ & & & .101 \\
\hline \multicolumn{6}{|l|}{ Friendship } \\
\hline Percentage of males & & & .022 & -.370 & -.570 \\
\hline Percentage of migrants & & & .071 & .081 & .075 \\
\hline Average school performance & & & .067 & .285 & $.626^{*}$ \\
\hline Average school motivation & & & .031 & -.210 & -.540 \\
\hline Average parental education & & & $-.040^{* * *}$ & $-.032^{* *}$ & $-.330^{*}$ \\
\hline Average parental income & & & $.052^{*}$ & .023 & -.005 \\
\hline Average parental communication & & & -.690 & -.690 & .192 \\
\hline Number of friends among regular school-leavers & & & & -.120 & .047 \\
\hline Number of friends among early school-leavers & & & & $.232^{* * *}$ & $.168^{* * *}$ \\
\hline \multicolumn{6}{|l|}{ School and class* class level predictors } \\
\hline \multicolumn{6}{|l|}{ Class level at age 12} \\
\hline \multicolumn{6}{|l|}{ Pre-vocational track (ref.) } \\
\hline Pre-college track & $-.685^{* * *}$ & $-.573^{* * *}$ & $-.697^{* * *}$ & $-.620^{* * *}$ & $-.575^{* * *}$ \\
\hline Pre-university track & $-.887^{* * *}$ & $-.811^{* * *}$ & $-.938^{* * *}$ & $-.870^{* * *}$ & $-.815^{* * *}$ \\
\hline Degree of urbanization & $.094^{* * *}$ & $.087^{* * *}$ & $.095^{* * *}$ & $.095^{* * *}$ & $.090^{* * *}$ \\
\hline Percentage of migrant students & $.499^{* *}$ & $.475^{*}$ & $.464^{*}$ & .381 & .369 \\
\hline \multicolumn{6}{|l|}{ Heterogeneity } \\
\hline \multicolumn{6}{|l|}{ Only pre-vocational track (ref.) } \\
\hline All tracks & $-.211^{* * *}$ & $-.175^{* *}$ & $-.226^{* * *}$ & $-.176^{* *}$ & $-.157^{* *}$ \\
\hline Only pre-college and pre-university track & $-0.422^{* *}$ & $-.363^{* *}$ & $-.443^{* * *}$ & $-.370^{* *}$ & $-.339^{* *}$ \\
\hline Only pre-university track & -.069 & -.059 & -.084 & -.038 & -.033 \\
\hline Class size & .000 & .000 & -.002 & .002 & -.001 \\
\hline \multicolumn{6}{|l|}{ Random effects } \\
\hline Variance at class level & -2.569 & -11.110 & -2.572 & -4.674 & -11.800 \\
\hline Intraclass correlation & .023 & .000 & .023 & .002 & .000 \\
\hline
\end{tabular}

Source: VOCL'99.

Notes; Sample size is 10,898 students. Data clustered in 576 school $^{*}$ class groups. $^{* * *}=p<.01{ }^{* *}=p<.05^{*} p<.10$ 
among future early school-leavers (logit $\left.=.101^{* *}\right)$. At the same time, we find a positive effect of having friends among future early school-leavers (logit $=.168^{* * *}$ ), while the effect of having friends who are future regular school-leavers is very small and not significant $($ logit $=.047)$. Peer characteristics have hardly any additional effect in this last model, since most of the effect is captured by controlling for the school-leaving status of the peers.

\subsubsection{Predicting peer selection}

Since people tend to choose their peers based on similarity, it is difficult to separate effects of peer selection from peer influence. To enable us to assess whether early school-leaving of peers has a causal effect on a student's own risk of leaving school early, we investigated how the probability that one peer selects the other as someone they liked is predicted by similarity on a number of characteristics, such as gender, migrant status, cognitive and non-cognitive skills and measures of social class. From our student sub-sample of 10,898 students, we computed all possible unique dyads or possible peer relations, resulting in 113,835 dyads. For each dyad, we compared the characteristics of the two students to assess whether they are the same or not, as described in section 5.2.2. Table 5.3.4 shows the rate of similarity within dyads for the variables used in our previous models. For example, the table shows that within the total group of possible dyads, 58 percent is of the same gender. However, when we look at the dyads where one peers chose the other as someone they liked, 96 percent has the same gender. As the table shows, students who selected one another are almost always the same in gender. They also tend to be slightly

\subsubsection{Descriptives for dyadic similarity by school-leaving status}

\begin{tabular}{|c|c|c|c|c|}
\hline & \multirow{2}{*}{$\begin{array}{l}\text { Percentage of } \\
\text { similar peers } \\
\text { Total }\end{array}$} & \multicolumn{3}{|c|}{ Percentage of similar peers by peer relationship } \\
\hline & & $\begin{array}{l}\text { One indicated } \\
\text { the other as a } \\
\text { peer they liked }\end{array}$ & $\begin{array}{l}\text { No relationship } \\
\text { between peers }\end{array}$ & T-value \\
\hline \multicolumn{5}{|l|}{ Similarity within dyads in: } \\
\hline Gender & .578 & .958 & .526 & $-99.586^{*}$ \\
\hline Migrant status & .776 & .795 & .774 & $-5.664^{*}$ \\
\hline School performance & .364 & .397 & .360 & $-8.617^{*}$ \\
\hline School motivation & .228 & .248 & .226 & $-5.812^{*}$ \\
\hline Parental education & .359 & .378 & .357 & $-4.841^{*}$ \\
\hline Parental income & .227 & .234 & .226 & -1.962 \\
\hline Parental communication & .236 & .247 & .235 & -3.099 \\
\hline Early school-leaving status & .762 & .772 & .760 & -3.896 \\
\hline
\end{tabular}

Source: VOCL'99.

Notes: Sample size is 113,835 dyads. ${ }^{*} p<.001$ 
more similar in migrant status, school performance, school motivation, and parental education, than students who did not select one another. For parental income, and parental communication and early school-leaving status, differences in similarity are not significant at the 99 percent level.

Next we estimated two random effect models where the outcome variable was the probability that at least one person in this dyad had indicated the other as someone they liked, predicted on the basis of similarity in individual characteristics. The results are presented in table 5.3.5.

Our results from model (1) show that especially similarity in gender, and to a minor extent also similarity in migrant status, school performance, school motivation, parental education, parental income, and the parents talking to children about school increase the likelihood of a friendship relation being formed in a dyad. In model (2), we add the similarity in school-leaving status to the model. Results for all other variables hardly change and similarity in school-leaving status has a small but significant positive relationship with the selection of peers. More specifically, dyads that are similar in schoolleaving status are $e^{.112}=1.12$ times more likely to nominate the other as peer than dyads

\subsubsection{Random effects logit model for the probability of nominating a peer as someone they like (b-coefficients reported)}

\begin{tabular}{lcc}
\hline Fixed effects & (1) & (2) \\
\hline & & \\
Intercept & $-4.718^{* *}$ & $-4.805^{* *}$ \\
Individual level predictors & & \\
& & \\
Dyadic similarity in: & & \\
Gender & $3.038^{* *}$ & $3.039^{* *}$ \\
Migrant status & $.149^{* *}$ & $.145^{* *}$ \\
School performance & $.144^{* *}$ & $.145^{* *}$ \\
School motivation & $.051^{* *}$ & $.052^{* *}$ \\
Parental education & $.073^{* *}$ & $.080^{* *}$ \\
Parental income & $.041^{*}$ & $.041^{*}$ \\
Parental communication & $.046^{*}$ & $.047^{*}$ \\
Early school-leaving status & & $.112^{* *}$ \\
& & \\
Random effects & & \\
& & \\
Variance at class level & & \\
Intraclass correlation & & \\
$\chi^{2}$ & & \\
& & \\
\end{tabular}

Source: VOCL'99.

Note: Sample size is 113,835 dyads. ${ }^{* *} p<.001,{ }^{*} p<.01$ 
that are not similar in school-leaving status, net of the other effects. This seems to suggest that future early school-leavers are more likely to associate with other future early schoolleavers, and future regular school-leavers are more likely to associate with other future regular school-leavers. However, adding similarity in future school-leaving status results only in a very small improvement of the model fit (the pseudo $\mathrm{R}^{2}$ raises from 52.15 to 52.87 , with a $\chi^{2}=23.0, d f=1, p=.000$.), thus the impact of similarity in school-leaving status similarity is rather small. Other characteristics like gender, migrant status, or school performance are more important in predicting peer relations than future school-leaving status. It is likely that all these effects are overestimated by not taking into account the interdependence among dyads (Lubbers \& Snijders, 2007). As the effect of similarity in school-leaving status in our analysis is smaller than that of similarity in gender, migrant status, and school performance, we can conclude that the formation of friendship relations is only to a small extent based on future school-leaving status. Therefore, it is unlikely that our association between peers' school-leaving status and the probability of becoming an early school-leaver can be attributed to homophily.

\subsection{Conclusions and discussion}

This chapter addresses three research questions: do characteristics of peers at age 12 affect the risk of students of becoming an early school-leaver later on in education? Are there effects of both friends (those nominated by students) as well as popularity (those who nominated the students)? And can these effects be accounted for by peer selection based on homophily? Our results showed that both popularity and friendship correlate with early school-leaving. This is in line with findings by others (Diehl et al., 1998; Vandell \& Hembree, 1994) who found additive effects of the two measures on school adjustment. Peer characteristics such as gender, migrant status, peers' cognitive skills, and the socioeconomic status of peers at age 12 do not affect the future risk of a student of leaving school early over and above the school-leaver status of the peer. However, being popular among future early school-leavers as well as being friends with future early school-leavers is both associated with an increased risk of early school-leaving, although these effects are in part redundant. Also, being popular among regular school-leavers appears to protect against the risk of early school-leaving. In conclusion, our study confirms that peer acceptance can actually have a detrimental effect, if it is acceptance by the "wrong" crowd (Asher, MacEvoy, \& McDonald, 2008; Ream \& Rumberger, 2008).

One issue in studying peer influence is that peers select their friends based on similarity in various characteristics. This makes it difficult to differentiate between selection effects (similarity causes the formation of relationships) and true peer influence (relationships 
cause similarity). However, our robustness check of the peer selection process showed that while similarity in characteristics does play a role in the formation of peer relations, similarity in future school-leaving status influenced peer selection only very moderately. The large and representative sample and our controls for alternative explanations of early school-leaving inspire confidence in our results. Nevertheless, further research is needed to gain a better insight into the causal mechanisms behind the association between peer relations and peer characteristics on the one hand and students' risk of early schoolleaving on the other. Although we provided some reassurance in showing that the selection of friends is not much affected by the peers' future school-leaving status, the question remains, of course, whether there is a true causal effect that makes students leave school early if they have peers who also leave school early. One way to address this issue would be by using longitudinal information of changes over time in peer relations and the characteristics of a respondent's peers as well as indicators of changes over time in school attachment. In that case one could use a Difference-in-Difference model to address unobserved heterogeneity, and provide insight into how the process of the risk of early school-leaving develops in the course of the education career. Stochastic actor-based modeling for network dynamics (SIENA; Snijders, van de Bunt, \& Steglich, 2010; Steglich, Snijders, \& Pearson, 2010) could also be used to investigate the co-evolution of peer relations and scholastic attributes, to disentangle peer selection and peer influence while controlling for the dependence structure in networks. Unfortunately, this type of data is not available for the Netherlands, nor have we found them for other countries, as they would be very costly and time-consuming to gather. An alternative to this approach would be to use an Instrumental Variable (IV)-estimator or some form of natural experiment to estimate the causal effect. However, finding a strong instrument to reach this goal will be challenging.

Adolescent peer affiliations with future early school-leavers seem to increase the risk of early school-leaving. At the same time, however, characteristics of the individual largely determine who is successful in school and who is not. This implies that policies to reduce early school-leaving should focus primarily on the individual, to tackle those at risk of leaving school-early. However, the relevance of group structures in secondary school should certainly not be overlooked. 


\subsection{Appendix}

\subsubsection{Additional random effects model for the risk of early school-leaving based on reciprocal friendship}

\section{(5a)}

Fixed effects

Intercept

Individual level predictors

Student characteristics

Gender

Male

Female (ref).

Migrant status

Migrant

Native (ref).

School performance

School motivation

Parental education

Parental income

Parental communication

Popularity

Percentage of males

Percentage of migrants

Average school performance

Average school motivation

Average parental education

Average parental income

Average parental communication

Number of nominations by regular school-leavers

Number of nominations by early school-leavers

Friendship

Percentage of males

Percentage of migrants

Average school performance

Average school motivation

Average parental education

Average parental income

Average parental communication

Number of friends among regular school-leavers

Number of friends among early school-leavers

School and class* class level predictors

Class level at age 12

Pre-vocational track (ref.)

Pre-college track

Pre-university track

Degree of urbanization

Percentage of migrant students (5b)

(6)

$2.629^{* * *}$

$2.544^{* * *}$

$2.579^{* * *}$

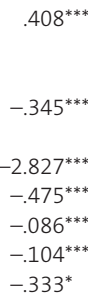

$.381^{* * *}$

$.362^{* * *}$

$345^{* * *}$

$-.327^{* * *}$

$-.341^{* * *}$

$2.827^{* * *}$

$2.773^{* * *}$

$-.466^{* *}$

$-.086^{* * *}$

$-.100^{* * *}$

$-.319^{*}$

$88,{ }^{* * * *}$

$-.458^{* *}$

$-.084^{* * *}$

$-.100^{* * *}$

$-.317^{*}$

$-.037$

.153

.134

.396

.020

.002

$-.012$

$-.134^{* * *}$

$.129^{* *}$

.042

.143

.047

$-.283$

$-.010$

$-.069^{*}$

$-.387$

$-.711^{* * *}$

. $.969^{* * *}$
$.092^{* * *}$

$.546^{* * *}$
.069

$-.175$

.064

$-.260$

$-.019$

$-.063$

$-.365$

$-.004$

.101

$-.576^{* * *}$

$-.826^{* * *}$

$.084^{* * *}$

$.544^{* *}$ 


\subsubsection{Additional random effects model for the risk of early school-leaving based on reciprocal friendship (end)}

$(5 a) \quad(5 b)$

$\begin{array}{lll}-.254^{* * *} & -.219^{* *} & -.192^{* * *} \\ -.491^{* * *} & -.435^{* *} & -.390^{* *} \\ -.143 & -.126 & -.086 \\ -.003 & -.002 & -.001\end{array}$

Heterogeneity

Only pre-vocational track (ref.)

All tracks

Only pre-college and pre-university track

Only pre-university track

Class size

$-2.435$

.026

$-3.198$

.012

$-10.498$

Intraclass correlation

Source: VOCL'99.

Notes: Sample size is 10,898 students. Data clustered in 576 school $^{*}$ class groups. $^{* * *}=p<.01{ }^{* *}=p<.05{ }^{*} p<.10$ 


\section{Conclusion}

\subsection{Introduction}

The aim of this thesis was to address some of the key factors that are related to early school-leaving in the Netherlands, thus furthering the understanding of how and why some adolescents stay in school whilst others do not. We investigated four research problems, integrating theoretical approaches from different disciplines as well as a number of different methodologies. In chapter 2, we applied a classical economic and sociological approach by using Human Capital Theory and stratification theory (Becker, 1964; Boudon, 1974) to answer the question:

1. What family resources, school composition factors and background characteristics influence the risk of early school-leaving? Do the effects of family resources, school composition factors and background characteristics differ between subgroups of early school leavers?

Then in chapter 3 , we addressed the issue of the strong correlation between early schoolleaving and juvenile behavior. One possible explanation for this correlation is a lack of social bonding that causes adolescents to both commit crime and drop out of school. We use one of criminology's most widespread theories developed by Travis Hirschi (1969), Social Bonding Theory to answer the question:

2. Can differences in social bonding explain differences in juvenile delinquency and school dropout behavior? In addition, does preceding delinquency affect early school-leaving?

Chapter 4 is a more psychological approach of early school-leaving, where we assessed the impact of differences in cognitive skills next to non-cognitive skills such as motivation and personality traits. We use the Expectancy Theory by psychologist Victor Vroom, who stated that performance is a multiplication of both ability and motivation. We answer the question:

3. Can differences in non-cognitive abilities explain individual differences in educational success above and beyond cognitive ability?

Chapter 5 addressed the impact of peer relations on dropout behavior. We applied aspects of Social Network Theory to see if having certain types of peers affects one's own dropout 
risk while acknowledging the implications of peer selection effects. In this chapter the research question is:

4. Does having future dropout friends at age 12 increase one's own dropout risk even when controlling for other peer characteristics?

In the following sections, the findings from these four chapters are summarized. In section 6.2, the most important findings of this study are summarized. In section 6.3 the conclusions that can be drawn from this study are presented, including some strengths and weaknesses of this study as well as some suggestions for future research.

\subsection{Summary of findings}

\subsubsection{The role of family resources, school composition and background characteristics in early school-leaving}

The first study (chapter 2) described the impact of individual factors (sex, ethnicity, cognitive skills, and participation and identification), family resources (economic capital, human capital, social capital, and cultural capital), and school-level factors (share of ethnic minorities, municipality, school heterogeneity) on the risk of leaving school early. Instead of dichotomizing early school-leaving, we discerned between four groups of students. Those with no qualification, those in apprenticeship programs, those with only lower secondary education and those with at least a full upper secondary qualification. The aim of this chapter was to answer the questions what family resources, school composition factors and individual characteristics affect the risk of a student leaving school without a starting qualification? And do the effects of these factors differ between the different types of early school leavers? For this study, we used the VOCL'89 study that describes the educational careers of 20 thousand students that were in first grade of secondary school in September 1989 and were followed throughout their educational careers. The data also include a large number of characteristics of the students and their parents as well as characteristics of the schools.

Our findings showed that one important mechanism driving early school-leaving is cognitive abilities and especially school performance. What a student is able to do affects the perceived cost of further investments in one's educational career while the level of motivation affects what a student is willing to do. A second important mechanism is through family resources. Lacking financial, human, social and cultural capital will increase 
the risk of leaving school early. Although, in part this effect is due to differences in a family's ability to afford schooling, there is also an effect of perceived costs, where the returns to education are perceived lower for lower class families. Finally, we found evidence that schools themselves affect a students' risk of dropping out. Having high shares of ethnic minorities as well as offering only lower level educational tracks increases the risk for individual students to leave school without a proper qualification despite their individual characteristics.

By using a model that integrated all of these factors into one, we were able to identify which factors are more important over others and we were therefore better able to identify the risk factors of early school-leaving. An important result was the stronger effect of cognitive skills and motivation for boys over girls, suggesting that there are other mechanisms at stake for girls that have not yet been identified. Another surprising result was the absence of an ethnicity effect when controlling for family resources, indicating that the increased risk for ethnic minorities is not due to factors such as cultural differences and language proficiency, but due to a lack of family resources. And importantly, students of native descent with equally low resources are therefore equally high at risk of leaving school early compared to ethnic minorities.

In this study we differentiated between different types of school leavers, discerning between those with no education at all and groups that have some qualification but one that is not considered to be sufficient for entering the labor market. The results showed that risk factors systematically are stronger for true dropouts (those without any diploma) than for the other two groups of early school leavers, assuming the underlying dimension is a continuum rather than a simple distinction between groups. An important lesson to be learned from this is to acknowledge the fact that some students are better able to cope with theoretical education whilst others are better off by 'learning by doing'. In the Netherlands, a combination of theoretical and practical education is offered within several educational tracks. By offering these types of education, a safety net is provided for those that would otherwise drop out of school when lacking the ability or the motivation to continue in general education tracks.

\subsubsection{Social Bonding, Early school-leaving, and Delinquency}

The second study (chapter 3) aimed at gaining a better understanding of the correlation between delinquency and early school-leaving. We applied Hirschi's theory of social bonding (Hirschi, 1969) as a possible mechanism for both dropping out of school and delinquent behavior. The results showed that social bonding is negatively linked to both delinquency before and after school-leaving and the risk of early school-leaving. Our results also make clear that past risk behavior is a very strong predictor of future risk behavior and give credence to theories that highlight individual as well as social restraint factors. However, not all elements of social bonding have proven to be of equal importance 
and our more stringent modeling specifications suggest that school performance is the one that matters in the end. Targeting the poorest performers at an early age should therefore be advocated, as this would appear to be the most efficient means to reduce their sequential participation in all forms of risk behavior. This conclusion was mitigated, however, by the finding that the returns to higher school performance levels are less important for students who had been arrested while still at school compared to those for pupils who had not been involved in criminal activity. This would suggest that investment in the improvement of school performance to reduce adolescent risky behavior should be coupled with policies preventing risk behavior of children and young adolescents in order to increase their self-control and the returns to school bonding.

\subsubsection{The effects of Cognitive and Non-Cognitive Skills on Educational Success}

Chapter 4 investigated if non-cognitive skills, i.e. motivation and personality traits, had additional effects above and beyond cognitive. We applied the psychological framework of Vroom (Vroom, 1964), which suggests that performance is actually a function of the multiplication of both cognitive and non-cognitive skills. This assumes that the effect of non-cognitive skills is stronger when cognitive skills are higher. The results showed that Cognitive Skills measured at age 12 indeed have a strong and direct effect on the risk of becoming an early school-leaver, and this is hardly affected by differences in motivation or personality traits. However, Non-Cognitive Skills also explain part of the individual differences in drop-out risk. Motivation, conscientiousness, agreeableness, and openness to experience all have a direct impact on the risk of early school-leaving. At the same time however, the impact of conscientiousness, agreeableness, and openness to experience differs depending on the level of cognitive skills. In general, I concluded that Cognitive Skills are indeed an important predictor of early school-leaving. Some adolescents simply lack the Cognitive Skills to finish a certain level of education. However, Non-Cognitive Skills play an important role in explaining why some students choose to leave the education system in spite of the fact that they have the Cognitive Skills to obtain a full upper secondary qualification. For some, the education system just does not match their Personality, making it hard for them to comply with school rules and regulations and even making it less likely that they will stay in school after compulsory education.

\subsubsection{That's what friends are for? The impact of peer characteristics on dropping out of school}

Our final study (chapter 5) described the impact of peer networks on a student's dropout risk, addressing three research questions: do characteristics of peers at age 12 affect the risk of students of becoming an early school-leaver later on in education? Are there effects 
of both friends (those nominated by students) as well as popularity (those who nominated the students)? And can these effects be accounted for by peer selection based on homophily? The results showed that both popularity and friendship correlate with early school-leaving. Peer characteristics such as gender, migrant status, peers' cognitive skills, and the socio-economic status of peers at age 12 do not affect the future risk of a student of leaving school early over and above the school-leaver status of the peer. However, being popular among future early school-leavers as well as being friends with future early school-leavers is both associated with an increased risk of early school-leaving, although these effects are in part redundant. Also, being popular among regular school-leavers appears to protect against the risk of early school-leaving. In conclusion, our study confirmed that peer acceptance can actually have a detrimental effect, if it is acceptance by the "wrong" crowd. Adolescent peer affiliations with future early school-leavers seemed to increase the risk of early school-leaving. At the same time, however, characteristics of the individual largely determine who is successful in school and who is not. This implies that policies to reduce early school-leaving should focus primarily on the individual, to tackle those at risk of leaving school-early. However, the relevance of group structures in secondary school should certainly not be overlooked.

One possible issue when studying peer group effects is the issue of homophily, i.e. people tend to like people that are much like themselves. This makes it difficult to separate peer selection effects from causal effects. In this chapter, we addressed this issue by estimating the probability that within each possible dyad of two students in our sample, one nominates the other. We included dummies for the two being similar on a large number of predictors, such as gender, ethnicity, cognitive skills and socioeconomic status to see if it is indeed similarity that makes people like each other. This is indeed the case. However, when adding similarity in dropout status to the model, the fit of the model hardly improved. Thus, knowledge of the future dropout status of one's peers does not affect the probability of nominating them. This gives credence to the idea that the effect of peer dropout is not due to peer selection.

\subsection{Conclusion and discussion}

\subsubsection{Risk and protective factors against early school-leaving}

The aim of this thesis was to gain better understanding of the factors that explain why some adolescents are more likely to leave school early than others. The main conclusion 
from this thesis is that cognitive ability is by far the most important predictor of early school-leaving. Other protective factors are motivation, school perception, having family resources, conscientiousness, agreeableness, being surrounded by a positive peer group, and being in homogeneous schools. Factors that increase the risk of becoming an early school-leaver include delinquent behavior at a young age, lacking family resources, a high score on Openness to Experience, and having friends who themselves are early schoolleavers.

One very remarkable result that emerged throughout this study is the correlation between migrant status and early school-leaving. Many studies have described how students from Moroccan, Turkish and other non-western backgrounds are much more at risk of early school-leaving (see among others Herweijer, 2008). In chapters 2, 4, and

5 , we show that students from migrant backgrounds, if any, are less at risk of becoming an early school-leaver when controlling for social background. So in other words, when comparing native Dutch youth to Moroccan or Turkish youth with identical backgrounds, native Dutch youth are at least just as much at risk. So in turn, the elevated number of early school-leavers among certain ethnic groups is not due to their cultural heritage, but a result of the fact that they more often come from low social classes. This is in line with previous finding by Van der Steeg \& Webbink (2006). In terms of policy relevance, this finding does not imply that policies combating early school-leaving should not focus on these specific groups, since they do in fact represent a large group of at-risk students. However, policies should not approach the high early school-leaving rate among minority groups as a cultural issue but acknowledge the impact of the social constraints that are at play.

\subsubsection{What can schools do to prevent early school-leaving?}

What can schools do to reduce early school-leaving rates? As we have shown throughout this study, there are large differences between schools in their students' risk of early school-leaving. Although we have taken up only a limited number of school characteristics in our analysis, the results clearly show that schools differ systematically in early schoolleaving: schools with high proportions of ethnic minorities show higher dropout rates, as well as schools in highly urbanized regions. An important finding from our study is that students in school that offer lower as well as higher educational tracks show lower rates of early school-leaving than schools that only offer the low track. So instead of being deterred by being in a more academic environment, students in lower levels of education appear to be encouraged to stay in school as a result of the more academic climate. This finding is very much in line with school effectiveness research showing a multiplier effect where students in schools with a high concentration of lower track or lower performing students experience an additional negative effect across a range of outcomes (Willms, 2006). 
Our study on the impact of peer groups showed that although individual characteristics largely determine the risk of early school-leaving, affiliating with at-risk peers can increase this risk. This again stresses the importance of how students are grouped within schools. Not only is it important to combine children from different tracks within a school, but class composition can also affect the early school-leaving rate. As we have shown, children tend to affiliate with those that are most alike themselves in a number of ways. At the same time, future early school-leaving was not a factor of importance in group formation yet affiliating with peers who themselves are future early school-leavers does increase one's own risk of becoming an early school-leaver. By ensuring that classes reflect a well-advised mixture of students in terms of cognitive ability as well as social background, schools may be able to prevent from clustering potential early school-leavers within the same classes. This may on the one hand prevent early school-leaving creating a certain climate within the class where performing well is the standard. On the other hand, schools may be able to stimulate positive peer relations while discouraging strong bonding between at-risk peers.

Schools play an important role in the prevention of early school-leaving. In the spring of 2012 the Ministry of Education, Cultural Affairs and Science has signed agreements with several schools and municipalities to ensure a reduction of the rate of early school-leaving. However, a recent study among early school-leavers has shown that 45 percent of the early school-leavers feel that nobody had helped them to prevent them from leaving school (Research Centre For Education and the Labour Market (ROA), 2012). At the same time, 19 percent of the early school-leavers indicated that they had not talked to anybody about their plans to leave school. The figures raise some serious questions about how well the current system of monitoring and prevention works. Off course, one cannot expect schools to be on top of every single student. However, if nearly half of all early schoolleavers was able to 'just leave' without being noticed and without anybody trying to prevent them from leaving school, this is a serious indication that current policies do not work for every school and for every student.

A second conclusion from the recent ROA study is the fact that school-related factors are the main reason for students to leave school. In 45 percent of the cases, early schoolleavers indicate that factors such as the content of the education not being what they thought it would be, ill organization of the education, the education being too difficult for them, or failing the exam, caused them to not continue their education. Apparently, there is still a lot of work to be put in improving the tie-up between lower secondary and upper secondary education, and the counseling of students in choosing their educational career path. In general, it seems that the perceived safety network of schools and municipalities involved in the RMC-law (see 1.2) does not work at its best. Students are not sufficiently guided through the educational system and are able to quit without any intervention. Does this mean that schools do not feel responsible? Has the network designed to keep students from leaving school early become too complex? There is no clear indication that this is the case, but it is clear however, that the current system does not function at the best of its ability. 


\subsubsection{What is the role of the parents?}

As was shown throughout this thesis, social background is an important factor in early school-leaving. We found clear evidence that the different forms of family capital (economic, human, social and cultural) affect the chances of early school-leaving. Part of these effects can be interpreted as affecting the costs of investing in education; the more resources are available within the family, the better they are able to invest in the education of their child. Another part however, must be interpreted as affecting the relative benefits of investment in education. In low social classes, attaining a high level of education is much less valued than in high social class. This makes the perceived returns to staying in school much lower for those in low social classes compared to high social classes. Although these mechanisms may be hard to change, parents are able to positively affect the risk of their children becoming early school-leavers by communicating with their child about school, about their performance, about what their homework for the day is, and how they scored on yesterday's test. Even when controlling for a number of social background factors, we repeatedly found evidence that parents do have the ability to consciously affect their children's' educational careers in a positive way.

\subsubsection{Implications for researchers and policy makers}

The most important reason to combat early school-leaving from a societal point of view is the fact that technological innovations increase skill requirements so that those with limited skills will increasingly face more difficulty finding a job (Rumberger, 2011, European Parliament, 2000). However, studies have shown that while computerization has changed the content of work tasks by enabling routine tasks to be mechanized, this has strongly affected the number of jobs in the middle of the earnings distribution while employment shares in the lower third and the upper third of the wage tercile increased (Autor, 2010, Allen and Van der Velden, 2012). This means that our society is not necessarily in need of less low educated workers. It is especially the middle group of those with non-routine manual and cognitive tasks that will be of concern in the near future. Allen and Van der Velden (2012) point out that this polarization of the labor market will be especially problematic for those in vocational education, who may perform very well in their specific craft, but lack skills such as language, math or civics to fit into this changing environment just as narrowly gifted students in general secondary education. This raises the question about the sustainability of current policies to require students to attain at least the pre-college track (HAVO), pre-university track (VWO) or upper secondary vocational education of at least two years (MBO at level two). If it is especially this group that is most likely to face the consequences of the polarization of the job structure. Why would one then want to force those that have lower cognitive skills, but who are very well able to make a valuable contribution to economy and society 
with their crafts, to attain a level of education that will not make them better off in the end?

From this study, one can conclude that the level of cognitive skills is the most important predictor for early school-leaving. In addition, traits such as motivation and school perception, socio-economic background, and gender all are helpful in predicting who becomes an early school-leaver and who does not. At the same time, one can conclude that the predictability of early school-leaving is disappointingly low. Based on quite elaborate models, explained variance remained as low as about 25 percent. This indicates that even if a large number of predictive characteristics of a student are known, one is able to correctly educational success in merely 25 percent of the cases. So despite of the numerous studies regarding early school-leaving, the reason why some students leave school low educated still remains a black box. First, we need to accept that some students simply lack the ability to reach a certain level of education. When looking at international figures (see figure 1.3.1), it becomes clear that even in those countries with the lowest numbers of early school-leavers, about 5 to 8 percent of the population is not able to meet the criteria for the basic skilled worker. Thus when setting goals to diminish early schoolleaving, one has to question if it is reasonable to continually cut down these goals. We have to acknowledge the fact that there is a hard-core of students of some $5-8 \%$ who will never be able to gain the "starters qualification". Second, policy makers should question themselves if it is opportune to connect such far-reaching consequences to early schoolleaving as is currently done in the Netherlands. Those that do not meet the criteria for a starting qualification are not only stigmatized by the label of being 'unfit' for the labor market, but they can also be denied of social assistance if they do not meet the criteria for the 'leerwerkplicht' (see 1.1). If the concept of the minimum level of education does in fact not fit the true consequences of a changing labor market, and the process of who becomes an early school-leaver and who does not is so inscrutable, is it then worthwhile to simply impose such requirements on all without question?

\subsubsection{Limitations of the study}

The most obvious strength of this study lies in the exceptional data used. The VOCL panel studies provide educational careers for nearly 20 thousand students per cohort as well as a multitude of additional information about the students, the family, their schools, their friends, and their teachers. In addition, the possibility to match other (administrative) data sources on an individual level provides an array of possibilities for additional research. However, the data also has some shortcomings when studying early school-leaving. The first issue is the selection of schools in the school sample. For all VOCL studies, only schools that offer regular secondary education are selected. Schools that provide special education for special needs children are not included in the initial sample. However, children with (learning) disabilities are an important part of the population of early school leavers. 
Therefore, the findings can only be generalized to the population of students in regular education. At the same time, selection bias was an issue in the main part of this study. Students that were most at risk of becoming an early school-leaver, i.e. males, ethnic minorities, students with low cognitive skills, and students in pre-vocational education were found to be underrepresented in the subsamples used. This resulted in an underestimation of the effects found in my analyses.

The second issue with our data was the fact that these studies were not specifically designed for this purpose and therefore the measurements available were quite general. This means that there was a lack of in-depth relevant information. For one, it would be valuable to have more information on the reason why students left education and their destination. In the VOCL'99, there was a questionnaire designed for school leavers. Unfortunately, this was only administered to those students that were still in education in the exam year. Students that had left early were not in that subsample. In addition to that, a problem of most large-scale panel is the problem of panel attrition. While the students were in the responding schools of the initial sample, attrition problems were quite small because schools had committed to the study. When transferring to other schools, students became less and less easy to find and these new schools lacked the commitment to provide data to Statistics Netherlands. This made it more and more problematic to follow students throughout their career with individual questionnaires. For the educational careers, administrative data were used to retrieve enrolment and examination data, so attrition was not considered a problem in that respect.

The third issue with these data is that they provided only very limited means to establish causality. Although I was able to model the data in such a way to ensure a causal ordering of events, this does not provide full assurance that a causal effect is at hand. To be able to test hypotheses of causal effects, one would ideally want to use some sort of instrumental variable or perform a (quasi) experiment. Unfortunately, the VOCL data did not provide any clues for developing a strong instrument or experimental setting.

\subsubsection{Suggestions for future research}

As was shown throughout all chapters, early school-leaving is not a sudden decision yet it is a process that has already started off when entering secondary school. Future research should therefore focus more on early indicators for early school-leaving, including early misconduct and delinquency at very young ages. In the Netherlands, there are some largescale longitudinal studies among primary school students such as the current COOL study that may provide valuable new insight in the issue of early school-leaving. However, these studies start at the beginning of primary school, ignoring potential important events taking place in the first years of a child's life. It may be valuable to look into ways of collecting data starting at birth on order for us to get better insight in why some youngsters are more successful in education than others. 
As was also shown throughout, cognitive skills and school performance in particular are the most important indicators of early school-leaving. However, it is still unclear how and why. Is this caused by the simple fact that some people simply lack the ability to attain a certain level of schooling? To gain a better understanding of this issue one would need more and better measures of cognitive ability, especially intelligence. Also, one would want to have multiple measures throughout the educational career to be able to monitor changes in individual performance, preferably starting in primary school. 



\section{Samenvatting (Summary in Dutch)}

Het terugdringen van het aantal voortijdig schoolverlaters heeft zowel nationaal als internationaal sinds het begin van dit decennium hoge prioriteit. Voortijdig schoolverlaten is immers niet alleen nadelig voor individuen, maar heeft ook haar weerslag op de samenleving. Voortijdig schoolverlaters vinden minder makkelijk een baan, en als ze wel werk vinden is dat vaker een flexibel contract. Bovendien vinden voortijdig schoolverlaters veelal werk in minder aantrekkelijke segmenten van de arbeidsmarkt met lage inkomens. Op maatschappelijk niveau heeft het aantal voortijdig schoolverlaters enerzijds natuurlijk invloed op de kosten van het sociale zekerheidsstelsel, hoe meer werklozen, des te hoger die kosten, maar daarnaast komt ook het aanbod aan geschoold personeel in het geding naarmate meer jongeren met weinig of geen diploma het onderwijs verlaten. De afgelopen jaren is het aantal voortijdig schoolverlaters flink afgenomen van 273000 in 2001 tot 162000 in 2010. Toch blijft het aandeel jongeren dat zonder diploma of met zeer beperkte kwalificaties het onderwijs verlaat relatief hoog. Van alle 18 tot 24 jarigen had in 2001 15,1 procent geen startkwalificatie, d.w.z. een diploma op het niveau van Havo, Vwo of Mbo-2. In 2010 bedroeg dit aandeel nog altijd 10,1 procent.

Dit proefschrift beschrijft een aantal factoren die van invloed zijn op voortijdig schoolverlaten. Hoewel er uitgebreide literatuur bestaat over dit onderwerp, zijn deze onderzoeken vaak erg uni-dimensionaal in de zin dat ze vaak maar één aspect belichten en er weinig gebruik wordt gemaakt van kennis vanuit andere disciplines. In dit proefschrift komt een aantal belangrijke voorspellers van voortijdig schoolverlaten samen. Er worden theorieën en technieken gebruikt uit de sociologie, de economie, de criminologie en de psychologie om zo beter inzicht te krijgen in welke kinderen een groter risico lopen om voortijdig schoolverlater te worden. Het proefschrift maakt gebruik van een aantal zeer unieke en waardevolle bestanden als het gaat om onderzoek naar determinanten van voortijdig schoolverlaten. Voor hoofdstuk 2 is gebruik gemaakt van het Voortgezet Onderwijs Cohort Leerlingen 1989 (VOCL'89). Voor de hoofdstukken 3 tot en met 5 is gebruik gemaakt van VOCL'99. Beide studies zijn grootschalige cohortstudies waarbij ongeveer 20000 leerlingen uit de brugklascohorten 1989/ 90 dan wel 1999/ O0 gevolgd zijn tot op het moment dat zij het onderwijs verlieten. Naast gedetailleerde informatie over de schoolloopbaan van deze kinderen is er ook een zeer uitgebreide set aan aanvullende informatie beschikbaar. Zo is er vragenlijstinformatie over de ouders, zijn er op een aantal tijdstippen toetsen afgenomen bij de kinderen met betrekking tot hun taal- en rekenniveau en zijn er aanvullende onderzoeken gedaan onder de kinderen 
met betrekking tot onderwijsmotivatie, persoonlijkheid en omgang met klasgenoten (die laatste twee onderzoeken zijn alleen in VOCL'99 beschikbaar). Doordat deze cohortonderzoeken zijn opgezet als clustersteekproeven van klassen binnen scholen, is het bovendien mogelijk om uitspraken te doen over factoren op het school- en klasniveau. Naast de cohortstudies is ook gebruik gemaakt van de mogelijkheid om op individueel niveau gegevens van leerlingen te koppelen. In hoofdstuk 3 wordt in gegaan op de relatie tussen voortijdig schoolverlaten en de criminele carrière van jongeren. Daarvoor is een koppeling gemaakt met het Herkenningsdienst Systeem (HKS) van het Korps Landelijke Politie Diensten (KLPD). In het HKS wordt op individueel niveau vastgelegd welke personen er in een kalenderjaar in aanraking kwamen met de politie en voor welk soort vergrijp. Daarmee is het mogelijk om voor de leerlingen in deze studie naast hun schoolloopbaan ook hun criminele loopbaan te volgen.

Hoofdstuk 1 beschrijft hoe voortijdig schoolverlaten is gedefinieerd binnen het Nederlandse onderwijssysteem. Daarnaast wordt een overzicht gegeven van de omvang van de groep voortijdig schoolverlaters in Nederland, zowel in nationaal perspectief alsook in internationaal opzicht. Ook wordt ingegaan op de veranderingen in de meetmethode in de afgelopen jaren en de op handen zijnde wijzigingen. Bovendien wordt in dit hoofdstuk uitvoerig beschreven welke beleidsmaatregelen van kracht zijn om het aantal voortijdig schoolverlaters terug te dringen en welke maatregelen in de komende jaren effectief zullen worden. Daarnaast wordt in hoofdstuk 1 kort ingegaan op de onderzoeksvragen die aan bod komen in de hoofdstukken 2 tot en met 5 van het proefschrift en hoe dit aansluit bij eerder onderzoek. Deze bevindingen worden hieronder kort samengevat.

\subsection{De invloed van gezinskenmerken, schoolsamenstelling en achtergrondkenmerken op voortijdig schoolverlaten}

In hoofdstuk 2 wordt bekeken in hoeverre individuele factoren (geslacht, herkomst, cognitieve competenties, participatie en identificatie), gezinskenmerken (economisch, menselijk, sociaal en cultureel kapitaal) en schoolkenmerken (aandeel niet-westerse allochtonen, urbanisatiegraad, schoolsamenstelling) van invloed zijn op de kans dat een leerling een voortijdig schoolverlater wordt. Daarbij wordt onderscheid gemaakt tussen 4 groepen 
schoolverlaters, namelijk degenen die het onderwijs ongediplomeerd verlaten, degenen die naar het leerlingwezen vertrekken, degenen die met een Vmbo-diploma uit het onderwijs vertrekken en degenen die minimaal een Havo- of een Vwo-diploma hebben behaald. De centrale vraag in dit hoofdstuk is of individuele factoren, sociale herkomst en schoolsamenstelling van invloed zijn op de kans een voortijdig schoolverlater te worden en of die invloed verschillend is voor de onderscheiden groepen. Voor dit hoofdstuk is gebruik gemaakt van de gegevens in het VOCL'89, waarbij alleen is gekeken naar die leerlingen die hun onderwijsloopbaan zijn begonnen in een Vmbo-brugklas.

De resultaten laten zien dat cognitieve vaardigheden en in het bijzonder de schoolprestaties in de brugklas een belangrijke zo niet de belangrijkste voorspeller zijn voor voortijdig schoolverlaten. Het effect van cognitieve competenties alsook de invloed van motivatie blijkt bovendien sterker te zijn voor jongens dan voor meisjes. Daarnaast speelt ook sociale herkomst een belangrijke rol. Een gebrek aan financiële, culturele, sociale of menselijke hulpbronnen vergroot de kans op voortijdig schoolverlaten, ongeacht verschillen in cognitieve competenties. Daarbij speelt dan onder meer een rol dat binnen bepaalde sociale klassen de kosten van onderwijs zwaarder wegen dan de baten van het behalen van een diploma. Er is dus niet alleen sprake van een direct effect van bijvoorbeeld te weinig financiële middelen om onderwijs te kunnen betalen. Een derde belangrijke bevinding is dat er duidelijke verschillen bestaan tussen scholen. Deels is dat te verklaren door verschillen in schoolsamenstelling. Op scholen met hoge percentages niet-westerse allochtonen is de kans op voortijdig schoolverlaten groter dan op zogenaamde 'witte' scholen. Ook is de kans dat leerlingen voortijdig de school verlaten groter op scholen die uitsluitend Vmboonderwijs aanbieden in vergelijking met scholen die ook Havo- en wellicht ook Vwoonderwijs geven. Opmerkelijk is het feit dat de invloed van herkomst verdwijnt als rekening gehouden wordt met verschillen in sociale herkomst. Dit wijst erop dat de verhoogde kans van niet-westerse allochtonen om voortijdig schoolverlater te worden te wijten is aan het feit dat zij relatief vaak behoren tot lagere sociale klassen en niet vanwege culturele verschillen dan wel taalproblemen. Binnen de lagere sociale klassen zijn allochtone leerlingen net zo vaak voortijdig schoolverlater als autochtone leerlingen. In dit hoofdstuk werden vier groepen schoolverlaters met elkaar vergeleken. Onze resultaten laten zien dat de risicofactoren voor voortijdig schoolverlaten het sterkst van invloed zijn wanneer gekeken wordt naar diegenen die ongediplomeerd het onderwijs verlaten. Voor die groep zijn factoren als slecht presteren, een lage motivatie, een laag brugklasadvies en ' het niet leuk vinden op school' allemaal belangrijke factoren naast sociale herkomst en schoolkenmerken. Voor de Vmbo-schoolverlaters zijn deze risicofactoren ook relevant, maar in minder sterke mate. Voor degenen die naar het leerlingwezen (de tegenwoordige beroepsbegeleidende leerwegen) uitstromen, zijn het vooral de schoolprestaties en een gebrek aan motivatie die een rol spelen. Dat duidt erop dat dit een groep leerlingen is die wel willen leren, maar die duidelijk behoefte hebben aan een meer praktische benadering van onderwijs. Deze bevinding onderstreept het belang van een gedifferentieerd onderwijsstelsel. 


\subsection{Sociale binding, voortijdig schoolverlaten en delinquentie}

In hoofdstuk 3 wordt antwoord gezocht op de vraag of individuele verschillen in sociale binding met school een verklaring kunnen bieden voor enerzijds voortijdig schoolverlaten en anderzijds delinquent gedrag. De idee dat een gebrek aan sociale binding van invloed is op delinquent gedrag vloeit voort uit de theorie van Hirschi (1969). In dit hoofdstuk wordt allereerst gekeken in hoeverre elementen van sociale binding met school, namelijk genegenheid, betrokkenheid, vertrouwen en schoolprestaties (die kunnen worden gezien als een indicatie voor de mate van betrokkenheid bij de school), een positief effect hebben op de kans dat iemand voortijdig schoolverlater wordt en/of delinquent gedrag vertoont. Daarnaast wordt gekeken naar de mate waarin delinquentie en voortijdig schoolverlaten een rechtstreekse invloed hebben op elkaar, naast de invloed die verloopt via het mechanisme van de sociale binding. Daarvoor wordt onderscheid gemaakt tussen delinquentie die plaatsvond voordat iemand van school ging versus delinquentie die pas plaatshad nadat iemand van school ging.

De resultaten laten in de eerste plaats zien dat sociale binding met school van invloed is op voortijdig schoolverlaten en delinquent gedrag, en dan vooral schoolprestaties in de brugklas. Slechte schoolprestaties in het eerste leerjaar vergroten de kans op zowel voortijdig schoolverlaten als delinquent gedrag gedurende en na de onderwijsloopbaan. Daarnaast blijkt dat als een leerling in aanraking is geweest met de politie, de kans op voortijdig schoolverlaten wordt vergroot en daarnaast dat voortijdig schoolverlaten de kans op delinquent gedrag na de schoolloopbaan vergroot. Er lijkt daarmee bijna een soort van keten van gebeurtenissen te ontstaan, die ertoe leiden dat een leerling steeds verdergaande negatieve gevolgen van zijn of haar gedrag ervaart.

Goed presteren op school blijkt een beschermende factor te zijn tegen zowel voortijdig schoolverlaten als delinquentie. Deze bevinding kan in zekere mate opgevat worden als een instrument om vroegtijdig in te grijpen. Onze resultaten hebben echter ook aangetoond, dat de impact van schoolprestaties veel kleiner is voor die leerlingen die al gedurende hun onderwijsloopbaan in aanraking zijn gekomen met de politie. Voor die groep zijn de schoolprestaties niet meer zo'n belangrijke voorspeller van voortijdig schoolverlaten. Dit betekent dat naast het stimuleren van onderwijsprestaties ook preventie van risicogedrag, waaronder jeugddelinquentie, een belangrijke beleidsdoelstelling in het gevecht tegen voortijdig schoolverlaten zou moeten zijn. 


\subsection{De invloed van cognitieve en niet-cognitieve vaardigheden op schoolsucces}

In hoofdstuk 4 wordt ingegaan op de vraag of motivatie en persoonlijkheidskenmerken van invloed zijn op voortijdig schoolverlaten, wanneer rekening gehouden wordt met individuele verschillen in cognitieve competenties en verschillen in achtergrondkenmerken. Daarvoor is gebruik gemaakt van VOCL'9g en de uitgebreide vragenlijst die werd afgenomen in het tweede leerjaar, waarmee de zogenaamde Five Factor Personality Inventory (FFPI) is vast te stellen. Met de FFPI kunnen de typerende kenmerken van een persoon worden vastgesteld op de eigenschapsdimensies Extraversie, Mildheid, Ordelijkheid, Emotionele Stabiliteit en Autonomie. Als theoretisch kader is de Verwachtingstheorie van Vroom (1964) toegepast, die stelt dat prestatie in feite de vermenigvuldiging is van iemands cognitieve competenties maal zijn of haar motivatie. Dit houdt in dat voor mensen met lage cognitieve competenties, een hoge mate van motivatie dus ook veel minder rendement heeft in termen van uiteindelijke prestaties dan voor mensen met hoge cognitieve competenties.

Onze resultaten laten zien dat cognitieve competenties in de brugklas inderdaad een sterk en direct effect hebben op de kans om een voortijdig schoolverlater te worden terwijl deze relatie nauwelijks wordt beïnvloed door verschillen in motivatie dan wel persoonlijkheid. Tegelijkertijd is wel gebleken dat zowel motivatie als Ordelijkheid (hoe een leerling met taken omgaat), Mildheid (hoe een leerling met anderen omgaat) en Autonomie (onafhankelijkheid in denken en beslissen) een directe invloed hebben op voortijdig schoolverlaten. De mate waarin deze persoonlijkheidskenmerken van invloed zijn op voortijdig schoolverlaten hangt echter af van de cognitieve competenties. Zo is Ordelijkheid vooral van invloed voor leerlingen met lage cognitieve competenties, waar ogenschijnlijk een gebrek aan competenties gecompenseerd kan worden door de mate waarin iemand georganiseerd en stipt is. Mildheid is vooral van invloed op leerlingen die een gemiddelde mate van cognitieve competenties bezitten terwijl voor die leerlingen die erg hoog of erg laag scoren op cognitieve vaardigheden, verschillen in de omgang met anderen niet zozeer van invloed zijn op voortijdig schoolverlaten. Waarschijnlijk hangt dit samen met het feit dat populariteit onder medeleerlingen een belangrijke voorspeller is voor schoolsucces. Autonomie blijkt alleen een positieve invloed te hebben voor die leerlingen die hoog scoren op cognitieve vaardigheden. Dat hangt waarschijnlijk samen met het feit dat autonomie een eigenschap is die vooral past in binnen het hoger onderwijs, waar zelfdenkendheid en probleemoplossend vermogen belangrijk gevonden worden in plaats van simpelweg het reproduceren van lesstof. 
Al met al zijn cognitieve competenties de belangrijkste voorspeller voor voortijdig schoolverlaten. Dat betekent dat men moet accepteren dat er een groep leerlingen is die gewoonweg niet over de vaardigheden beschikt om een diploma op het niveau van de startkwalificatie te behalen. Daarnaast is er echter een groep die wel beschikt over de juiste cognitieve competenties, maar die door een gebrek aan motivatie en/of bepaalde persoonlijkheidskenmerken toch niet in staat zijn dit minimale niveau te voltooien.

\subsection{Daar heb je vrienden voor. De invloed van kenmerken van vrienden op voortijdig schoolverlaten.}

In hoofdstuk 5 worden drie onderzoeksvragen beantwoord: zijn kenmerken van vrienden in de brugklas van invloed op de kans dat een leerling zelf voortijdigs schoolverlater wordt? Gelden die effecten voor zowel degenen die de leerling zelf als vriend beschouwt alsook voor degenen die de leerlingen als vriend noemen? En worden deze effecten veroorzaakt doordat kinderen geneigd zijn diegenen als vriend te kiezen die het meest op henzelf lijken. Voor dit hoofdstuk is gebruik gemaakt van VOCL'99 en de sociometrische vragenlijst die in de loop van het eerste leerjaar is afgenomen. Hierin werd onder meer aan leerlingen gevraagd welke drie kinderen zij in hun klas het aardigst vonden. Op basis van die gegevens is vastgesteld hoeveel vrienden een leerling heeft (wie heeft de leerling zelf genomineerd) en wie dit zijn. Daarnaast is vastgesteld hoe populair een leerling is (door hoeveel leerlingen is de leerling genomineerd). In een aanvullende analyse is daarnaast ook gekeken naar een striktere meting van vrienden, namelijk die gevallen waarin twee leerlingen elkaar noemen als iemand die ze aardig vinden. De bevindingen zijn echter gelijk aan de in het hoofdstuk gerapporteerde conclusies.

Onze resultaten laten zien dat zowel het aantal vrienden als populariteit in de klas van invloed zijn op voortijdig schoolverlaten. Het soort mensen waarmee men omgaat in de brugklas in termen van geslacht, herkomst, school prestaties en socio-economische status heeft hierop echter geen additioneel effect. Wel laten onze analyses zien dat leerlingen die omgaan met leerlingen die later voortijdig schoolverlater bleken te worden, zelf ook een vergrote kans hebben om voortijdig schoolverlater te worden. Dit geldt zowel voor vriendschappen als populariteit. Om na te gaan of dit het gevolg is van het feit dat kinderen 
vooral omgaan met kinderen die veel op hen lijken, is nagegaan of voortijdig schoolverlaten een determinant is in de selectie van vrienden. Onze resultaten laten zien dat dit zeer onwaarschijnlijk is.

Populariteit kan dus gezien worden als een beschermende factor tegen voortijdig schoolverlaten, maar populariteit onder 'foute vrienden' heeft juist een tegengesteld effect. Tegelijkertijd zijn kenmerken van het individu zelf veel belangrijkere voorspellers voor voortijdig schoolverlaters. Beleid gericht tegen voortijdig schoolverlater zal zich dus ook op de eerste plaats moeten richten op het individu. De invloed van groepsstructuren moet hierbij echter niet worden onderschat.

\subsection{Conclusie}

De doelstelling van dit proefschrift was om beter inzicht te krijgen in de mechanismen die voortijdig schoolverlaten beïnvloeden. De belangrijkste conclusie die we kunnen trekken uit dit proefschrift is dat voortijdig schoolverlaten een proces is dat al op jonge leeftijd in gang gezet is. Factoren zoals schoolprestaties, motivatie, schoolbeleving en de samenstelling van de vriendengroep werden gemeten gedurende het eerste leerjaar, als de leerlingen gemiddeld 12 jaar oud zijn, en dus ver voorafgaand aan het feitelijke moment van (voortijdig) schoolverlaten. Dit doet ook de vraag rijzen of interventies en preventieve maatregelen die pas gedurende het voortgezet onderwijs en soms later worden ingezet, niet in feite al te laat komen.

Na cognitieve competenties blijkt sociale herkomst een belangrijke voorspeller voor voortijdig schoolverlaten. Een gebrek aan ouderlijke hulpbronnen kan de kans op voortijdig schoolverlaten van hun kinderen nadelig beïnvloeden. Deels doordat er eenvoudigweg een gebrek is aan middelen om kinderen te laten studeren, maar daarnaast ook als gevolg van verschillen in de kosten-baten afweging die mensen maken ten aanzien van onderwijs. Daar waar het in sommige kringen een hoog aanzien geniet om een bepaald onderwijsniveau te behalen, is binnen lagere kringen soms eerder het tegenovergestelde het geval. Hoewel het niet eenvoudig is om een gebrek aan hulpbronnen te veranderen, kunnen ouders wel degelijk iets doen om hun kinderen te stimuleren hun onderwijsloopbaan succesvol af te ronden. Het praten met kinderen over school, over hun prestaties, overleggen over hun huiswerk etc. blijkt een preventieve werking te hebben die in ieder geval ook ten dele kan compenseren voor verschillen in socio-economische status.

Ook voor scholen is er een rol weggelegd in het voorkomen van voortijdig schoolverlaten. Zoals is gebleken in verschillende hoofdstukken in dit proefschrift zijn er grote verschillen tussen scholen in de kans dat een leerling een voortijdig schoolverlater wordt. Zo is die kans hoger op relatief zwarte scholen, scholen in stedelijke gebieden en op scholen die 
uitsluitend Vmbo-onderwijs aanbieden in vergelijking met bredere scholengemeenschappen. Dit komt overeen met resultaten uit andere onderzoeken die hebben laten zien dat kinderen in scholen met grote concentraties laagopgeleide of slecht presterende leerlingen nadelen ondervinden op meerdere terreinen. 


\section{References}

Ackerman, P. L., \& Heggestad, E. D. (1997). Intelligence, Personality, and Interests: Evidence for Overlapping Traits. Psychological Bulletin, 121 (2), 219-245.

Akers, R. L., \& Lee, G. (1999). Age, Social Learning, and Social Bonding in Adolescent Substance Use. Deviant Behavior: An Interdisciplinary Journal,, 19, 1-25.

Alexander, K., Entwisle, D., \& Horsey, C. S. (1997). From first grade forward: early foundations of high school dropout. Sociology of Education, 70, 87-107.

Alexander, K., Entwisle, D., \& Kabbani, N. (2001). The dropout process in life course perspective: early risk factors at home and school. Teachers College Record (103), 760-822.

Allen, J., \& Van der Velden, R. (2012). Skills for the 21st century: Implications for Education. Maastricht: Research Centre for Education and the Labour Market.

Allen, J., \& Meng, C. (2010). Voortijdig schoolverlaters: aanleiding en gevolgen. Maastricht: Research Centre for Education and the Labour Market.

Asher, S. A., MacEvoy, J. P., \& McDonald, K. L. (2008). Children's peer relations, social competence, and school adjustment: A social tasks and social goals perspective. In M. L. Maehr, S. Karabenick \& T. Urdan (Eds.), Advances in motivation and achievement. Amsterdam: Elsevier.

Audas, R., \& Willms, J. D. (2001). Engagement and dropping out of school: A life course perspective. Unpublished Working Paper for the Applied Research Branch, Strategic Policy, Human Resources Development.

Autor, D. (2010). U.S. Labor Market challenges over the Longer term, October 2010, paper prepared for the Federal Reserve Board of Governors.

Bandura, A. (1977). Social Learning Theory. New York: Prentice Hall.

Barrington, B. L., \& Hendricks, B. (1989). Differentiating characteristics of high school graduates, dropouts and nongraduates. Journal of Educational Research, 82(6), 309-319.

Baucal, A., Pavlovic-Babic, D., \& Willms, J. D. (2006). Differential selection into secondary schools in Serbia. Prospects 36(4), 539-546. 
Becker, G. S. (1964). Human Capital: A Theoretical and Empirical Analysis, with Special Reference to Education. Chicago: University of Chicago Press.

Beckers, I., \& Traag, T. (2005a). Jongeren op de arbeidsmarkt. Sociaaleconomische trends, $2005(1), 22-26$.

---(2005b). Meteen startkwalificatie betere kansen op dearbeidsmarkt. Sociaaleconomische trends, 2005 (4), 23-28.

Beekhoven, S. (2004). De rol van participatie en identificatie bij het voortijdig schoolverlaten van jongens. Pedagogische Studiën, 81, (104-116).

Bhrolcháin, M. N., Chappell, R., Diamond, I., \& Jameson, C. (2000). Parental divorce and outcomes for children: Evidence and interpretation. European Sociological Review, 16(1), 67-91.

Binet, A., Simon, T., \& Kite, E. S. (1916). The development of intelligence in children (The BinetSimon Scale). Baltimore, MD: Williams \& Wilkins Co.

Blom, M., Oudhof, J., Bijl, R. V., \& Bakker, B. F. M. (2005). Verdacht van criminaliteit. Allochtonen en autochtonen nader bekeken. Den Haag/Voorburg: CBS/WODC.

Borghans, L., Duckworth, A. L., Heckman, J. J., Ter Weel, B. (2008). The economics and psychology of personality traits. Maastricht: Research Centre for Education and the Labour Market.

Bosker, R. J., Hofman, W. H. A., \& Van der Velden, R. K. W. (1985). Een generatie geselecteerd. Deel I: De loopbanen. Groningen: RION.

Boudon, R. (1974). Education, opportunity and social inequality. New York: John Wiley.

Bourdieu, P., \& Passeron, J. C. (1977). Reproduction in education, society and culture. London: Sage.

Breen, R., \& Goldthorpe, J. H. (1997). Explaining educational differentials. Towards a formal rational action theory. Rationality and Society, 9(3), 275-305.

Buhs, E. S., \& Ladd, G. W. (2001). Peer rejection as antecedent of young children's school adjustment: An examination of mediating processes. Developmental Psychology, 37(550-560).

Bukowski, W. M., \& Hoza, B. (1993). Popularity and friendship: Issues in theory, measurement, and outcome. In W. Damon \& B. P. Laursen (Eds.), New directions for child development: Vol. 6o. Close friendships in adolescence (pp. 23-37). San Francisco.: Jossey-Bass. 
Burfeind, J., \& Bartusch, D. J. (2010). Juvenile Delinquency: An Integrated Approach. Sudbury, MA: Jones \& Bartlett Learning.

Cairns, R. B., Cairns, B. D., \& Neckerman, H. J. (1989). Early school dropout: configurations and determinants. Child Development, 60, 1437-1452.

Chamorro-Premuzic, T., \& Furnham, A. (2003a). Personality predicts academic performance: Evidence from two longitudinal university samples. Journal of Research in Personality, 37, $319-338$.

--- (2003b). Personality predicts academic performance: Evidence from two longitudinal university samples. Journal of Research in Personality, 37, 319-338.

--- (2005). Personality and intellectual competence. New Jersey: Lawrence Erlbaum Associates.

--- (2006). Intellectual Competence and the Intelligent Personality: A Third Way in Differential Psychology. Review of General Psychology, 10(3), 251-267.

Coleman, J. S. (1988). Social capital in the creation of human capital. American journal of Sociology, 94, S95-S120.

De Fruyt, F., \& Mervielde, I. (1996). Personality and interests as predictors of educational streaming and achievement. European Journal of Personality, 10(5), 405-420.

De Graaf, N. D., \& De Graaf, P. M. (2002). Formal and popular dimensions of cultural capital: Effects on children's educational attainment The Netherlands' Journal of Social Sciences, 38(2), 167-186.

De Graaf, P. M. (1986). The impact of financial and cultural resources on educational attainment in the Netherlands. Sociology of Education, 59(237-246).

De Wit, W., \& Dekkers, H. (1997). Drop-out of startkwalificatie. Omvang, achtergronden en gevolgen van voortijdig schoolverlaten in de eerste vijf jaren voortgezet onderwijs. Tijdschrift voor Onderwijsresearch, 22(4), 211-227.

Diehl, D. S., Lemerise, E. A., Caverly, S. L., Ramsay, S., \& Roberts, J. (1998). Peer relations and school adjustment in ungraded primary children. Journal of Educational Psychology, 90(506-515).

DiMaggio, P. (1982). Cultural capital and school succes: The impact of status culture participation on the grades of U.S. high school students. American Sociological Review, 47, 189-201. 
Driessen, G., \& Van der Werf, M. P. C. (1992). Het functioneren van het voortgezet onderwijs. Beschrijving steekproefen psychometrische kwaliteit instrumenten. Groningen/Nijmegen: RION/ITS.

Eitle, T. M., \& Eitle, D. J. (2007). School commitment and alcohol use: The moderating role of race and ethnicity. Education Policy Analysis Archives, 15(22), 1-17.

Ensminger, M. E., \& Slusarcick, A. L. (1992). Paths to high school graduation and dropout: a longitudinal study of a first-grade cohort. Sociology of Education, 65, 95-113.

European Commission (2010). Commission Staff Working Paper. Reducing early schoolleaving. Retrieved. from.

European Parliament (2000). Lisbon European Council 23 and 24 March 2000 Presidency Conclusions. Retrieved from http://www.europarl.europa.eu/summits/lis1_en.htm.

Eurostat (2011). Early leavers from education and training by sex and employment status from http://appsso.eurostat.ec.europa.eu/nui/show.do?dataset=edat_Ifse_14 \& lang=en

Farmer, T. W., Estell, D. B., Leung, M. C., Trott, H., Bishop, J., \& Cairns, B. D. (2003). Individual characteristics, early adolescent peer affoliations, and school dropout: an examination of aggressive and popular group types. Journal of School Psychology, 41, 217-232.

Fruyt, F. d., \& Mervielde, I. (1996). Personality and interests as predictors of educational streaming and achievement. European Journal of Personality, 10(5), 405-420.

Furnham, A. (2008). Personality and intelligence at work: exploring and explaining individual differences at work. New York: Routledge.

Furrer, C., \& Skinner, E. (2003). Sense of relatedness as a factor in children's academic engagement and performance. Journal of Educational Psychology, 95(1), 148-162.

Geerdes, S. (2009). School-To-Work Transitions of Second Generation Migrants in West Germany and the Netherlands. Jacobs University, Bremen.

Goldsmith, P. A. (2004). Schools' racial mix, students' optimism, and the black-white and Latino-white achievement gaps. Sociology of Education, 77, 121-147.

Goldstein, H. (1995). Multilevel statistical models. London: Edward Arnold.

Gottfredson, M. R., \& Hirschi, T. (1990). A general theory of crime. Stanford, CA: Stanford University Press. 
Heard, H. E. (2004). The life course of family structure and adolescent school achievement: Racial and ethnic differences. Unpublished Paper presented at the Population Association of America 2004 meeting, Boston.

Heckman, J. J., \& Rubinstein, Y. (2001). The Importance of Noncognitive Skills: Lessons from the GED Testing Program. The American Economic Review, 91(2), 145-149.

Heckman, J. J., Stixrud, J., \& Urzua, S. (2006). The effects of cognitive and noncognitive abilities on labor market outcomes and social behaviour. Journal of Labor Economics 24(3), $411-482$.

Hendriks, A. A. J., Kuyper, H., Offringa, G. J., \& Van der Werf, M. P. C. (2008). Assessing Young Adolescents' Personality With the Five-Factor Personality Inventory. Assessment, 15(3), $304-316$.

Hendriks, A. A. J., Perugini, M., Angleitner, A., Ostendorf, F., Johnson, J. A., de Fruyt, F., Hřebíčková, M., Kreitler, S., Murakami, Bratko, D., Conner, M., Nagy, J., Rodríguez-Forneus, A., I. Ruisel, (2003). The five factor personality inventory: Cross-cultural generalizability across 13 countries. European journal of personality, 17, 347-373.

Hermans, H. J. M. (1970). A questionnaire measure of achievement motivation. The Journal of Applied Psychology, 54, 353-363.

Herweijer, L. (2008). Gestruikeld voor de start: de school verlaten zonder startkwalificatie. Den Haag: Sociaal Cultureel Planbureau.

Hirschi, T. (1969). Causes of delinquency. Berkeley: University of California Press.

Hustinx, P. W. J., Kuyper, H., Van der Werf, M. P. C., \& Dijkstra, P. (2009). Achievement motivation revisited: New longitudinal data to demonstrate its predictive power. Educational Psychology, 29, 561-582.

Hymel, S., Comfort, C., Schonert-Reichel, K., \& McDougall, P. (1996). Academic failure and school dropout: The influence of peers. In J. Juvonen \& K. R. Wentzel (Eds.), Social motivation: Understanding children's school adjustment. Cambridge: Cambridge University Press.

Jarjoura, G. R. (1993). Does dropping out of school enhance delinquent involvement? Results from a large-scale national probability sample. Criminology, 31(2), 149-172.

Jenkins, P. H. (1995). School Delinquency and School Commitment. Sociology of Education, 68(3), 221-239. 
--- (1997). School Delinquency and the School Social Bond. Journal of Research in Crime and Delinquency, 34(3), 337-367.

Johnson, M. K., Crosnoe, R., \& Elder, G.H. (2001). Students' attachment and academic engagement: The role of race and ethnicity. Sociology of Education, 74, 318-340.

Judge, T. A., Higgins, C. A., Thoresen, C. J., \& Barrick, M. R. (1999). The big five personality traits, general mental ability and career success across the life span. Personnel Psychology, $52(3), 621-652$.

Ketterlinus, R. D., \& Lamb, M. E. (1994). Adolescent problem behaviors: issues and research. Hillsdale, NJ: Lawrence Erlbaum

Krohn, M. D., \& Massey, J. L. (1980). Social Control and Delinquent Behavior: An Examination of the Elements of the Social Bond. The Sociological Quarterley, 21 (Autumn 1980), 529543.

Kuyper, H., Dijkstra, P., Buunk, A. P., Van der Werf, M. P. C. (2011). Social comparisons in the classroom: An investigation of the better than average effect among secondary school children. Journal of School Psychology, 49, 25-53.

Kuyper, H., Lubbers, M. J., \& Van der Werf, M. P. C. (2003). VOCL'99-1: Technisch rapport. Groningen: GION.

Kuyper, H., \& Van der Werf, M. P. C. (2003). VOCL'99: De resultaten in het eerste leerjaar. Groningen: GION.

Kuyper, H., Van der Werf, M. P. C. \& Lubbers, M. J. (2000). Motivation, meta-cognition and self-regulation predictors of long term educational attainment. Educational Research and Evaluation, 6(181-205).

Ladd, G. W., Kochenderfer, B. J., \& Coleman, C. C. (1997). Classroom Peer Acceptance, Friendship, and Victimization: Destinct Relation Systems That Contribute Uniquely to Children's School Adjustment? Child Development, 68(1181-1197).

Lamb, S. (1994). Dropping out of school in Australia: Recent trends in participation and outcomes. Youth and Society, 26(2), 194-222.

Lubbers, M. (2004). The social fabric of the classroom. Peer relations in secondary education. Groningen: GION. 
Lubbers, M. J., \& Snijders, T. A. B. (2007). A comparison of various approaches to the exponential random graph model: A reanalysis of 102 student networks in school classes. Social Networks, 29, 489-507.

Lubbers, M. J., Van der Werf, M. P. C., \& Kuyper, H. (2009). Social comparison with friends versus non-friends. European Journal of Social Psychology, 39, 52-68.

Lubbers, M. J., Van der Werf, M. P. C., Kuyper, H., \& Offringa, J. (2006a). Predicting Peer Acceptance in Dutch Youth: A Multilevel Analysis. Journal of Early Adolescence, 26(1), $4-35$.

Lubbers, M. J., Van der Werf, M. P. C., Snijders, T. A. B., Creemers, B. P. M., \& Kuyper, H. (2006b). The impact of peer relations on academic progress in junior high. Journal of School Psychology, 44, 491-512.

Marks, G. N. (1998). Attitudes to school life: Their influences and their effects on achievement and leaving school. Camberwell: Australian Council for Educational Research

Marks, G. N., \& Fleming, N. (1999). Early school-leaving in Australia: Findings from the 1995 year 9 LSAY cohort. Camberwell: Australian Council for Educational Research.

Marks, G. N., \& McMillan, J. (2001). Early School Leavers: Who Are They, Why Do They Leave, and What Are the Consequences?, from http://research.acer.edu.au/research_ conference_2001/2

Matthews, G., Zeidner, M., \& Roberts, R. D. (2006). Models of Personality and Affect for education: A Review and Synthesis. In P. A. Alexander \& P. H. Winne (Eds.), Handbook of educational psychology (pp. 173). Mahwah, NJ: Lawrence Erlbaum.

McCrae, R. R., \& Costa, P.T. (1997). Personality Trait Structure as a Human Universal. American Psychologist, 52, 509-516.

McKenzie, J., \& Tindell, G. (1993). Anxiety and academic achievement: Further Furneaux factor findings Personality and Individual Differences, 15(6), 609-617

McLanahan, S., \& Sandefur, G. (1994). Growing up with a single parent. What hurts, what helps? Cambridge: Harvard University Press.

McPherson, M., Smith-Lovin, L., \& Cook, J. M. (2001). Birds of a feather: Homophily in social networks. Annual Review of Sociology, 27, 415-444. 
Mikiewiecz, P. (2011). School dropout in secondary education: the case of Poland. In S. Lamb, E. Markussen, R. Teese, J. Polesel \& N. Sandberg (Eds.), School Dropout and Completion: International Comparative Studies in Theory and Policy. Dordrecht: Springer Science+Business Media B.V.

Ministry of Education Cultural Affairs and Science. (2012). Nieuwe voortijdig schoolverlaters. Convenantjaar 2010-2011. Voorlopige cijfers.

Moffitt, T. (1993). Adolescence-limited and life-course-persistent antisocial behavior: a developmental taxonomy. Psychological Review, 4, 674-701.

National Youth Council of Ireland (2001). Submission to the NESF project team on early school-leaving. Dublin: National Youth Council of Ireland.

Nicholson, N., Soaneb, E., Fenton-O'Creevy, M., \& Willmand, P. (2005). Personality and domain-specific risk taking. Journal of Risk Research 8(2).

Nord, C. W., \& West, J. (2001). Fathers' and others' involvement in their children's schools by family type and resident status. Washington, DC: U.S. Department of Education. National Center for Education Statistics.

O'Brien, M. (2003). Girls and transition to second-level schooling in Ireland: 'Moving on' and 'moving out'. Gender and Education, 15(3), 249-267.

O'Connor, M. C., \& Paunonen, S. V. (2007). Big Five personality predictors of post-secondary academic performance. Personality and Individual Differences, 43, 971-990.

OECD. (2007). Education at a glance. Paris: OECD.

Parker, J. G., \& Asher, S. R. (1987). Peer relations and later personal adjustment: Are lowaccepted children at risk? Psychological Bulletin, 102(3), 357-389.

Patrick, H., Ryan, A. M., \& Kaplan, A. (2007). Early adolescents' perceptions of the classroom social environment, motivational beliefs, and engagement. Journal of Educational Psychology, 99(1), 83-98.

Petrides, K. V., Chamorro-Premuzic, T., Frederickson, N., \& Furnham, A. (2005). Explaining individual differences in scholastic behaviour and achievement. British Journal of Educational Psychology, 75, 239-255.

Poropat, A. E. (2009). A meta-analysis of the five-factor model of personality and academic performance. Psychological Bulletin, 135(2), 322-338. 
Ream, R. K., \& Rumberger, R. W. (2008). Student engagement, peer social capital, and school dropout among Mexican American and Non-Latino white students. Sociology of Education, 81, 109-139.

Research Centre For Education and the Labour Market. (2012). Voortijdige schoolverlaters. ROA fact sheet. Maastricht: Research Centre For Education and the Labour Market.

--- (2011). Schoolverlaters tussen onderwijs en arbeidsmarkt 2010. Maastricht: Research Centre For Education and the Labour Market.

Risi, S., Gerhardstein, R., \& Kistner, J. (2003). Children's Classroom Peer Relationships and Subsequent Educational Outcomes Journal of Clinical Child \& Adolescent Psychology, 32(3), $351-361$.

Rothstein, M. G., Paunonen, S. V., Rush, J. C., \& King, G. A. (1994). Personality and cognitive ability predictors of performance in graduate business school. Journal of Educational Psychology, 86(516-530).

Rumberger, R. W. (1983). Dropping out of high school: The influence of race, sex and family background. American Educational Research Journal, 20(2), 199-220.

--- (1987). High school drop-outs: A review of issues and evidence. Review of Educational Research, 87(2), 101-121.

--- (1995). Dropping out of middle school: A multilevel analysis of students and schools. American Educational Reaearch Journal, 32(3), 583-625.

--- (2011). High School Dropouts in the United States In S. Lamb, E. Markussen, R. Teese, J. Polesel \& N. Sandberg (Eds.), School Dropout and Completion. International Comparative Studies in Theory and Policy. Dordrecht: Springer.

Shavit, Y., \& Blossfeld, H. (1993). Persistent Inequalities: a Comparative Study of Educational Attainment in Thirteen Countries. Boulder Colorado Westview Press.

Sims, R. L. (2002). Ethical Rule Breaking by Employees: A Test of Social Bonding Theory Journal of Business Ethics, 4O(2), 101-109.

Snijders, T. A. B., \& Bosker, R. J. (1999). Multilevel analysis. An introduction to basic and advanced multilevel modeling. London/Thousand Oaks/New Delhi: Sage. 
Snijders, T. A. B., Van de Bunt, G. G., \& Steglich, C. E. G. (2010). Introduction to actor-based models for network dynamics. Social Networks, 32(44-60).

Statistics Netherlands (1991). Schoolloopbaan en achtergrond van leerlingen: cohort 1989. Deel 1: instroom. . Den Haag: Statistics Netherlands.

Steglich, C. E. G., Snijders, T. A. B., \& Pearson, M. (2010). Dynamic Networks and Behavior: Separating Selection from Influence. Sociological Methodology, 40(329393).

Steinmayr, R., \& Spinath, B. (2008). Sex differences in school achievenment: What are the roles of personality and achievement motivation? European journal of personality, 22, 185209.

Thornberry, T. P., Moore, M., \& Christenson, R. L. (1985). The Effect of Dropping out of high school on subsequent criminal behavior. Criminology, 23, 3-18.

Traag, T., Lubbers, M. J., \& Van der Velden, R. K. W. (2012). That's what friends are for? The impact of peer characteristics on early school-leaving. Maastricht: Research Centre for Education and the Labour Market.

Traag, T., Marie, O., \& Van Der Velden, R. K. W. (2010). Social Bonding, Early School-leaving, and Delinquency. Maastricht: Research Centre For Education and the Labour Market

Traag, T., \& Van der Velden, R. (2011). Early school-leaving in the Netherlands: The role of family resources, school composition and background characteristics in early schoolleaving in lower secondary education. Irish Education Studies, 30(1).

Van Berkel, K. (1999). Steekproef voor schoolloopbaan onderzoek VOCL'99. Heerlen: Statistics Netherlands.

Van der Slik, F. W. P., Geert, W. J. M., \& De Bot, K. L. J. (2005). Ethnic and Socioeconomic Class Composition and Language Proficiency: a Longitudinal Multilevel Examination in Dutch Elementary Schools. European Sociological Review, 223,(293-308).

Van der Steeg, M., \& Webbink, D. (2006). Voortijdig schoolverlaten in Nederland: omvang, beleid en resultaten. Den Haag: Centraal Planbureau.

Van der Werf, M. P. C., Lubbers, M. J., \& Kuyper, H. (2002). Het interne rendement van het voortgezet onderwijs. Groningen: GION. 
Van Heesch, M. M. J., Bosma, H., Traag, T., \& Otten, F. (2011). Hospital admissions and school dropout: a retrospective cohort study of the 'selection hypothesis'. European Journal of Public Health, 22(4), 550-555.

Van Tilborg, L., \& Van Es, W. (2006). De uitkomsten van de RMC analyse 2005. Amsterdam: Sardes.

Vandell, D. L., \& Hembree, S. E. (1994). Peer social status and friendship: Independent contributors to children's social and academic adjustment. Merrill-Palmer Quarterly: Journal of Developmental Psychology, 40(4), 461-477.

Veendrick, l., Tavecchio, L., \& Doornenbal, J. (2004). Jongens als probleem. Pedagogiek, 241, 12-22.

Vitaro, F., Larocque, D., Janosz, M., \& Tremblay, R. E. (2001). Negative Social Experiences and dropping out of school. Educational Psychology, 21(4), 401-414.

Voelkl, K. E. (1995). School warmth, student participation and achievement. Journal of Experimental Education, 632, 127-138.

Vroom, V. H. (1964). Work and Motivation. New York: Wiley.

Walters, K., \& Bowen, G. L. (1997). Peer group acceptance and academic performance among adolescents participating in a dropout prevention program. Child and Adolecent Social Work Journal, 14(6), 413-426.

Wentzel, K. R. (1996). Introduction. New perspectives on motivation at school. In J. Juvonen \& K. R. Wentzel (Eds.), Social motivation: Understanding children's school adjustment. Cambridge: Cambridge university press.

--- (2003). Sociometric Status and Adjustment in Middle School: A Longitudinal Study. Journal of Early Adolescence, 23, 5-28.

Willms, J. D. (2006). Learning divides: Ten policy questions about the performance and aquity of schools and schooling systems. Montreal: UNESCO Institute for Statistics.

Zettergren, P. (2003). School adjustment in adolescence for previously rejected, average and popular children. British Journal of Educational Psychology, 73, 207-221. 
